\title{
Recht und Sittlichkeit.
}

\section{Ein Beitrag}

zur kategorialen Begründung der praktischen Philosophie.

Mit besonderem Bezug

auf Hermann Cohens "Ethik des reinen Willens"

und Rudolf Stammlers "Theorie der Rechtswissenschaft“. ${ }^{1}$ )

Von Paul Natorp in Marburg.

$\S$ 1. (Methode und Fragestellung.) An einem Werke über die "Theorie der Rechtswissenschaft" geht wohl mehr als irgendeine andere Frage den Philosophen die Frage an nach dem Verhältnisse des Rechts zur Sittlichkeit; der Wissenschaft oder der Philosophie des Rechts zur Ethik, als Wissenschaft oder Philosophie der Sittlichkeit. Das rechtsphilosophische Grundwerk eines Juristen zumal, der als Philosoph allgemein und mit Grund der Kantischen, der „kritischen" Schule beigerechnet wird, würde diese Gedankeneinstellung auch dann fordern, wenn nicht gerade über die genannte Frage eine Kontroverse schwebte zwischen ihm und dem führenden Philosophen, insbesondere Ethiker dieser Schule in unserer Zeit: Hermann Cohen.

Ein wissenschaftlicher Streit kann aber nur dann sachfördernd sein, wenn ersteus die Streitenden überhaupt auf gemeinsamem Boden, auf dem Boden gemeinsamer Methode stehen, und wenn zweitens über die Frage selbst, um die gestritten wird, auf beiden Seiten Klarheit vorhanden ist. Daher muss es unser Erstes sein, über die methodischen Grundlagen zu einem möglichen Austrage des Streites, und über die Fragestellung uns die nötige Klarheit zu verschaffen.

Was die Methode betrifft, so kann unter Philosophen, die auf den entscheidenden Errungenschaften Kants zu fussen behaupten, darüber schlechterdings keine Meinungsverschiedenheit

1) Zugleich Besprechung dieses Werkes (Halle, Buchhandlung des Waisenhauses, 1911, VIIT u. 852 s. $8^{\circ}$ ).

Kantstadion XVIr. 
obwialten, dass beide, Recht und Sittlichkeit, derselben, im letzten Betracht einen und unteilbaren Gesetzlichkeit reiner praktischer Vernunft unterstehen müssen; dass nicht bloss es ein Apriori des Rechts sowohl als der Sittlichkeit geben muss, sondern dass auch die apriorische Grundlage für beide in letzter Instanz nur eine, nicht zweifach sein kann. Diese erste Voraussetzung wird in der Tat von beiden, Cohen wie Stammler, unumwunden anerkannt. Für den ersteren bedarf es eines besonderen Beweises hierfür nicht; der letztere aber hat, wie schon in seinen früheren auf Rechtsphilosophie bezüglichen Werken, so besonders in diesem neuen sich $\mathrm{zu}$ jener Überzeugung mit einer grundsätzlichen Entschiedenheit bekannt und sie kousequent durch das ganze Werk hindurch festgehalten, die auch den letzten Zweifel uiber diese erste Vorfrage, wie man hoffen darf, fortab und für immer ausschliesst.

Damit ist aber zugleich das Fundament gesichert für die Klärung der Fragestellung. Unterhalb der gemeinsamen Voraussetzung nämlich eines identischen letzten Gesetzesgrundes für Recht und Sittlichkeit ist allerdings noch Raum für weitgehende Neinungsverschiedenheit über das genauere Verhältnis zwischen beiden. Es fragt sich, ob, das gémeinsame Grundgesetz vorausgesetzt, doch unterhalb desselben eine Scheidung beider aufgrund einer ausschliessenden Disjunktion zu behaupten ist, oder eine partielle, oder vollständige, Koinzidenz. Und diese Frage kann wiederum in zweifacher Hinsicht verstanden werden: dem Umfang und dem Inhalt nach. In ersterer Beziehung ist die Frage, ob die Sphären, die Problemgebiete des Rechts und der Sittlichkeit ganz auseinanderliegen und allenfalls nur in der Grenze sich berühren, oder zum Teil, oder vollständig identisch sind. Aber auch bei völliger Deckung der Sphären, das heisst, wenn etwa jede menschliche Willenshandlung, ohne Ausnahme, sowohl rechtlicher als sittlicher Beurteilung zu unterstellen ist, kann es sich fragen, ob nicht dem Gesichtspunkt nach beide Beurteilungsweisen von einander verschieden und $\mathrm{zu}$ trennen sind. Und es muss wiederum diese Scheidung der Betrachtungsrichtung nach, dịe bei völliger Identität des Betrachteten möglich ist, nicht notwendig eine absolute sein; sondern es könnte die rechtliche Beurteilung durch die sittliche, oder die sittliche durch die rechtliche logisch bedingt sein, so aber, dass im ersteren Fall für eine nichtrechtlich-sittliche, im zweiten für eine nichtsittlich-rechtliche $\mathrm{Be}$ - 
urteilung daneben Raum bliebe. Es könnte aber auch sein, dass, während auf jede menschliche Willenshandlung beide Beurteilungsweisen anzuwenden sind, in gewissem Betracht die rechtliche $\mathrm{Be}-$ urteilung zugleich die sittliche, die sittliche zugleich die rechtliche um ihrer selbst willen forderte, ja einschlösse, in gewissem Betracht aber sowohl eine nichtrechtlich-sittliche als auch eine nichtsittlich-rechtliche Beurteilung statthaft und, da jedenfalls beide Beurteilungsweisen rein und allgemein durchzuführen sind, auch notwendig wäre. Ist nämlich die Beurteilungsweise überhaupt, der Voraussetzung nach, verschieden, so fordert auf der einen Seite jede für sich nach ihrer strengsten Eigenart, also in reiner abstrakter Sonderung von der andern, festgehalten und durchgeführt zu werdẹ; doch aber kann auf der andern Seite zwischen beiden ein logischer Zusammenhang solcher Art obwalten, dass die volle konkrete Durchführung jeder von beiden Betrachtungsarten die andere herbeizwingt. Um das so vielleicht noch immer nicht deutlich genug Gesagte durch eine einfache Analogie zu erläutern, mag das geläufige Schulbeispiel reziproker Begriffe, das vom gleichseitigen und glcichwinkligen Dreieck dienen. Das gleichseitige ebene Dreieck ist zugleich das gleichwinklige, und umgekehrt, das heisst, beide Begriffe decken sich dem Umfang nach; während sie dem Inhalt nach verschieden sind: gleiche Seiten haben bedeutet nicht gleiche Winkel haben, und umgekehrt. Solange nun allein nach der Länge der Seiten gefragt wird, ist nicht nach den Winkeln, solange nach den Winkeln, nicht nach den Seiten zu fragen; und es mag Betrachtungen geben, in denen diese abstrakte Scheidung sich in voller Strenge festhalten lässt und festgehalten werden muss. Da aber die Seiten im konkreten, d. h. als die des ebenen Dreiecks, die Winkel, und die Winkel die Seiten zugleich fordern, ja ihrem konkreten Begriff nach einschliessen, so wird allerdings die voll durchgeführte Betrachtung der Seiten auch auf die Winkel, die voll durchgeführte Betrachtung der Winkel auf die Seiten ihren logischen Einfluss erstrecken, und es wird so die anfangs zweiseitige Betrachtung dieses selbigen Objekts, des gleichseitig-gleichwinkligen Dreiecks, sich zu einer vollkommenen konkreten Einheit wieder zusammenschliessen müssen. Vielleicht dass es mit dem Recht und der Sittlichkeit sich dem ähnlich verhält. Gerade daun wäre es begreiflich, dass dem Philosophen, dem als solchem vor allem an der konkreten Einheit liegen muss, die abstrakte Scheidung sich vier- 
bergen kann, die dagegen dem Juristen wichtig sein wird, und nun vielleicht ihn verleiten könnte, sei es die'Scheidung schroffer als richtig durchzuführen, oder wenigstens über der an sich vollberechtigien Beachtung der einen, ihm näherliegendén Seite, nämlich der Eigenheit auch nichtsittlich-rechtlicher Betrachtung, die andere, der dennoch wesentlichen, innern Beziehung des Rechts zur Sittlichkeit, in den Hintergrund treten zu lassen.

§ 2. (Historische Beleuchtung. Kants "Legalität" und "Moralität"). Nachdem so die Fragestellung eine wenn auch noch so vorläufige Klärung schon erfahren hat, scheint es sachdienlich, zur historisch-kritischen Beleuchtung der Streitlage zunächst auf $\mathrm{Kant}$ als den gemeinsamen Ausgangspunkt $\mathrm{zl}$ rückzugehen. Kant unterscheidet, wie man weiss (Kr. d. pr. V., I, 1, 3. Hauptst., Akad.-Ausg. V, 71 ff.) Legalität, als „objektive" Übereinstimmung mit dem reinen praktischen Gesetz, obne Frage nach der "subjektiven Triebfeder", d. h. danach, ob die Handlung aus reiner Achtung vor dem Gesetz oder aus sonstigen Beweggründen geschah, von Moralität, die, über jene objektive Übereinstimmung hinaus, auch diese subjektive Triebfeder verlangt. Oder "legal“ heisst ihm die pflichtgemässe Handlung, ohne Frage, ob sie auch „aus Pflicht" geschieht, "moralisch" dieselbe Handlung, sofern sie zugleich „aus Pflicht" geschieht. Für "Triebfeder" tritt in feststehendem Wortgebrauch auch "Gesinnung" ein; es wird also zur Moralität die Übereinstimmung nicht der Handlung allein, sondern zugleich der Gesinnung mit dem reinen praktischen Gesetz erfordert.

Auf .Grund dieser Unterscheidung aber trenni Kant (Metaph. d. Sitten, Einl. I, Ak. VI, 214, und III, 218 ff., Rechtsl. Einl. § C, I; Tugendl. Einl. VI u. ö.) unterhalb der Gesetzeslehre der reinen praktischen Vernunft ("Metaphysik der Sitten“) Rechtslehre und Tugendlehre, oder juridische und ethische Gesetzgebung. Die "Gesetze der Freiheit" heissen, sofern sie „nur auf blosse äussere Handlungen und deren Gesetzmässigkeit gehen," juridisch; fordern sie aber auch, dass sie (die Gesetze) selbst die Bestimmungsgründe der Handlungen sein sollen, so sind sie' ethisch (Ak. VI, 214). Diejenige (Gesetzgebung), welche eine Handlung zur Pflicht und diese Pflicht zugleich zur Triebfeder macht, ist ethisch; diejenige aber, welche das letztere nicht im Gesetze miteinschliesst... ist juridisch (ebenda). Die Pflichten nach der rechtlichen Gesetzgebung können nur äussere Pflichten 
sein ... die ethische Gesetzgebung dagegen macht auch innere Handluugen zu Pflichten. Aber nicht etwa mit Ausschliessung der äusseren; sondern sie geht auf alles, was Pflicht ist, überhaupt; nur eben darum, weil die ethische Gesetzgebung die innere Triebfeder der Handlung (die Idee der Pflicht) in ihr Gesetz miteinschliesst, welche Bestimmung durchaus nicht in die äussere Gesetzgebung einfliessen muss (d. h. darf und soll), so kann die ethische Gesetzgebung keine äussere ... sein, ob sie zwar Pflichten, die auf einer anderen, nämlich äusseren Gesetzgebung beruhen, als Pflichten in ihre Gesetzgebung zu Triebfedern aufnimmt (219). Sie nimmt ... das Gesetz und die diesem korrespondierende Pflicht aus der Rechtslehre als gegeben an. Also nicht in der Ethik, sondern im Jus liegt die Gesetzgebung ...., die Ethik lehrt hernach (!) nur, dass, wenn die Triebfeder, welche die juridische Gesetzgebung mit jener Pflicht verbindet, nämlich der äussere $\mathrm{Z}$ wang, auch weggelassen wird, die Idee der Pflicht allein schon zur Triebfeder hinreichend sei. Rechtslehre und Tugendlehre unterscheiden sich also nicht sowohl durch ihre verschiedenen Pflichten, als vielmehr durch die Verschiedenheit der Gesetzgebung ... Die ethische Gesetzgebung (die Pflichten mögen allenfalls auch äussere sein) ist diejenige, welche nicht äusserlich sein kann, die juridische ist [die], welche auch äusserlich sein kann. Die Ethik hat daher mit dem Recht Pflichten, aber nur nicht die Art der Verpflichtung gemein. Einmal unterscheidet Kant auch zwischen sittlicher Richtigkeit der Handlung, als Tat, und sittlichem Wert derselben, als Gesinnung (Kr. d. pr. V., Methodenl., Ak. 159); wo also, was sonst als Recht und Moralität unterschieden wurde, unter dem gemeinsamen Oberbegriff des Sittlichen zusammengefasst wird. Dies rechtfertigt den gemeinsamen Titel "Metaphysik der Sitten“. Übersetzt man andrerseits „ethisch" oder "moralisch" mit „sittlich", so hat eben Kant zwei Begriffe des Sittlichen, den weiteren, der das Recht.mitumfasst, und den engeren, der es ausschliesst.

Wie man aus den angeführten Sätzen ersieht, bezieht sich die Unterscheidung, welche Kant zwischen Ethik und Rechtslehre trifft, wesentlicher auf den Inhalt, als auf den Umfang beider: Begriffe. Nicht darauf kommt es in letzter Instanz ihm an, ob die Sphären beider ganz zusammen- oder teilweise (keinesfalls ganz) auseinanderfallen; sondern ob die "Gesetzgebung“, ob die „Art der Verpflichtung“ verschieden sei. Und es wird diese Ver- 
schiedenheit in dem bestimmten Sinne behauptet, dass die Gesetzgebung oder Verpflichtungsart beim Recht „äussiere“, bei der Sittlichkeit „innere" ${ }^{\text {u }}$ sei. Dieser Unterschied kann stattfinden, auch wo eine und dieselbe Handlung den Gegenstand der Beurteilung bildet. Damit rückt die Frage überhaupt in die zweite Linie, ob es eine Sphäre bloss rechtlicher, nichtsittlicher, und andrerseits sittlicher, nichtrechtlicher Pflichten gibt oder nicht. Was die "Materie“ der Verpflichtung, wozu man verpflichtet sei; ob die Verpflichtung, ihrem Inhalte nach, sich auf den Verpflichteten allein, oder auch auf Andre, auf die Gemeinschaft erstrecke; selbst ob sie eine gewisse Gesiunung oder deren Bekundung in äusserlich fassbarer Tat, oder nur die Tat selbst fordert oder verbietet, das alles kommt für die letzte begriffliche Unterscheidung zwischen Recht und Sittlichkeit nicht, sondern allenfalls erst folgeweise in Frage. Im allgemeinen mag wohl die „äussere" Verpflichtungsart auch nur das Äussere der Handlung und deren nach aussen (d. h. auf Andre oder auf eine gegebene Gemeinschaft) sich erstreckende Folgen, nicht oder nur sekundär, als deren Grund, das Innere der Gesinnung des Handelnden betreffen; während die

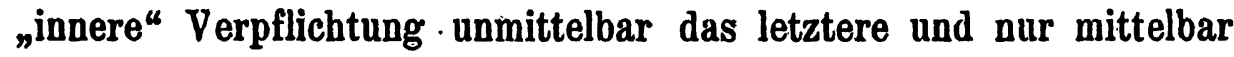
auch das erstere angeht. Jedenfalls sind dies zwei verschiedene Fragen; die lugisch primäre aber ist, nach Kants Auffassung, die nach der "Art der Verpflichtung" oder nach der "Gesetzgebung“: ob sie, als „äussere“, nur "objektiv" bestimmt, was zu wollen, wie zu handeln sei, oder, als „innere": in welchem Gesinnungsgrunde, welcher "Triebfeder" solches Wollen; solche Handlung sich $z \mathfrak{u}$ begründen und $\mathrm{zu}$ bestimmen habe, die Handlung selbst mag nun eine "äussere" (nach aussen wirkende) oder "innere" (in der Gesinnung des Handelnden verbleibende) sein.

Diese Kantische Unterscheidung ist es, welche Stammler in der "Lehre von dem richtigen Rechte“, unter ausdrücklicher Angabe ihrer Herkunft (s. das. S. 53), vollinhaltlich übernommen und in Schärfe durchzuführen versucht hat. Die "Theorie der Rechtswissenschaft" sieht von dieser historischen Anlehnung geflissentlich ab (S. 489); aber sie fusst sachlich auf der gleichen Grundvoraussetzung, die sie nur noch bestimmter als früher in der soeben angedeuteten Richtung, nämlich dahin zu präzisieren bemüht ist, dass es auf die "Art der Verpflichtung" entscheidend ankomme, die Frage nach dem Inhalt der Verpflichtung der ersteren logisch untergeordnet bleiben müsse. Übrigens war dies auch in 
dem älteren Buche bereits deutlich ausgesprochen worden: die "Materie" sei für richtiges Recht und sittliche Lehre identisch und bloss die Methode (der Bestimmung und Begründung) verschieden. Übrigens sollte schon dort auch die letztere nicht etwa dauernd geschieden bleiben, denn „beide haben dieselbe Wurzel; sie ... müssen daher der gleichen Gesetzmässigkeit unterstehen ... erst in ihrer Verschmelzung kann es gelingen die Einheit einer grundsätzlichen Gesamtauffassung zu erhalten" (R.R.S.56f.). Nur die Fragerichtung bleibt immer jene doppelte, und zwar bei jeder Willensbetätigung ohne Ausnahme; daher muss auch die Antwort "jeweils in eigener Weise vom Grundgesetze des Wollens abgeleitet werden" (S. 60). Nämlich die rechtliche Art der Bindung, als äussere und gegenseitige, fragt als solche nicht, ob der Verpflichtete sich selbst vor sich selbst gebunden erachte; die sittliche, als rein innere, nimmt ihrerseits, als solche, darauf keinen Bezug, ob Andre die gleiche Pflicht auch ihrerseits anerkennen. Ausdrücklich auch wird vorausgesetzt, dass aller Inhalt des menschlichen Wollens, den die Sittenlehre ergreifen mag, auf das Verhalten zu den Mitmenschen und das richtige Zusammenleben mit ihnen geht (73.90 u. ö.). Also ist kein wesentlicher Unterschied im Inhalt der Verpflichtung zwischen Recht und Sittlichkeit angenommen. Andrerseits wird aber darüber schlechterdings kein $\mathrm{Z}$ weifel gelassen, dass nach beiden Richtungen das menschliche Wollen und zwar alles, mag es im Innern der „Gesinnung" verbleiben oder in Wort und Tat nach aussen sich ausdrücken, einer und derselben letzten Gesetzlichkeit untersteht; dass beide "Methoden", obgleich als solche vèrschieden, doch auf das gleiche oberste Gesetz für menschliches Wollen sich zurückführen und so nicht bloss zu einer einheitlichen Gesetzesordnung hinterher sich vereinigen, sondern dem letzten Gesetzesgrunde nach eins sind (S. 68. 71. 85. 86). Ein Widerspruch zwischen beiden Gesetzlichkeiten kann daher gar nicht stattfinden. Widerspruch gibt es wohl zwischen sittlicher und positiv-rechtlicher Norm; aber dann widerspricht die letztere ebensowohl dem „richtigen“ ${ }^{d}$. h. seine Idee erfüllenden, gerechten Recht (68.89. 196 ff. u. durchweg). Man wird nicht leugnen können, dass diese Lehre streng auf Kantischem Boden steht und dem Leitgedanken der praktischen Vernunftlehre Kants treu bleibt. 
§ 3. (Fichte.) Es verlohnt aber, ausser Kant auch noch Fichte zur Vergleichung heranzuziehen. Es scheint erst neuerlich Beachtung gefunden $\mathrm{zu}$ haben, dass dieser Philosoph in unserer Frage eine scheinbar radikale Wandlung durchgemacht hat. In der "Grundlage des Naturrechts nach Prinzipien der Wissenschaftslehre" (1796) hält nämlich Fichte Kants Scheidung der reinen praktischen Philosophie in Rechts- und Tugendlehre aufgrund des Unterschieds zwischen Legalität und Moralität nicht etwa bloss aufrecht; sondern. verschärft sie zu einer grundsätzlichen Trennung. Der Begriff des Rechts wird nicht irgendwie aus dem Grundgesetze der Sittlichkeit hergeleitet, sondern gänzlich unabhängig von ihm, dennoch rein apriori, als eine „Bedingung des Selbstbewusstseins" (Finl. II, 6), „zugleich mit seinem Objekt" deduziert. Er hat mit dem Sittengesetz „nichts zu tun, ist ohne dasselbe deduziert", unmöglich aus ihm zu deduzieren (1. Hptst., $\S 4$, Coroll. 2). Beide Wissenschaften sind "schon ursprünglich ... durch die Vernunft geschieden, und sind völlig entgegengesetzt“. Das Sittengesetz nämlich gebietet kategorisch, das Recht nur bedingt. Im Naturrecht hat „der gute Wille nichts zu tun. Das Recht muss sich erzwing en lassen, wenn auch kein Mensch einen guten Willen hätte ... Physische Gewalt, und sie allein, gibt ihn auf diesem Gebiete die Sanktion" (I, § 4, Coroll. 3). „Der Rechtsbegriff ist der Begriff eines Verhältnisses $\mathbf{z}$ wischen Vernunftwesen. Er findet daher nur unter der Bedingung statt, dass solche Wesen in Beziehung auf einander gedacht werden." Aber (4) „nur durch Handlungen, Äusserungen ihrer Freiheit in der Sinnenwelt, kommen vernünftige Wesen in Wechselwirkung miteinander: der Begriff des Rechts bezieht sich sonach nur auf das, was in der Sinnenwelt sich äussert: was in ihr keine Kausalitä́t hat, sondern im Innern des Gemüts verbleibt, gehört vor einen andern Richterstuhl, den der Moral“ (5). „Nur inwiefern vernünftige Wesen wirklich in Verhältnisse miteinander stehen, und so handeln können, dass die Handlung des Einen Folgen habe für den Andern, ist zwischen ihnen die Frage voun Rechte möglich, wie aus der geleisteten Deduktion, die immer eine reelle Wechselwirkung voraussetzt, hervorgeht." (Ebenda IV:). „Es lässt sich gar kein absoluter Grund aufzeigen, warum jemand sich die Rechtsformel: beschränke deine Freiheit so, dass der Andere neben dir auch frei sein kömne, zum Gesetze seines 
Willens und seiner Handlungen machen sollte. Soviel lässt sich einsehen, dass eine Gemeinschaft freier Wesen, als solcher, nicht bestehen könne, wenn nicht jeder diesem Gesetze unterworfen ist; und dass sonach, wer diese Gemeinschaft wolle, notwendig das Gesetz auch wollen müsse; dass es also hypothetische Gültigkeit habe ... Aber die Bedingung sogar, die Gemeinschaft freier Wesen, is t abermals bedingt durch ein gemeinschaftliches Wollen. Keiner kann durch seinen blossen Willen eine solche Gemeinschaft mit einem Andern realisieren, wenn der Andere nicht denselben Willen hat..." Die bis dahin von Keinem recht erkannte Schwierigkeit liege hier darin: "Wie mag doch ein Gesetz gebieten dadurch dass es nicht gebietet?" (Nämlich das Recht bestimmt nicht positiv zum Handeln, sondern sichert nur jedem seine Freiheit zu handeln.) Antwort: dadurch dass das Gesetz sich eine bestimmte Sphäre begrenzt und alles, was ausser dieser Sphäre liegt, freilässt. „Das Sittengesetz ist nicht von der Art. Es setzt sich keine bestimmte Sphäre, soudern gebietet über alles Handeln der vernünftigen Geister, folglich hätte man aus ihm den Rechtsbegriff nicht ableiten sollen" (ebenda in der Anmerkung; vgl. Einl. III mit Bezug auf Kant: Das Rechtsgesetz ist ein bedingtes Gesetz, also von dem schlechthin unbeding ten und daher unbeschränkten sittlichen Gesetz unmöglich abzuleiten.)

Immerhin erhält das Recht durch das Sittengesetz eine "neue Sanktion für das Gewissen" (Einl. II, 5): Ich muss mich notwendig in Gesellschaft mit Andern denken, aber ich kann dies nicht, ohne meine Freiheit durch die ihrige beschränkt zu denken; nach diesem notwendigen Denken muss ich nun auch handeln, sonst stehe ich mit mir selbst im Widerspruche; ich bin im Gewissen, durch mein Wissen, wie es sein soll, verbunden, meine Freiheit zu beschränken. Von dieser moralischen Verbindlichkeit ist aber in der Rechtslehre nicht die Rede, jeder ist nur verbunden durch den willkürlichen Entschluss, mit Anderen in Gesellschaft zu leben; und wenn jemand seine Willkür gar nicht beschränken will, so kann man ihm auf dem Gebiete des Naturrechts weiter nichts entgegenstellen, als das, dass er sodann aus aller menschlichen Gesellschaft sich entfernen müsse. (Schroffer noch 2. Hptst. § 7, II: „Man kann in Naturrecht jedem nur sagen, das und das werde aus seiner Handlung folgeu. Übernimmt er dies nun, oder hofft er ihm zu ent- 
gehen, so kann man weiter kein Argument gegen ihn brauchen.") Andrerseits ist „dem Gerechten kein äusseres (Zwangs-) Gesetz gegeben; er ist von demselben ganz befreit, und durch seinen eigenen guten Willen davon befreit" (2. Kap. der Rechtsl. § 14).

Die Scheidung wird unverändert festgehalten im "System der Sittenlehre" von 1798. Selbst noch das "System der Sittenlehre" v. J. 1812 tut keinen Schritt, sie etwa rückgängig zu machen. Zwar der Sittliche muss die Sittlichkeit Aller wollen; der sittliche Wille hat stets zum Ziele eine Sittlichkeit ausser sich (S. 85); denn "das Objekt des Menschen ist immer der Mensch. Ich weiss nicht, ob dies jemals in der Sittenlehre deutlich ausgesprochen worden ist" (S. 83). Aber die Hervorbringung der Sittlichkeit d. i. des absolut guten Willens im ganzen Geschlechte ist anzustreben - nicht auf dem Wege des Rechts, im Staat, sondern in der Kirche, als Moralisierung Aller, "Erbauung Aller zu einer einzigen sittlichen Gemeinde" (S. 77). Mit den Staat hat es die Sittenlehre "nicht zu tun" (S. 103). Nirgends findet man hier die Spur einer Zurückleitung des Rechtes selbst auf die Sittlichkeit.

Indessen hat gerade unter Fichtes letzten Voraussetzungen diese Trennung etwas Gewaltsames. Deshalb verwundert man sich weniger, dass im letzten Stadium seiner Entwicklung, in den Vorlesungen über die Staatslehre vom Sommer 1813 (Angewandte Philosophie; 3. Abschn. Von der Errichtung des Vernunftreiches. Voraussetzungen; Bd. IV, S. 432) der frühere Standpunkt auf einmal verlassen wird. Fichte erklärt hier: das Vernunftgesetz, dass keiner die Freiheit eines Andern und des Ganzen stören oder aufhalten soll, d. b. das Rechtsgesetz, „ist selbst ein sittliches Gesetz, denn es ist die Bedingung aller Sittlichkeit. Das Recht soll also schlechthin herrschen, so gewiss die. Sittlichkeit schlechthin sein soll." Dabei bleibt jedoch die früher behauptete Eigenheit des Rechts voll gewahrt; denn unmittelbar nach obigen Sätzen heisst es weiter: „Und zwar ist es das Gesetz der Bedingung." Aber dieses steht eben selbst zuletzt unter dem unbedingten Gesetze der Sittlichkeit.

Nicḥt. als Gegensatz oder gar Widerstreit zwischen Recht und Sittlichkeit, sonderu nur als Antinomie innerhalb des selbst sittlichen Gesetzes des Rechts - eine Antinonie, die aus dessen letzter Begründung sich verstehen und daher auch auflösen lassen muss - tritt daher jetzt auf die Entgegensetzung, auf die ja die 
Unterscheidung von Recht und Sittlichkeit ganz und gar gegründet wurde: von Freiheit und Zwang (ebenda S. 433): „Das Reich der Freiheit schliesst aus jeden Zwang, dies liegt im Rcchtsgesetze; der Zwang ist absolut gegen das Recht“; denn „er raubt die innere (!) Freiheit des Individuums" (!). Indessen „was im Rechtsbegriffe liegt, soll schlechthin sein; denn das einen jeden gebotene Sittliche soll schlechthin sein. Ohne Freilheit"die das Recht eben sicherzustellen hat - „ist aber sittlicher Zweck gar nicht ausführbar"; der Rechtsbegriff müsste darum sogar mit Zwang und mit Gewalt durchgesetzt werden ... Für das Recht ist sonach der Zwang sogar geboten; wie viel mehr also erlaubt." Die Lösung der Antinomie beruht darauf: der "Satz“ (der absoluten Freiheit) erkennt solche nur an „in der sittlichen Welt; einer andern sie gar nicht zugestehend"; der "Gegensatz" (vom Zwang) nimmt beide Welten ins Auge und will den Übergang von der einen zur andern auch als Freiheit erfassen: „auch im Übergange zu jener Welt, in der du nicht geboren bist, bist du dein eigenes Prinzip“. Daher redet der Satz vom Willen, nicht von der Tat, der Gegensatz von der Tat, nicht vom Willen. "Will also jener, dass das Rechtswidrige geschehe, die Naturgewalt herrsche? Wie kann er, ohne die Erscheinung des sittlichen Reiches ganz unmöglich zu machen? Nur will er, es solle aus Einsicht, aus den Willen bewegender Einsicht unterlassen werden; unterlassen also freilich. Über die Unterlassung, als unbedingt notwendig, sind beide einig; der letztere fügt bloss einen Bestandteil hinzu, den der erstere überging. Und so ist denn ihr Verhältnis gefunden. Der erste will, wobei angehoben werden muss, der zweite, was nachgeholt werden soll"; das heisst, das Rechtswidrige, die ungezähmte Naturgewalt, muss anfangs bloss durch Zwang, ohne Einsicht und guten Willen, unterdrückt werden, aber Einsicht und guter Wille muss nachkommen. So ist der $\mathrm{Z}$ wang gerechtfertigt, jedoch nur unter der Bedingung, dass mit der $\mathrm{Z}$ wangsanstalt eine zweite verbunden werde, um alle zur Einsicht der Rechtmässigkeit des Zwanges und so - zur Entbehrlichkeit desselben zu bringen (S. 437). „Das aber, wozu gezwungen wird, und das, was durch Erziehung der Einsicht hingelegt wird, ist durchaus dasselbe; das letztere kanu aber uur der Vernunftbegriff sein vom Rechte; denn über nichts anderes kann die Einsicht Aller sich vereinigen" (S. 438). „Rechtszwang wird nur durch beigefügte Erziehung“ des 
gezwungenen Volkes zur Einsicht und zum guten Willen „rechtmässig; ausserdem ist er rechtswidrig“. Also „kein Zwang, ausser in Verbindung mit der Erziehung zur Einsicht in das Recht ... . der Zwingherr zugleich Erzieher . . . dadurch ist erst die Gleichheit wiederhergestellt; der Zwingherr macht den Gezwungenen wieder zu seinem [verstehe: seinem eigenen] Richter" (S. 437 f.).

Das vorzüglich Belehronde in diesen Sätzen (deren weitere Durchführung hier beiseite bleiben muss) erkennen wir darin: dass in der nun so sicher erreichten Vereinigung von Recht und Sittlichkeit das Motiv, das früher zu ihrer Scheidung geführt hatte, doch nicht untergegangen ist: es bleibt der Unterschied äusserer und innerer Verpflichtungsart, der im "Naturrecht" in Schärfe so bestimmt wurde: dass die Rechtspflicht bedingt, und zwar durch eine nicht bloss gedachte, sondern reelle Wechselwirkung Mehrerer bedingt, daher nicht von dem Willen des Einen allein abhängig, unter der gesetzten Bedingung aber (dass Gemeinschaft sein solle) für jeden, ohne Frage, ob er will, äusserlich, heteronom - die sittliche Verpflichtung als solche bedingungslos, von keiner reellen Wechselwirkung Mehrerer abhängig, daher für einen jeden für sich, innerlich, autonom - bindend ist. Beides gilt nur jetzt mit- und in enger Beziehung zu einander: indem das autonome Sittengesetz selbst für die Sphäre der äusseren Verbindung mehrerer Willen, das heisst für die Aufgabe der Herbeiführung einer Gesetzesordnung, die noch nicht ist, aber werden soll, die Heteronomie, den Zwang des äusseren Rechts rechtfertigt, ja notwendig macht. So stehen nicht mehr zwei Gesetzlichkeiten erst beziehungslos nebeneinander, um allenfalls hinterher ihre Vereinigung zu suchen; wohl aber bleibt unterhalb des einen letzten Gesetzes der Freiheit dennoch die Zweiseitigkeit der Betrachtung, wie wir sagen würden: vom Zentrun der Selbstgesetzgebung aus (als sei sie, und nur sie, von Haus aus da), und von der Peripherie einer vorerst naturartigen Wechselbeziehung aus, die zur sittlichen erst den Weg sucht, aber allerdings nur im Hinblick auf das gedachte, stets an sich voraus zu denkende Zentrum diesen Weg finden und bestimmen kann. In dieser allgemeinen Richtung dürfte aber die Lösung der Frage überhaupt nur gesucht werden können.

$\S$ 4. (B. Wischeslavzeff.) Auf die soeben berührte „Antinomie" in Fichtes "Staatslehre" von 1813 hat kürzlich Boris 
Wischeslavzeff in dankenswerter Weise aufmerksam gemacht (s. Philos. Abhandlungen, H. Cohen z. 70. Geburtstag dargebracht, Berlin, Br. Cassirer, 1912, S. $190 \mathrm{ff}$.) ; und es wird sich zweckdienlich erweisen, auch darauf in kurzem einzugehen. Für ihn löst sich die Antinomie so: das Recht erstrebt eine bewusste Organisation gemeinschaftlichen Handelns, d. i. eine bewusste zweckmässige Wechselbeziehung aller Subjekte durch ihre Willenshandlungen, so dass jeder zugleich Mittel, wie andrerseits Zweck, für die Andern sei. Nicht die ganze Person aber darf als Mittel für fremde Zwecke in Anspruch genommen werden, sondern nur ihre äusseren Handlungen. Darum aber wird die zweckmässige Vereinigung der Handlungen durch das Recht nur negativ bedingt, nicht positiv konstruiert; nur die "Wechselbegrenzung der Sphären der Freiheit oder der Willkür" hat das Recht zu vollziehen. Es sichert daher nur die Möglichkeit der Handlung, deren Konkretisierung zur wirklichen Handlung es einer überjuridischen Sphäre freilässt, welche aber darum nicht überethisch sein kann: der der individuellen Moral. Nicht als ob dem Rechte das Gebiet des Innern und Individuellen, der Moral (i. e. S.) das des Äusseren, Sozialen verschlossen sein solle; aber das Innere und Individuelle geht das Recht nur an im Hinblick auf ein äusseres, ins soziale Leben sich erstreckendes Handeln, umgekehrt das Äussere, Soziale die Moral nur als Darstellung des Innern, Individuellen. Moral und Recht bedeuten also nicht zwei Seiten der Ethik, etwa die subjektive und die objektive, oder die individuelle und die soziale; sondern zwei Stufen, unterschieden lediglich nach dem modalen Verhältnisse der Möglichkeit und der Verwirklichung. „Die Harmonie der (äusseren) Organisation (des Rechts) ist für die Moral erforderlich, ist in ihr enthalten, sie ist ihre Bedingung, wie die richtige Stimmung der Saiten Bedingung jeglicher Melodie ist. Doch ist auch die vollkommenste Stimmung der Saiten nicht die Bestimmung der Melodie, die erklingen soll." Das Moment der Organisation verbleibt zwar auch der ideellen, moralischen Gemeinschaftsordnung; daher wird z. B. die Gemeinschaft der Heiligen von Augustin als Gottesstaat (Civitas Dei) d. h. nach Analogie einer Rechtsordnung gedacht. „Doch wird die Allheit hier tiefer und inuerlicher harmonisiert, weil jetzt das Innerliche und Individuelle in ihr erklingt.“ Die Atome der Rechtssubjekte werden zu Monaden in innerlicher IVechselbeziehung; als „lebendige Spiegel“ des einen, unendlichen 
(sittlichen) Universums durch die F'esseln der Liebe, der Freundschaft verbunden. Der Zwang des Rechts ist nutwendig, aber nur um der Freiheit willen; so ist sein Zwang selbst - Befreiung.

In dieser Lösung liegen, nebeu Anfechtbarem, einige sehr förderliche Anregungen. Wie man leicht erkennt, ist für Wischeslavzeff der Unterschied zwischen Recht und Sittlichkeit keineswegs bloss ein methodischer, sondern zugleich ein inhaltlicher; so aber, dass die juridische Sphäre in der moralischen eingeschlossen liegt, alles rechtlich Geforderte (wie bei Kant und Fichte) auch moralisch gefordert bleibt, nämlich als Bedingung, aber nur negative Bedingung des eigentlich und im engern Sinne Sittlichen, das erst oberhalb der Sphäre des Rechtes beginnt. Dies will nun so nicht einleuchten. Das Recht, sogar in seiner unvollkommenen Wirklichkeit, vollends seiner reinen Idee nach verstauden, ist sicher nicht bloss negativ bedingend, mag es auch die entfernteren Vorbedingungen eines einheitlichen Zusammenwirkens, die man als negative immerhin bezeichnen mag, leichter und sicherer, daher tatsächlich in viel weiterem Umfang, in bestimmtem Sinne sogar erschöpfend, schon heute erfassen, während die Erfassung des positiven Wirkens bisher höchst unvollkommen und nichts weniger als allgemein gesichert ist. Aber entfernt nicht kann behauptet werden, dass das Recht überhaupt, seinem Wesen nach, nur negativ verbinden könne und verbinden wolle. Die Wehrpflicht z. B., doch gewiss eine rechtliche Pflicht, bestimmt den Verpflichteten wahrlich nicht bloss negativ. Und wenn durch die Verpflichtung des vom Staat bestellten Lehrers (z. B. der Wissenschaft), oder des Richters, des Abgeordneten etc. die Art, wie im besondern er sein Amt zu versehen habe, bis auf wenige negative Beschränkungen nicht buchstäblich rechtlich festgelegt sondern seiner eignen Einsicht und Gewissenhaftigkeit anheimgestellt wird, so ist er darum nicht weniger von Gesetzes wegen, also in rechtlicher Art, verpflichtet, positiv sein Bestes an seiner Stelle zu tun, und nicbt bloss negativ, jene sehr groben äusseren Schranken nicht zu überschreiten. Und eben damit ist schon gesagt, dass das Recht nicht bloss äusserlich fassbares "Tun" normiert, sondern in das Innere der "Gesinnung" sogar tief. eingreift. Nur vermag es freilich durch seine gewöhnlichen Zwangsmittel nicht allgemein die Gesinnung, sondern allgemein allenfalls nur das äussere Tun, und selbst bei diesem nur die Innehaltung gewisser Schranken, wirklich sicherzustellen. Hiernach ḳam es aber nicht richtig sein, dass 
der Zwang dus Recht konstituiere. Er konstituiert nicht einmal das sogenannte positive, geschweige das ideale Recht. Die Grenzen des Erzwingbaren sind entfernt nicht und in keinem Sinne die Grenzen des Rechts.

Wischeslavzeff betont doch selbst - und gerade darin erkennen wir ein tiefer in die Sache führendes Motiv - : dass überhaupt nicht an sich der Gegensatz des Innern und Äussern, oder des Individuellen und Sozialen, nämlich sofern beides auf den Inhalt des Gesetzes bezogen wird, die Grenze zwischen Sittlichkeit und Recht bestimmen kann, da beide Gegensätze für beides, Recht wie Moral, Geltung haben; nur mit dem Unterschied, der eben der Unterschied ihrer Methode ist: dass das Recht das Innere vom Äussern her, die Moral umgekehrt das Äussere vom Invern her bestimmt. So ist es aber möglich, und es ist zugleich ideal gefordert, dass die Sphären beider, wenn nicht schon sich decken, dann mehr und mehr zur Deckung gebracht werden, oder ihr stetig angenähert werden müssen, jedoch so, dass immer die geraden Linien des Rechts gleichsam von der Peripherie zum Zentrum, die der Moral vom Zentrum zur Peripherie den Weg suchen. So scheinen beide auseinander zu fallen oder auf ihre Vereinigung allenfalls erst hinzustreben, nämlich sofern uud solange beide in der Durchführung ihrer Methode noch nicht weit genug gelangt sind. Denn freilich nur in ihrer idealen Vollendung würden sie vollständig, der Sphäre nach, zusammenfallen, danit aber auch der Unterschied des "Gesichtspunkts", der theoretisch immer seine Geltung behält, für jede praktische Erwägung so gut wie bedeutungslos werden. Indessen, da tatsächlich diese vollständige Decknng nicht erreicht ist, ja nie erreicht sein kann, so bebält der Unterschied, praktisch wie theoretisch, immer seine nicht zu übersehende Bedeutung und Tragweite. In solchem Sinne also dürfte eine strenge, wiewohl nur ideelle Vereinigung von Recht und Moralität, unbeschadet ibres sicheren methodischen Unterschieds, zu behaupten sein.

$\S 5$. (Das Problem der kategorialen Begründung der praktischen Philosophie.) Noch besondere Aufmerksamkeit aber verdient Wischeslavzeffs "modale“ Unterscheidung beider nach "Möglichkeit" und „Verwirklichung“. Es fragt sich: wie verhält diese sich einerseits $\mathrm{zu}$ der methodischen Unterscheidung der „äusseren“ und „inneren“ Verpflichtungsart, andererseits zu der inhaltlichen Unterscheidung der Bestimmung des äusseren Verhaltens 
und der inneren Gesinnung, oder der Beziehung der Verpflichtung auf das Zusammenwirken in der Gemeiuschaft und anf die Verfussung des isoliert betrachteten Einzeluen" Diese Frage aber fïhrt tief hinein in die ganz neue, von wenigen erst in ihrer Bedeutung klar erkannte Aufgabe einęr kategorialen Begründung der praktischen Philosophie überhaupt. Anf diese Aufgabe hat besonders $\mathrm{H}$. Cohen die Aufmerksankeit gelenkt; vorgreifend mag hier nur beispielshalber (auf das Sachliche der Frage kommen wir zurück) daran erinnert werden, dass Cohen jedes Ausgehen vom Individuum, sei es in der Rechtslehre oder in der Ethik, mit der Begründung abwehrt, dass zufolge der "Logik der reinen Erkenntnis" das Einzelne überhaupt keine konstitutive, sondern allenfalls nur eine modale Kategorie sei. Es ist ersichtlich, dass hier manche Verwickelung ihrer Auflösung erst harrt, ehe man von Innerem und Äusserem, Individuum und Gemeinschaft bei Begründung der Rechtsphilosophie mit logischem gutem Gewissen überhaupt reden kann.

Die Rechtsphilosophie, welche eine wenngleich bedingt selbstständige Stellung des Rechts gegenüber oder innerhalb der Sittlichkeit behauptet, stützt sich, wie sich gezeigt hat, wesentlich und fundamental eben auf die Unterscheidung des Inneren und Äusseren; sie hat stets die Rechtsordnung als äussere der sittlichen als innerer Bestimmung des Willens gegenübergestellt. In der T'endenz aber, bei dieser schwerlich ganz wegzuwerfenden in ethodologischen Unterscheidung die schliessliche sachliche Einheit von Recht und Sittlichkeit doch zu behaupten, glaubten wir diese Unterscheidung dahin präzisieren zu müssen: dass das Recht "von der Peripherie zum Zentrum", die Sittlichkeit "vom Zentrum zur Peripherie hin“ ihre Richtlinien zu beschreiben babe. Es fragt sich, was dies in Hinsicht der kategorialen Begründung. beider, des Rechts und der Sittlichkeit, genau besage. Indem ich diese Frage zu beantworten versuche, kann ich wobl nicht anders als die Ordnung der Kategorien, so wie sie sich mir bis dahin in der Logik der theoretischen Erkenntnis bewährt hat, zunächst gleichsam als Hypothese zugrunde zu legen; ihre Bewährung in der Begründung der praktischen Philosophie mag dann zu einem neuen Prïfstein für die Richtigkeit der allgemein-logischen Aufstellung dienen.

In Hinsicht der Quantität würde, nach meiner Auffassung derselben, zentrale Betrachtung die zu nennen sein, welche vom allgemeinen und zwar unbedingt allgemeinen, $d . h$. dem Um- 
fang nach allumfassenden Gesetze her das Besondere und Einzelne, peripherische die, welche vom Einzelnen her, als sei es gegeben, auf dem Wege über das Besondere, das Allgemeine irgendwelches Umfangs zu bestimmen sucht.

In Hinsicht der Qualität wäre zentrale Betrachtung die, welche vom Kontinuum der Gattung, als qualitativer Allheit, diszernierend, also spezifizierend, das qualitativ Besondere und schliesslich Einzelne, die Sonderart und Einzelart (Individualität) des jeweils Bestimmbaren dem Inhalt nach bestimmt, peripherische die, welche vom letzteren aus, als sei es gegeben, zur Vereinigung im qualitativen Kontinuum erst hinstrebt.

In Hinsicht der Relation, im bestimmten Kantischen Sinne der dynamischen Beziehung, würde zentrale Betrachtung die sein, welche vom reinen Gegenseitigkeitsbezug im System aus in gleichsam linearer Bestimnung bedingende Verhältnisse des Besonderen, und erst zuletzt eine etwaige Substantialität des Einzelnen, Individuellen $\mathrm{zu}$ bestimmen unternimmt, während die peripherische Betrachtung von der letzteren aus, als sei sie gegeben, über die besonderen Bedingungsverhältnisse zu einer systenartigen Erfassung dynamischer Wechselbeziehungen erst hinaufstrebt.

In Hinsicht der Modalität endlich würde die zentrale Betrachtung von der apriori zu fordernden Notwendigkeit, d. h. absoluten (methodisch absoluten, nicht weiter bedingten) Einheit der logischen Bestimmung aus den Stufengang der Verwirklichung dieses Notwendigen und die über das auf gegebener Stufe Verwirklichte hinaus offen bleibenden Möglichkeiten zu erfassen suchen; die peripherische von supponierten Möglichkeiten aus, mit deren versuchsweise gewagter Aufstellung sie in dem flutenden Meere des Bestimmbaren nur überhaupt einmal fusszufassen vermag, in Schritt um Schritt vordringender Verwirklichung des Möglichen dessen schliesslich geforderte Verankerung im Notwendigen (Vernotwendiguug) anstreben.

Es fragt sich nun: entspricht die Unterscheidung des Rechts als „äusserer", der Sittlichkeit als „innerer" Willensbestimmung dieser vierfachen kategorialen Bedeutung des Äusseren und Inneren, und zwar in Hinsicht der Inhaltsbestimmung der beiderseitigen Verpflichtung sowohl als der Art der Verpflichtung?

Zunächst diese doppelte Fragerichtung selbst, auf die wir uns wieder und wieder hingewiesen sahen, der methodischen und inhaltlichen, oder formalen und materialen Erwägung, scheint 
genau auf den Unterschied der konstitutiven, eben den Inhalt der Erkenntnis konstituierenden, und der modalen, die "Art", den Modus des Procedere betreffenden Bestimmungsweise zurückzugehen.

In Hinsicht des Inhalts nun. führt sich die Unterscheidung des Äusseren und Inneren sofort rein und zweifelsfrei im erklärten Sinne kategorial durch. Nämlich das Recht erfasst die Handlung peripherisch, indem es sie, quantitativ, allemal als Einzelfall, d. h. subsumierend, durch Besonderung irgend eines begrenzt Allgemeinen - qualitativ als individuell, im Sinne der Spezifikation, stets doch im Hinblick auf eine, vorerst aber nur begrenzte Gattungskontinuität bestimmte - dynamisch als die des einzelnen Wirkenden, in bestimmt bedingter Wirkungsreihe, obzwar immer im Hinblick auf ein gefordertes, vorerst jedoch begrenztes Sys te m der Wechselwirkung, ins Auge fasst. Die sittliche Beurteilung dagegen, als „innere“, stellt ohne jede Einschränkung den Gesichtspunkt der Allgemeinheit der Willensbestimmung überhaupt, der kontinuierlichen Einheit alles zulässigen Willensinhalts, und der wechselseitigen Verbundenheit der Zwecke in einem allbefassenden $Z$ wecksystem, der dynamischen Bedingtheit nach, an die Spitze und verlàngt, dass der Urteilende, nämlich sein eignes Wollen Beurteilende streng und ausschliesslich von dieser Zentralstellung aus - die besonders von Cohen, unter dem Namen der "Allheit“, unablässig betont wird - alles Peripherische am beurteilten Wollen richte und bestimme.

Nicht ganz so unmittelbar einleuchtend scheint unsere kategoriale Interpretation des Verhältnisses des Äusseren und Inneren nach der andern, der modalen oder methodischen Richtung sich zu bewähren. Das Recht als „äussere" Regelung soll in methodischer Hinsicht äussere d.h. gegenseitige Bindung bedeuten; es könnte danach scheinen gerade vom System, mindestens von der Forderung, vom Gedanken des Systems und also der gesetzlichen Notwendigkeit aus, also zentral, das Einzelwollen zu bestimmen; während die Sittlichkeit des Individuums alles auf Selbstbestimmung vom Einzelnen aus abstelle und so all sein Wollen, auch das nach aussen, auf die Gemeinschaft (als Allheit) gerichtete, von „innen“ d. h. eben vom Einzelnen her, also peripherisch regle, zur zentralen Bestimmung des Handelns im Sinne der Allheit erst vom engeren Bereich aus hinstrebe: So konnte Kant gradezu die recht- 
liche Bestimmung als „objektive“ der sittlichen als „subjektiver" gegenüberstellen.

Allein eben diese zunächst auffällige Wendung führt sofort auf den rechten Weg. Nämlich das sich selbst bestimmende „Subjekt" ist ja, eben nacb Kant, nicht das Individuum, im Sinne des isoliert betrachteten einzelnen Subjekts; es ist, nach seiner Redeweise, nicht das e mpirische, sondern das intelligible Subjekt. Die von Kant gemeinte "Subjektivität" der Bestimmung, nämlich die Autonomie, vertritt daher gerade die echteste Objektivität der Willensbestimmung, aus dem Standpunkte der unbedingt reinen Gesetzlichkeit; während die sogenannte „Objektivität“ eines bestimmten Rechtsgesetzes immer mehr oder minder (in transzendentalen Sinne) "subjektiv" bedingt, nämlich auf irgend einen empirisch beschränkten Standpunkt der Beurteilung bezogen bleibt.

Weil aber das unbedingt bestimmende "Selbst" der Sittlichkeit nicht das des Individuums, im Sinne des isoliert betrachteten Einzelsubjekts, sondern das ideale Selbst ist, das nicht mehr meines als eines Andern ist, so muss die von ihm aus getroffene Bestimmung auch gerade im Sinne unbedingter Gleichheitlichkeit und Gegenseitigkeit, also im vollen und reinen Systemsinn erfolgen, während in der rechtlichen Regelung, als bedingter, auch die angestrebte Gegenseitigkeit und Gleichheit nur bedingterweise erfüllt sein, also auch nur als bedingte vom Rechte selbst vorausgesetzt werden kann. Gerade deshalb bedarf es hier der heteronomen Bindung, der Verpflichtung gegeneinander, also von aussen her, die dagegen für den Standpunkt der reinen Sittlichkeit darum überhaupt nicht. in Frage kommen kann, weil für sie die "innere" Verpflichtung, nach Massgabe des reinen Gesetzes, bloss als solchen, als genügend gelten muss, das besondere, einzelne Wollen mit unbedingter Notwendigkeit zu bestimmen. Sittlich ist gewiss, dem Inhalt nach, ein jeder in Hinsicht des Andern, aber darum nicht dem Andern verpflichtet (nicht der Andere verpflichtet ihn), sondern er bedarf nur des eigenen Bewusstseins des reinen Gesetzes, um sich, und zwar unbedingt, verpflichtet $z \mathfrak{u}$ wissen. Das allein ist der echte Individnalcharakter der Sittlichkeit. So aber verpflichtet die Sittlichkeit innerlich a. h. zentral, vom Zentrum der unbedingten Gesetzesforderung aus. Dagegen beruht die Eigenheit des Rechts als „änsserer" Bindung genan daranif, dass die rechtliche Regelung 
als solche, nämlich die jedesmal bestehende rechtliche Ordnung, jederzeit nur bedingt ist und sein kann. Als bedingte kann sie nicht unbedingt verpflichten, darum genügt für sie nicht die "innere" Bindung, die nur als unbedingte, aus dem reinen Bewusstsein des praktischen Gesetzes, ohne anderweitige "Triebfeder", verständlich ist.

Damit aber klärt sich nunmehr der modale Charakter der rechtlichen Bestimmung, als Bestimmung im Sinne der Möglichkeit, nicht aber der vollendeten Wirklichkeit und Notwendigkeit der Gesetzesordnung, auf den wir durch Wischeslavzeff aufmerksam gemacht worden. Das Recht, als wirklich bestehendes, ist stets nur ein Versuch, durchgängige Übereinstimmung des Handelns herzustellen. Einstimmigkeit des Handelns überhaupt ist apriori gefordert, wie aber ein gegebenes, "gesetztes" Recht sie herzustellen . versucht und überhaupt nur versuchen kann, ist sie niemals unbedingt, sondern nur bei gegebener Lage, also bedingt notwendig: um überhaupt eine Zusammenstimmung, nicht sofort als unbedingte, zu ermöglichen. So erklärt und hebt sich zugleich der Sehein des bloss "negativ" vorbedingenden Charakters des Rechts. Die Ermöglichung der Zusammenstimmung zielt doch auf das Wirklichwerden einer solchen und zuletzt auf deren Notwendigkeit. Nur ist der Gang des Rechts eben dieser: von der Peripherie zum Zentrum, das heisst vom gleichsam hypothetischen Ansatz: so und so würde das Handeln einstimmig werden, in schrittweis vordringender praktischer Bewährung der „notwendigen“ Einstimmung asymptotisch sich nähernd. Die nicht unbedingt notwendige Zusammenstimmung muss eben "gesetzt", d. h. von aussen her bestimmt werden, sie ist insofern unvermeidlich "heteronom"; erst die ideale, unbedingt notwendige Zusammenstimmung würde keiner äusseren "Satzung" mehr bedürfen, weil sie, eben als unbedingte, von selbst einen jeden von ,innen" her bestimmen würde. Und so ist es allerdings an sich, und das heisst: vom Standpunkt reiner Sittlichkeit, gefordert.

So aber steht nun dieser ganze Stufengang bedingter $\mathrm{Z}$ weckordnung zuletzt doch unter demselben, unbedingten, autonomen Gesetze einheitlicher Zweckordnung, von welchem die Sittlichkeit sogleich den Ausgang nimmt, um aus seinem Standpunkt nach der Peripherie, das heisst zur bedingten Zweckbestimmung hin die Richtlinien zu entwerfen. Dabei aber kann sie nun umgekehrt garnicht umhin die heteronomen Bestimmungen 
jeweils gesetzten Rechtes wenigstens als Vorstufe und Schule zur Sittlichkeit gelten zu lassen und in ihren Dienst zu nehmen. Während daher das Recht unmittelbar stets heteronom ist, auf Autonomie erst von weitem hinzielt, spricht sich die sittliche Forderung unmittelbar als autonome aus, muss aber doch, sobald sie sich konkretisieren will, bloss bedingt Notwendiges gelten lassen. Auf solches aber kann sie, ihrem eigenen Prinzip zufolge, sich nicht mehr als autonome erstrecken; es kann somit, wenngleich immer zuerst und zuletzt unter dem Gesichtspunkte der sittlichen Gesetzgebung d. h. unter der Idee einer letzten, autonomen Willensbestimmung, dennoch selbst nur heteronom gefordert werden. So werden also die konkret verstandene Sittlichkeit und das konkret verstandene Recht den gleichen Charakter bedingter, also heteronomer Forderung zeigen, ja in den gleichen heteronomen Forderungen schliesslich zusammentreffen müssen, und allein die ideale sittliche Ordnung, die zugleich die ideale Rechtsordnung wäre, autonom gefordert sein. Und so wäre wiederum aller prinzipielle Unterschied zwischen Recht und Sittlichkeit aufgehoben, bliebe nicht eben der Unterschied der Betrachtungsrichtung, von der Peripherie zum Zentrum im Recht, vom Zentrum zur Peripherie in der Sittlichkeit; ein Unterschied der Methode, der mit der völligen Koinzidenz nicht bloss des letzten Prinzips, sondern auch der konkreten Einzelbestimmungen (als konkreter, mithin in bloss bedingter Geltung) wohl vereinbar ist, ja notwendig zusammengeht. Diese ganze Doppelrichtung reiner und positiver Betrachtung besteht in der praktischen Sphäre aus gleicher Notwendigkeit wie in der theoretischen, wo er den Unterschied und das Gegenverhältnis reiner Methodenund positiver Tatsachen-Wissenschaft begründet.

§ 6. (Cohens methodische Beziehung der Sittlichkeit auf das Recht.) Glauben wir so den sachlichen Grund sowohl der methodologischen Scheidung von Recht und Sittlichkeit als auch ihrer schliesslich notwendigen systematischen Vereinigung einzusehen, so sind wir hinreichend vorbereitet, nun die bestimmte Ausprägang dieses Gegensatzes sagen wir des Monismus und Dualismus des Rechtlichen und Sittlichen in den Theorieen von H. Cohen einerseits, R. Stammler andrerseits in Prüfung $\mathrm{zu}$ ziehen und den möglichen Ausgleich zwischen beiden zu suchen. Und zwar beginnen wir mit Cohens reiner Vertretung der monistischen Ansicht, um für die Beurteilung 
Stammlers, auf die es zuletzt hier abgesehen ist, die vollends gesicherte Grundlage zu gewinnen.

Die Einheit von Sittlichkeit und Recht wird bei Cohen, vielleicht zum ersten $\mathrm{Mal}$ in der ganzen Geschichte unseres Problems, dadurch zu einer fast absoluten, dass nicht nur das Recht ganz und gar in der Sittlichkeit, sondern in anderem Sinne die Sittlichkeit ganz im Recht gegründet und schon beinahe restlos auf es restringiert wird.

Und dies aus doppeltem Grunde. Erstens formal fordert Cohen, gemäss dem Grundgedanken der transzendentalen Methodik, für die Begründung der Ethik die strikte und ausschliessliche Beziehung auf das Faktum einer Wissenschaft; diese könne aber keine andre sein als die Rechtswissenschaft. Zweitens material gibt es nach Cohen Handlung überhaupt nur im Gegenverhältnis des Handelnden zum Andern; und zwar wie es im Staat, also unter dem Rechtsgesetz sich bestimmt. So wenigstens nach den weitestgehenden Formulierungen, die allerdings im besondern manche Einschränkung sich gefallen lassen müssen. Wir prüfen zunächst die erste, methodologische Aufstellung.

Die Ethik, als Glied des philosophischen Systems, als die Logik der Handlung, hat sich auf die Kultur, d. h. auf die Wissenschaft von ihr, zu beziehen, so wie die Logik der blossen Theorie (wir erlauben uns dafür abkürzend "Theoretik" zu setzen) auf die Natur, auf die Naturwissenschaft (Ethik ${ }^{2}$, S. 64). Wie aber diese in der Mathematik ihre allgemeine methodische Grundlage (Grundlegung) anerkennt und darum die Logik der Theorie engsten Bezug auf die Mathematik, als das Feld ihrer unmittelbaren Bewährung, zu nehmen hat - denn es ist "Geist von ihrem Geist", der in ihr Fleisch geworden ist (S. 65) - , so hat die Rechtswissenschaft, als systematische Entwicklung des praktischen Grundbegriffs der menschlichen Handlung, die methodische Grundlegung für die Kultur- oder Geisteswissenschaften insgesamt zu leisten, und ist also die Ethik, als die Logik der Geisteswissenschaften, anf die Rechtswissenschaft als deren allgemeine Methodik, als gleichsam die „Mathematik der Geisteswissenschaften:", angewiesen; sie ist das der eigentlichen Mathematik entsprechende "Analogon eines Faktums", an dem sie ihre Aufstellungen im gleichen Sinne zu präzisieren und zu sichern hat, wie die Logik der Naturwissenschaft an der Mathematik (S. 65-69). 
In einer zweiten, ausführlicheren Darlegung (227 ff.) wird derselbe Grundgedanke anf folgende Weise entwickelt. Die transzeudentale Methode kann nịcht für die Logik aufgenommen, für die Ethik aber verworfen werden. Wie nun die Logik in der Physik als deren Wurzel enthalten ist, also aus dieser die logischen Prinzipien selbst zu ermitteln sind, so liegen die Prinzipien der Ethik in Recht als dessen Wurzeln und sind daher aus der Rechtswissenschaft $z u$ ermitteln ja in ihr zu begründen. Es ist, nach Cohen, einer der ernstesten Fehler Kants, dass er bei der Grundlegung der praktischen Philosophie den obersten Gesichtspunkt der transzendentalen Methode verlassen, dass er die „Deduktion“ der Ethik nicht an der Rechtswisșenschaft vollzogen hat, wie die der Logik an der Naturwissenschaft (S. 227); dass er in der Rechtswissenschaft nicht das der Naturwissenschaft entsprechende Faktum einer Wissenschaft erkannt hat, auf welches die transzendentale Methode sich zu richten und zu orientieren habe, um als Ethik sich zu konstituieren und sich zu begründen. Denn „nicht allein das Recht ist von der Ethik abhängig, sondern auch die Ethik muss auf die Rechtswissenschaft zurückgehn", um an ihr, so wie die Logik an der Naturwissenschaft, „Kritik“ daraufhin zu üben, ob in ihr reine praktische Vernunft, reiner Wille in der Rechtshandlung in Vollzug trete und sich beglaubigen lasse (S. 228).

Denn allerdings nur auf die reinen, erzeugenden Grundbegriffe hat die Arbeit der Rechtsphilosophie in der Ethik, so wie die der Natur philosophie in der Logik, sich zu beschränken (S. 229). Dieser engere Bezug auf die Grundbegriffe ist es offenbar, welcher, nicht sowohl der Rechtswissenschaft als ganzer, mithin als positiver, aber einer in der Rechtswissenschaft eingeschlossenen reinen Rechtslehre die Bedeutung der „Mathematik der Geisteswissenschaften" zuweist. Hierdurch löst sich auch die scheinbare, äusserlich allerdings vorliegende Inkongruenz, dass die Rechtswissenschaft einmal der Naturwissenschaft, oder auch der Physik, ein andres Mal der Mathematik parallel gestellt wird. Die Mathematik ist, hier wie überhaupt bei Cohen, verstanden als die der Naturwissenschaft und der Natur selbst; Naturwissenschaft, im prägnanten Sinne, ist überhaupt nichts anderes als Mathematik der Natur. So also liegt im positiven Recht das reine; daher müsste, was an ihm den Begriff „Wissenschaft" rein erfüllt, sich auch ebenso rein herauslösen lassen wie das Mathematische der Naturwissenschaft, ohne das sie überhaupt nicht, in strikten Sinne, 
Wissenschaft wäre. So stellt auch die Übereinstimmung mit Kants Aufstellung bezüglich der Begründung der trániszendentalen Logik im zugehörigen Faktum einer Wissenschaft - die Übereinstimmung wenigstens mit dem innersten Motiv dieser Kantischen Aufstellung - sich genauer her. Denn freilich bezog Kant seine transzendentale Logik, streng genommen, nicht schlechtweg auf Mathematik, oder auf Naturwissenschaft als mathematische, sondern auf "reine“ Mathematik und "reine" Naturwissenschaft, das heisst auf die erzeugenden Grundbegriffe beider, die immerhin, gemäss ihrer unlöslichen Einheit, unter einem gehörig erweiterten Begriff reiner Mathematik oder "exakter Wissenschaft" zusammengefasst werden könnten. Dann wird es fast gleichgültig, ob man die Logik (der Theorie) auf Mathematik oder auf Naturwissenschaft (nämlich hinsichtlich ihrer reinen Grundlagen) als das zugehörige Faktum einer Wissenschaft bezieht. Dem analog kann also auch die Ethik strenggenommen nur in einer reinen Rechtslehre, nur nach lässlicherer Ausdrucksweise in der Rechtswissenschaft schlechtweg (oder gar in der positiven Rechtswissenschaft, nach S. 70, Z. 8 v. u.) die verlangte Grundlage der Bewährung an dem Faktum einer Wissenschaft suchen sollen (in der positiven jedenfalls nur; sofern in dieser die reine liegt).

Immerhin bleibt auch so noch ein Zweifel zurück. Reine, wenn auch vielleicht nicht in Vollständigkeit die reinen Grundlagen der Naturwișsenschaft liegen in eigener, in bestimmtem Sinne positiver, nicht als Ganzes etwa philosophischer Wissenschaft, eben in der Mathematik, deutlich zutage, in strenger und reiner Absonderung von positiver Naturwissenschaft, auch soweit sie mathematische ist. Und so wird die Zurückbeziehung der reinen Theoretik, als Philosophie der Naturwissenschaft, auf das sichere Faktum einer solchen, eben reinen und darum zweifellos gesicherten, dennoch positiven Wissenschaft begreiflich. Nicht ebenso liegen aber reine Grundlagen des positiven Rechts in eigener, wiederum (obwohl nicht im Sinne des "positiven" Rechts) positiver, dennoch reiner Wissenschaft unbestreitbar vor, sodass man auf sie als unabhängig gesichertes "Faktum" einer Wissenschaft sich zur Bewährung der ethischen Prinzipienlehre beziehen könnte, sondern sie liegen nur im positiven Rechte selbst, wie man annehmen muss, als seine Wurzeln, seine erzeugenden Faktoren zugrunde, aber tief untertage, und die eigne Arbeit der Philosophie hat sie erst zutage zu 
fördern. Welcher Philosophie aber? Offenbar der Ethik: die doch, um sich selbst zur Wissenschaft zu sichern und zu reinigen, der Begründung auf das Faktum dieser reinen, das Recht als Wissenschaft konstituierenden Faktoren erst bedürfen sollte! Unfraglich hat hier die Analogie in der Art der wissenschaftlichen Sicherung zwischen der praktischen und der theoretischen Philosophie eine Lücke. Mathematik ist selbst nicht Philosophie, sondern ist positive Wissenschaft: eben darum findet die Logik, als Philosophie der theoretischen Erkenntnis,. an ihr eine von ibr selbst in bestimmtem Sinne unabhängige Basis der Bewährung. Reine Rechtslehre dagegen liegt jedenfalls nicht deutlich und unzweifelhaft vor als im gleichen Sinne von Philosophie unabhängige, positive Wissenschaft, sondern die Philosophie der praktischen Erkenntnis selbst, die sich auf sie stïtzen soll, hat sie erst herauszuarbeiten. Geradezu wird daher bei Cohen die Ethik selbst zur Rechtsphilosophie, ja man sieht, bei der Strenge, in welcher Recht und Sittlichkeit von ihm aufeinander bezogen werden, nicht sogleich ein, wie sie überhaupt noch etwas andres dürfte sein wollen. Cohen spricht von einer "Arbeit der Rechtsphilosophie in der Ethik" (S. 229), welche die Grundbegriffe des Handelns aus der positiven Rechtslehre offenbar erst herauszuschälen hat. Aber er sagt mehr: die Ethik erst stellt das Problem einer Kritik der reinen (praktischen) Vernunft auf, welches die neue Formulierung des alten Problems der Rechtsphilosophie sei. Allein wo bleibt dann die von Philosophie unabhängige, positive und doch reine Wissenschaft, welche dieser Philosophie zur Sicherung und Beglaubigung dienen sollte?

Indessen, so dringend hier eine weitere Klärung noch $\mathrm{zu}$ fordern bleibt, so darf doch diese Schwierigkeit auch nicht übertriebeu werden. Sind die reinen Grundbegriffe des Rechts bis dahin nicht zweifelsfrei herausgestellt, sie liegen doch in der positiven Rechtswissenschaft selbst in faktischem, eben "positivem" Gebrauch vor, unabhängig von Philosophie, so unabhängig wie nur irgend Mathematik von Philosophie unabhängig ist. Wenn also der Philosophie des Praktischen es allerdings so leicht nicht gemacht ist wie der Philosophie der Theorie; wenn sie das der Mathematik analoge Geschäft der reinen Herauslösung und Entwicklung der Grundbegriffe grösstenteils selbst zugleich auf sich zu nehmen genötigt ist, so übernimmt sie damit etwas, was ejgent- 
lich vicht ihres Amtes ist, sondern vonseiten der positiven Rechtswissenschaft längst hätte geschehen müssen. Sie tut es gleichsam nicht kraft ihres eigentümlichen Auftrags als Philosophie, sondern nur anstelle einer annoch fehlenden positiven Wissenschaft von den reinen Grundbegriffen des Rechts; in Absicht eben auf den Gebrauch, den sie für ihre eigentümliche Leistung davon zu machen gedenkt. Nicht die Ethik als solche wird damit zugleich die positive Lehre von den reinen Rechtsbegriffen, sonderu nur der Ethiker nimmt, notweise, das Geschäft dieser bisher vermissten positiven Wissenschaft auf sich, insoweit als er für den davon verschiedenen, eigentümlichen $Z$ weck seiner Wissenschaft es zu tun nicht vermeiden kann. Nicht in derselben Funktion also ist er selbst zugleich der Mathematiker und der Philosoph der reinen Handlung; und so bleibt das, worauf es zuletzt und entscheidend hier ankommt: die Beglaubigung der Philosophie der Handlung an dem Faktum einer positiven, dennoch reinen Wissenschaft von ihr, doch an sich möglich. Das Desiderat dieser unabhängigen reinen Rechtslehre freilich bleibt bestehen. Und dies auszusprechen ist hier um so mehr Veranlassung, da es genau dieses Desiderat ist, welches - Stammler durch seine "Theorie der Rechtswissenschaft" hat erfüllen wollen.

§ 7. (Rationale und historische Methode.) Noch ein anderes, nicht minder naheliegendes; sachlich vielleicht noch tiefer einschneidendes Bedenken aber harrt hier erst der Beschwichtigung. Zunächst: die Logik reicht (wie Cohen ausdriicklich anerkennt, S. 85, vgl. Log. d. r. Erk., S. 30. 38) über die Mathematik der Sphäre nach hinaus, sie ist nicht nur Logik der Mathematik. So kann es vollends nicht zweifelhaft sein, dass die Ethik der Sphäre nach nicht auf das Gebiet des Rechts schlechthin eingeschränkt bleiben kann. Soll sie doch die Logik der Geisteswissenschaften sein, auf Kultur als Ganzes sich so beziehen wie die Logik der Theorie auf Natur. Zwar behauptet uun Cohen, wie die reine Gesetzlichkeit der Natur in der Mathematik, so liege die reine Gesetzlichkeit der Kultur überhaupt im Recbt. Denn alle Kulturarbeit vereinige sich in Staat, als der Welt - es darf daneben ruhig auch heissen: dem Reiche - der Geister (S. 247. 248). Der Staat aber sei notwendig Rechtsstaat, die Staatslehre notwendig Staatsrechtslehre (S. 63); ihre schliessliche formal-methodische Grundlagge bilde daher, soweit anch, der Materie nach, die Aufgabe des Staats gedacht werden möge, den- 
noch einzig das Recht. Und diese Ansicht scheint nach manchen Seiten sich sehr wohl durchführen zu lassen. Die Volkswirtschaft zunächst rechnet Cohen hier schlechterdings auf die Seite des Rechts; eine andere reine Grundlage als die des Rechts ist in ihr in der:Tat bisher nicht gefunden. So entspricht es (wie kaum der Erinnerung bedarf) ganz der bekannten These Stammlers in dem Buche "Wirtschaft und Recht". Auch vonseiten der Pädagogik ist ein Einspruch schwerlich zu besorgen, wenn nur diese, wie es in der Tat zu fordern ist, folgerecht als soziale begriffen wird und daher, unter dem Titel des "Bildungswesens", dem Verwaltungsrecht, also dem Staatsrecht sich angliedert. Von der Kunst ist hier insofern natürlich abzusehen, als sie in der Ästhetik ihre eigene philosophische Grundlegung sucht und findet; sonst aber, als ein Bestandteil oder eine Seite, sage man nun der humanen Bildung oder der humanen Kultur, dürfte sie, mit der Erziehungslehre, durch das Mittelglied eben des "Bildungswesens" oder allgemeiner der Kulturpflege den Gesichtspunkten des genügend weit verstandenen Staatsrechts sich zwanglos unterstellen. Und so wäre wohl, wenn man von der Religion einstweilen absieht, die noch eine besondere Betrachtung fordert, das Gebiet der Geisteswissenschaften, dem Objekte nach, umschrieben. Dies ganze Gehiet scheint also zuletzt der Idee des Siaates und damit der Methode des Rechtes wohl unterstellt werden zu dürfen.

Aber nicht nach dem Gebiet, sondern nach der Methode war hier die erste Frage. Die Geisteswissenschaften insgesamt, alle genannten und alle etwa noch vergessenen, scheinen aber in der Tat auch über eine ihnen eigentümliche Methode zu gebieten, die von der rechtlichen, so wie sie bis dahin von uns verstanden wurde, jedenfalls verschieden ist, nämlich die geschichtlichc. Die Geisteswissenschaften als Geschichtswissenschaften zu bcgründen, das war vielleicht die gewaltigste Leistung der nachkantischen deutschen Wissenschaft und Philosophie auf dem Gebiete eben des Geistigen, angesichts deren am ehesten Kants ganze Methodik, wenn auch nicht zu scheitern, doch ibre Scbranke zu verraten scheint. Will doch der Vorwurf nicht verstummen, dass die an Kant orientierte Philosophie, die Philosophie eben der „transzendentalen Mcthode“, zwar allenfalls der Naturwissenschaft gerecht werde, aber der neuen grossen Errungenschaft der historischen Wissenschaften und damit dem ganzen eigentlich "geistigen“ Gebiet nach seiner Sonderheit sich versage, daher es gewaltsam 
der Natur zu nähern, allenfalls nach Art einer zweiten, einer Übernatur, aber doch eben naturartig, nämlich rational zu konstruieren unternehmen müsse, statt ein schlechthin Überwatürliches, Irrationales in ihr anzuerkennen. Nur allzusehr aber scheint gerade die Beziehung der Ethik, als "Logik der Geisteswissenschaften“, auf das Recht, als "Mathematik" derselben, diesen Verdacht zu bestärken. Durchaus scheint sie dem Missverständnis Nahrung zu geben, als solle im Geistigen das geschichtliche Moment, das Moment des Werdens nicht nur, sondern Scbaffens, des Vorgriffs ins nicht schon Erkannte, überhaupt nie abschliessend Erkennbare, ins nicht schon Rationale noch je ganz zu Rationalisierende - als sollte der Unendlichkeitssinn des Geschichtlichen, und damit aller Charakter schöpferischer Genialität geleugnet werden, die geistige Welt sich, gleich der natürlichen, in ein plattes Rechenexempel verwandeln, und so der "Geist", der das höchste und wahrste Lieben bedeutet, eigentlich zu Materie d. h. zu Tode definiert und deduziert, in eine, wenn nicht endliche, doch allenfalls nur mathematisch unendliche, in ihrer Unendlichkeit immer berechenbar bleibende Summe oder allenfalls Potenzierung fixer, zeitloser Beziehungen schliesslich nur gedanklicher Art umgesetzt werden. Das hiesse aber ihn seiner eigensten "Natur" entfremden, ihn logisieren.

Wirklich ist vielleicht zu sagen, dass Cohen, seiner letzten Meinung nach, durch einen solchen Vorwurf nicht getroffen wird, da er gerade das Erschaffen der Zukunft, und zwar einer ewigen Zukunft (S. 399), als die eigentliche und letzte Bedeutung des Willens anerkennt und demgemäss den Charakter der unendlichen Aufgabe an ihm fort und fort hervorhebt. Aber freilich ist die volle Konsequenz daraus gerade nach der Seite der Methodik von inm nicht deutlich genug entwickelt, nicht durchgreifend genug in der Richtung aus- und durchgeführt worden, dass der historischen Methode, gegenüber der rationalen, volle Gerechtigkeit geschähe.

Zwar wird anerkannt: Geschichte, als Geschichte der Menschen und ihrer Werke und Taten, ist Geschichte des "Geistes". und der "Ideen“, oder aber es gäbe keine Weltgeschichte, sondern nur Naturgeschichte (S. 39). Aber es wird nicht ebenso bestimmt die geschichtliche Methode als gleichwesentliches Moment der Methode der Geisteswissenschaften neben dẹ rationalen, die wir als kategoriale erkannten, hervorgehoben und $\mathrm{zu}$ ihr in 
Verhältnis gesetzt. Besonders nimmt bei der ganzen, tiefgegriffenen Beziehung der Ethik auf die Rechtswissenschaft kein einziges Mal (soweit ich finde) die Reflexion die Richtung dahin, dass doch das Recht selbst gar nicht anders als in geschichtlicher Gestalt, d. h. ewig werdend, in Um- und Wiederumbildung begriffen, hoffentlich fortschreitend, vorliegt; dass sein „Faktum“, wesentlicher noch, möchte man sagen, als dâs der Naturwissenschaft, ein Fieri, nein ein Facere, ein Neu- und immer Neu-Erschaffen ist. Das wird besonders durch die Vergleichung mit der Mathematik eher verdunkelt als ins klare gestellt; denn wenn gewiss auch Mathematik Beziehungen und Beziehungen von Beziehungen ins Unendliche neu erschafft, so scheinen es doch immer Beziehungen unter solchem, was ewig nur ist, nicht wird, und somit selbst ewig, unveränderlich nur "seiende" Beziehungen zu sein.

Wird dagegen einmal Geschichte als eigentümliche Methode der Geisteswissenschaften anerkannt: wird dann nicht die Eithik für ihre faktische Bewährung, mindestens gleichermassen wie nach der rationalen Seite auf die Rechtswissenschaft, so nach dieser, noch genauer zu bestimmenden, neuen Dimension gleichsam auf die Geschichtswissenschaft zu orientieren sein?

Dass die Ethik ihrerseits die Voraussetzung, wie der Soziologie und damit der sozialen Entwicklung (S. 43), so der Geschichte überhaupt in jedem Sinne ist, kann jedenfalls diese nicht untauglich machen, gleich dem Recht und, als wesentlich Staatengeschichte, gewiss in allerengstem Bezug $\mathrm{zu}$ diesem, der Ethik umgekehrt auch zur Grundlage der Bewährung zu dienen, da ganz das Gleiche rom Rechte selbst gilt. Hätte etwa nicht die Mathematik die Logik zur Voraussetzung? Ist nicht vielmehr eben, weil sie, und zwar ganz und gar, aus ihren Wurzeln heraus, so rein wie keine andre Wissenschaft erwächst und sich entwickelt, umgekehrt aus ihr die Logik (der Theorie) zu ermitteln und an ihr zu beglaubigen? So, sollte man denken, die Ethik an der Geschichte, in und mit der und in deren Sinne auch das Recht überhaupt als "Faktum" nicht sowohl gegeben ist als neu und immer neu gegeben wird! Was bedarf es überhaupt hier noch weithergeholter Argumente? Ist Ethik die Lehre vom Menschen, vom Begriff, nein von der Idee des Menschen (Cohen, S. 3), ist aber der Begriff, die Idee des Menschen ohne die Allheit, ja 
ohne "mit der Allheit anzufangen“ (S. 7), nicht nur nicht zu vollenden, sondern überhaupt uicht aufzustellen - wo, in welcher andern methodisch wissenschaftlichen Gestalt gibt es denn diesen "Menschen" und gibt es diese Allheit: die "Menschheit", als in der Geschichte? Das dürfte. umso weniger von Cohen verneint werden, wenn es richtig bleiben soll, dass „der reine Wille der Wille des geschichtlichen Seins, der geschichtlichen Wirklichkeit werden soll" (S. 82). Denn zwar gewiss ist nicht, was vernünftig, schon wirklich, sondern es soll erst wirklich werden; und ebenso gewiss ist nicht die geschichtliche Wirklichkeit Mass und Prinzip der sittlichen Vernunft (S. 331), sondern umgekehrt das Soll, das sie ausspricht, erst die Begründung dieser Wirklichkeit; welche Begründung - nämlich in der Ewigkeit der Zukunft - ebendamit selbst nur eine ewige, nicht irgendeinmal abschliessend gelöste Anfgabe ist. Aber eben so muss ja an dieser eigen gearteten, der geschichtlichen „Wirklichkeit", die im ewigen Schaffen der Zukunft, also selbst in einem ewigen Sollen, überhaupt nur besteht, das reine Vernunftgesetz des Sollens sich darstellen, also aus ihr auch ermittelt werden können; so wie am ewig neuen künstlerischen Schaffen allein, und nicht an einem fertigen - das hiesse toten - Bestand künstlerischer "Schöpfungen“, das Gesetz der ästhetischen Vernunft sich darstellt und also zu ermitteln, also Kunstwissenschaft zwar nicht als Kunstgeschichte, aber jedenfalls nicht anders als auf Geschichtsgrund, nicht etwa rein rational, zu errichten ist.

Es fehlt für unsere These aber nicht an einer noch radikaleren, einer rein apriorischen Begründung, deren wir zugleich benötigt sind, um das Verhältnis des rationalen zum historischen Faktor in der Begründung der Ethik zur erforderlichen Klarheit zu bringen. Wir definierten die "rationale" $\mathrm{Me}$ thode im Unterschied von der historischen als kategoriale. Könnte denn aber die historische Methode der Herrschaft der Kategorieen gänzlich entzogen sein? Vielleicht liegt gerade hier der tiefste Grund der Skepsis gegen die Geschichte. Die Skepsis ist voll begründet gegen einen "Historismus", welcher des Halts an der Kategorie überhaupt entbehren zu können glaubte. Darf. aber dieser Halt der geschichtlichen Methode keinesfalls mangeln, so kann ihr Unterschied von der rationalen Methode schwerlich ein andrer - weder grösserer noch geringerer - sein als der 
des regulativen vom konstitutiven Gebrauch der Kategorieen.

Zwar scheint dieser Unterschied sich decken zu müssen mit dem der Idee überbaupt - also (schliesst man weiter) des Sollens, also der praktischen Erkenntnis vom „Verstandesbegriff", als Grundbegriff des "Seins“ im bloss theoretischen Sinne. Allein hiermit ist es wohl vereinbar, dass es den Unterschied des konstitutiven und regulativen Gebrauchs apriorischer Prinzipien nochmals innerhalb jedes der beiden Gebiete für sich gibt. Existiert doch auch empirische Theorie stets in dieser Doppelgestalt: an der Kategorie direkt, in ihrer konstitutiven Funktion gemessen: als (bedingt) rationales System; je nach der in ihr dargestellten systematischen Einheit gemessen an derselben in ihrer regulativen Erweiterung: als Stufe des „asymptotischen “ Fortschritts zur nie erreichten absoluten Systemeinheit. Als solche doppelte Betrachtungsart aber, sagen wir, muss es neben der konstitutiv-kategorialen die regulativ-kategoriale, d. h. neben der rationalen die historische Methode auch und erst recht im Praktischen geben; erst recht, denn es muss ja auf die regulative Betrachtungsart (weil auf die Aufgabe, auf das Sollen) hier sogar das Schwergewicht fallen. Diese aber deckt sich in der Tat mit der historischen, oder genauer, mit deren unterscheidendem Grundgesetz. Zwar unter der überhaupt bloss regulativen Idee der Zwecke steht alle praktische Erwägung, auch die als rational allgesehene. Aber das hindert nicht, den an sich nie stillstehenden Entwicklungsgang auf gegebener Stufe (eines bestimmten, „positiven" Rechtssystems, wie auf theoretischer Seite eines bestimmten, „positiven" Natursystems) gleichsam im Querschnitt für die Betrachtung stillzustellen und so unter gleichsam konstitutivkategoriale, also rationale Erwägung zu stellen; während die ganze Reihe solcher Querschnitte, unter regulativ-kategorialer d. i. historischer Erwägung, erst den Sinn des Praktischen als des ewig Gesollten, als ewige „Erzeugung der Zukunft" in der erreichbaren Vollständigkeit darstellt. Nach dieser Seite also möchte die methodologische Ansicht Cohens von der Begründung der praktischen Philosophie, nicht der Berichtigung, kaum der Ergänzung, aber immerhin einer Präzisierung ebenso fähig wie bedürftig sein.

Übrigens scheint Cohens Ethik selbst von einer andern Seite her auf eben diesen Punkt zu führen: nämlich durch die Ein- 
führung des Gottesbegriffs in die Ethik. Das bedarf noch einer besonderen Prüfung,

§ 8. (Der Gottesbegriff und die Geschichte in Cohens Ethik.) Dio Beziehung der Sittlichkeit auf das Recht nämlich erweist sich in der Durchführung zuletzt doch nicht erschöpfend, sondern über sie hinäus fordert ihr Recht noch die unleugbar faktisch vorliegende Beziehung der Sittlichkeit auf die Religion, oder, um diese sogleich auf ihren Reingehalt zurückzuführen, auf die Gottesidee. Es kann ja wohl nicht zweifelhaft sein, dass diese, mag auch mit gutem Grunde das Reich Gottes eben als "Reich" d. h. nach Analogie einer Rechtsordnung gedacht werden, über den blossen Rechtsbegriff wesentlich hinausgeht. Dies Hinausgehen kann aber, unter dem Gesichtspunkt reiner Methodik angesehen, zuletzt kein andres sein als das der historischen als der regulativen über die rationale als die konstitutive Erwägung. Denn das besondere Problem, welches das Übersteigen des blossen Rechtsbezugs der Ethik herbeiführt, ist nach Cohen eben das der fortschreitenden Verwirklichung des Sittlichen oder der "Erschaffung der Zukunft". Darin erkannten wir schon oben den eigentïmlichen Sinn geschichtlicher Erwägung. Die Frage der "Verwirklichung" aber ist eben die der regulativen Prinzipien.

Zwar führt Cohen, von dem Gesichtspunkte der Verwirklichung aus, die Gottesidee und mit ihr die Geschichte anscheinend auf ganz anderem Wege ein. Er fordert die Aufnahme des Gottesbegriffs in die Ethik aus der Rücksicht, dass die Ethik, die für sich zwar in völliger Unabhängịgkeit von ihm zu begründen sei, zu ihrem Abschluss noch einer letzten Vereinbarung mit der Logik (der theoretischen Erkenntnis) bedürfe. Nicht die Theoretik für sich, noch die Ethik für.sich, würde auf den Gottesbegriff führen, gefordert aber werde er durch die schliesslich notwendige (und zwar rein unter dem Gesichtspunkte der Methode notwendige, selbst rein methodische) Vereinigung beider. Denn zuletzt frage es sich nicht bloss, was das Sittliche sei, sondern es frage sich nach der Verwirklichung des Sittlichen, Wirklichkeit aber sei eine Kategorie und zwar die wesentlich unterscheidende Kategorie der Logik, das heisst hier: der Theoretik.

Indessen nicht unmittelbar wenigstens scheint mir die Verbindung der Ethik mit der Logik das hier Erforderliche zu leisten, sondern auf den Unterschied des konstitutiven und des regulativen 
Sinnes der eignen Prinzipien der Praktik kommt es ganz wesentlich an. Nämlich die reine Ethik, die unmittelbar, für sich, auf den Gottesbegriff nicht führen würde, genügt zwar, um das Sittliche seinem Begriff nach zu konstituieren, aber darüber hinaus erhebt sich schon auf dem Boden der Ethik selbst die Frage, ob das Sittliche, dem so konstituierten Begriffe gemäss, denn nun bestimmt sei, ewig nur Aufgabe zu bleiben, oder ob und nach welchen Gesetzen die Aufgabe wenigstens einer beständig fortschreitenden, wenn auch nie abschliessenden Lösung zugänglich gedacht werden dürfe und müsse. Das aber ist ersichtlich die Frage der regulativen Bedeutung der reinen Prinzipien der Ethik selbst, und nicht, jedenfalls nicht unmittelbar, eine Frage der Theoretik. In der Tat nicht die theoretische Grundkategorie der Wirklichkeit ist es, die etwa hier unmittelbar praktische Bedeutung gewänne: das Wirklichwerden des Sittlich en bleibt immer abgründlich verschieden vom Wirklichwerden des Natürlichen; es kann, es darf doch nicht ein Naturwerden des Sittlichen bedeuten, sonst wäre es eben nicht das Sittliche, das sich verwirklicht. Also kann nicht die Modalitätskategorie der reinen Theoretik zugleich einstehen für die Verwirklichung des Sittlichen, sondern nur ihr praktisches Analogon. Gewiss ist auch die enge Verbindung der Ethik mit der Theoretik zu fordern; aber diese Verbindung ist hinreichend gewahrt, wenn nur die Analogie der Begründung beider sich, unter voller Erhaltung ihres Unterschieds, aber auch ihrer genauen Wechselbeziehung, in reiner Konsequenz durchführt. So verhält es sich in der Tat nach unserer Vorstellung des Verhältnisses beider: die Logik der reinen Theorie bestimmt einerseits in konstitutiven Gesetzen, worin überhaupt eine "Natur" besteht, welchen „Bedingungen" sie genügen muss, um überhaupt als eine solche „möglich" zu sein; die wirkliche Darstellung der Erscheinungen aber im Zusammenhang einer oder vielmehr "der" Natur - nänlich in asymptotischer Annäherung an das unendlichferne $\mathrm{Ziel}$ ihres einzigen, geschlossenen Gesetzeszusammenhangs - bestimmt sich nach denselben logischen Grundgesetzen in ihrer Erweiterung zu Regulativen der Forschung. Damit tritt das Sollen, das in andrer Richtung die Praktik im Unterschied von der Theoretik begründet, in gewissem Sinne sogar in die Theoretik selbst ein, die ebendamit zugleich unter geschichtliche Erwägung tritt. Umgekehrt bedeutet die regulative Funk- 
tion der apriorischen Prinzipien der Praktik allerdings zugleich deren engste Wiedervereinigung mit der Theoretik, indem es die „Verwirklichung" der praktischen Idee, in gleichfalls asymptotischer Annäherung, ist, für die sie die Regulative aufstellt; nicht aber als ob das Sittliche je im Natursin n wirklich werden sollte oder könnte, sondern umgekehrt: indem alles natürlich Wirkliche und je zu Verwirklichende zugleich unter praktische Erwägung gestellt und der Verwirklichung des praktisch Seinsollenden dienstpflichtig gemacht wird. Die Ausführung der regulativen Erwägung aber zugleich nach beiden Richtungen, der theoretischen wie der praktischen, ist die Geschichte. So ergibt sich, dass unter dem Gesichtspunkte der Geschichte die Aufgaben beider, der Theoretik und der Praktik, sich methodisch aufs strengste vereinigen und zu einer einzigen Erwägung fortschreitender Geistesoder Kulturentwicklung zusammenschliessen. Naturwissenschaft, als menschliche Erkenntnis angesehen, fällt unter diesem Betracht selbst mit unter geistesivissenschaftliche Erwägung, so dass hier in der Tat aller Gegensatz von Natur- und Geistes- oder Kulturwissenschaft sich aufhebt und beide aufs vollständigste ineinandergreifen. ${ }^{1}$ ) Den obersten methodischen Richtpunkt aber findet diese zweiseitig regulative d. h. die historische Erwägung, in der höchsten Weite ihres Umfangs verstanden, unweigerlich in der endlichen Zuspitzung der "Idee" zum "Ideal", welche als den unzerstörbaren. reinen Kern des Gottesgedankens erkannt zu haben vielleicht das entscheidendste Verdienst Kants um die menschliche Kultur ist. Dass durch den Idealbegriff „Gott" der Begriff der Geschichte methodisch konstituiert wird, ist von Cohen oftmals ausgesprochen worden, und es wird bei jeder eindringenden Prüfung klar, erfordert daher hier ein längeres Verweilen nicht. Das bedeutet nicht die Aufhebung der Religion, sondern gerade ihre Bestätigung, nur aber zugleich ihre Reinigung zur erweiterten, nämlich in strenger Durchführung der Idee nach ihrer regulativen Bedeutung erweiterten, und durch eben diese mit der Theoretik in genaueste Verbindung gesetzten - Ethik.

§ 9. (Prüfung der ausschliesslichen Beziehung der Ethik auf das Recht, nach Seiten des Inhalts.) „Methodis anterertit omnem scientiam", sagt Kant (De mundi bes. $\$ 18$.

1) Man vergleiche hierzu die Ausführungen meiner Sozialpżdagogik, 
sens. etc. § 23) in kaum übersetzbarer Präguanz. Daher darf wohl erwartet werden, dass die gewonnene Klärung über die "Methode“ auch für die "Scienz" über Recht und Sittlichkeit, in Hinsicht ihres Objekts, einigen Gewinn abwerfen werde. Über die genaue Zusammengehörigkeit beider, über die letzte Einheit ihres Prinzips kann ein $Z$ weifel ferner nicht obwalten. Aber auch die engste, die ganz ausschliessliche Zurückbeziehung der Sittlichkeit auf das Recht könnte nichts daran ändern, fordert vielmehr erst recht, dass unterhalb des gemeinsamen Prinzips dem Rechte sein eigener Charakter: der der Positivität einer eigentlichen Objektwissenschaft im Unterschied von einer reinen Methodenwissenschaft, verbleibt. Dieser aber kann nur darin bestehen, dass es vom zu Bestimmenden aus, eben als dem „Positiven“, Konkreten, nämlich vom konkreten Problem aller praktischen Bestimmung, zur "reinen" Bestimmung erst den Weg beschreiben will, jenen Weg, den wir gleichnisweise als den von der Peripherie zum Zentrum, nicht vom Zentrum zur Peripherie, bezeichneten. Cohens Ethik unterliegt aber, gerade in der Strenge ihres aprioristischen Vorgehens, die ihre Hauptstärke ist, dem Verdacht, dass sie diesen Charakter des Positiven im Begriffe des Rechts allzuwenig zu seiner begründeten Geltung kommen lasse und so das Recht in der Sittlichkeit, damit aber auch die Sittlichkeit im Recht zu bedingungslos aufgehen lasse. Dies ist jetzt zu prüfen. Wille, behauptet Cohen, gibt es nur in einem Gegenverhältnis Wollender. Das Selbstbewusstsein sogar, welches eigentlich überhaupt nur als praktisches, nicht bloss theoretisches zu verstehen ist, ist durchaus bedingt durch das Bewusstsein des Andern (Kap. 4, S. 213). Daher gibt es überhaupt kein Individuum im ethischen Sinue ohne Rechtsgemeinschaft; das Individuum hat keine auf sich ruhende Bedeutung in der Ethik. Also kann es nicht eine besondere Sittlichkeit für das Individuum, eine besondere für die Gemeinschaft geben. Durch die Beziehung auf das Individuum einerseits, den sozialen Verein andrerseits, hat man nun, nicht bloss innerhalb der Ethik die individuale von der sozialen, sondern überhaupt die sittliche Gesetzgebung als Ordnung des Individuallebens von der rechtlichen als sozialer Ordnung unterscheiden und trennen wollen. Solche Scheidung also ist ganz und gar unstatthaft.

Zur letzten Begründung dieser Thesen bezieht sich Cohen (S. 234) darauf, dass nach Feststellung der Logik der theoretischen 
Erkenntnis das Einzelne überhaupt keine șelbständige Einheit darstelle. Das gelte vollends in der Ethik. Das einzelne, überhaupt nur "scheinbare" Individuum vermöchte gar nicht zu wollen noch zu handeln, es muss erst „befreit und erlöst werden von den Schranken seiner Einzelheit, um wollen und handeln zu können" (S. 189); auf die Allheit kommt ès beim Begriff der Handlung ganz und gar an. Das "Selbstbewusstsein", als Wille zum Selbst, erzeugt sich erst in der Handlung; Wille und Handlung aber vollzieht sich allein im Staat, unter einem Gesetz, also nach Rechtsbegriffen (S. 259 ff.). Oder, wenn man nach „Gesinnung“ und "äusserem Verhalten" zwischen Sittlichkeit und Recht scheiden will, so ist zu bedenken, dass Sittlichkeit und daher Ethik (S. 72) sich streng und ausschliesslich auf die Handlung zu beziehen, die Gesinnung allenfalls nur als Vorstufe der Handlung in Betracht zu ziehen hat; Handlung aber gibt es nur in den Wechselbeziehungen des sozialen Lebens, somit unter Rechtsbegriffen. In bezeichnendem Gegensatz etwa zu Schleiermacher, der Kant die einseitig juridische Auffassung der Sittlichkeit zum Vorwurf macht, findet daher Cohen an Kant zu beanstanden, dass er die Sittlichkeit noch lange nicht ausschliesslich genug auf das Recht bezogen habe (S. 342).

Schwerlich dürfte nun, was den Kern des Gedankens betrifft, dieser Auffassung zu widersprechen sein; am wenigsten könnte ich ihr widersprechen wollen, nachdem ich schon in der Schrift „Reli-

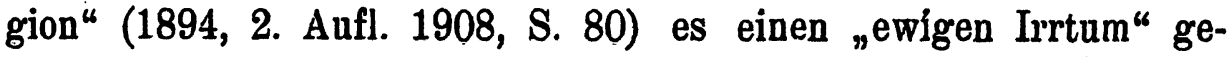
nannt habe, dass man ein Einzelner sei, und in der "Sozialpädagogik" (3. Aufl. S. 84) erklärt habe, das Individuum sei eine blosse Abstraktion gleich dem Atom des Physikers; ein Selbstbewusstsein gebe es allein in Entgegensetzung und zugleich positiver und zwar Willensbeziehung zum Andern (S. 90. 93).

Indessen wird dadurch der methodische Unterschied äusserer und innerer Willensbestimmung oder Verpflichtung, wie er sich oben ergeben hat, keineswegs zunichte. Der Materie nach bezieht sich - das wurde voll anerkannt die Willensbestimmung oder Verpflichtung allerdings stets auf das gegenseitige Verhalten in einem (wirklichen oder gedachten) sozialen Verein; auf den Einzelnen nur als Glied einer wenigstens ideellen Wechselbeziehung unter Vielen, schliesslich Allen. Aber formal, nach der Art und dem Sinne der Verpflichtung, oder nach dem unmittelbaren Bestimmungsgrunde, ist die Willensbestimmung in 
dieser doppelten Weise denkbar und notwendig zu denken: als „innere“, d. h. als unmittelbare Folge aus dem eignen Gesetze des Wollens im Wollenden selbst, durch das also dieser sich vor sich selbst (und wenn er allein in der Welt wäre) verpflichtet weiss, ungefragt ob das gleiche Gesetz auch vom Andern, auf den die gewollte Handlung sich in den Folgen erstrecken mag, oder von einem sozialen Vereine, dem er sich zugehörig denkt, anerkannt und gewollt wird, oder aber als „äussere", d. h. gemäss einem Gesetze, durch welches der Eine dem Andern, und zwar grundsätzlich immer wechselseitig, verpflichtet wird, daher die dem Einzelnen vorgezeichnete Richtung des Willens ihn bindend nur gedacht wird unter Voraussetzung der gleichen Bindung der Andern, mit denen er sozial verbunden ist. Im ersten Fall ist die bestimmende Rücksicht ausschliesslich die der inneren Zusammenstimmung des Willens des Einzelnen, dessen Wille bestimmt werden soll, unter dem Gesetze der praktischen Vernunft als dem seiner eigenen Vernunft; im andern die der äusseren Zusammenstimmung der sozial verbundenen Einzelnen untereinander in ihren Willenshandlungen, gewiss unter demselben obersten Gesetze der praktischen Vernunft d. h. der Zweckeinheit ü berhaupt, ohne Frage aber nach der inneren Zustimmung des so Verpflichteten. Der Materie nach werden innere und äussere Verpflichtung, wenigstens in jeweils letzter Erwägung, stets zusammenfallen, jedenfalls sich nicht widersprechen können, da ja für beide dasselbe letzte Gesetz (der schliesslichen Einheit der Zwecke) unbedingt bestimmend, und da die durchgängige Zusammenstimmung der eignen $Z_{w e c k e}$ für das im sozialen Verein überhaupt nur lebende und bestehende Individuum so wenig ohne schliessliche Zusammenstimmung mit den Zwecken der sozialen Vereinigung möglich ist wie diese ohne jene. Allein diese schliessliche materiale Koinzidenz hebt den formalen Unterschied der inneren und äusseren Bindung nicht auf. Das aber ist eben der Sinn der Unterscheidung der "moralischen" Verpflichtung als innerer von der rechtlichen als äusserer, so wie sie von Kant und denen seiner Nachfolger, welche dessen Gedanken aufgenommen und festgehalten haben, wesentlich und primär verstanden wird.

Es braucht von diesen gar nicht geleugnet $z \mathfrak{u}$ werden, wird auch, soviel ich erkennen kann, von ihnen nicht geleugnet, dass in der "Legalität" die "Moralität" als „immanente Kraft" enthalten sei, dass „Moralität der Legalität als einer ihr gleichartigen 
Kraft einwohne“ (Cohen S. 66). Ist wenigstens unter der „Kraft“ der Moralität die begründende Kraft der "praktischen Vernunft" gemeint (und es kann nichts andres gemeint sein), so ist sicherlich nur diese auch in der Legalität wirksam; deren „Kraft“ ist also mit der der Moralität nicht nur gleicher Art und gleichen Ursprungs, sondern eben in ihrem Ursprung identisch; nur die Bestimmungsrichtung ist in beiden verschieden, nämlich sie geht, wie wir sagten, im einen Fall von der Peripherie zum Zentrum, im andern vom Zentrum zur Peripherie. Diesen Unterschied aber scheint Cohen zu übersehen, wenn er dem Recht gegenüber der Sittlichkeit, und damit auch dieser gegenüber jener, durchaus keinen eigenen methodischen Charakter zugestehen zu wollen scheint. Er hätte ihn, unbeschadet alles dessen, was er mit der strengen und ausschliesslichen Beziehung der Ethik auf das Recht, des Rechts auf die Ethik beabsichtigt, unbedenklich zugestehen dürfen. Recht und Sittlichkeit bleiben, und zwar, ideell genommen, ihrem ganzen Umfang und Inhalt nach, aufeinander wechselseitig, ganz in der Strenge; wie Cohen es fordert, bezogen, auch wenn sie der methodischen Richtung nach in der von uns angenommenen Weise sich unterscheiden. Die Kreise (um im Bilde zu bleiben) decken sich, nur die Richtungen sind verschieden, zugleich aber zueinander streng korrelativ, eben wie die Wege von der Peripherie zum Zentrum und vom Zentrum zur Peripherie. Das Zentrum vertritt die in der Tat zentral bestimmende Vernunfteinheit des Wollens, die Peripherie das jeweils zu bestimmende Einzelwollen; die Bestimmung vom Zentrum her bedeutet demnach die reine, autonome, d. h. sittliche Willensbestimmung, die von der Peripherie her die zur Autonomie erst hinaufzuläuternde, zunächst aber unleugbar vorliegende Heteronomie; die äussere d. h. vom Bedingten den Ausgang nehmende, wenngleich auf die unbedingte Erhaltung des autonomen sittlichen Selbst zuletzt gerichtete Bestimmung des besonderen, konkreten. Wollens der Einzelnen, als idealer Glieder des in keinem gegebenen Zeitpunkt schon bestehenden, sondern erst angestrebten, ewig nur anzustrebenden „Reiches" der Zwecke.

Sollte; gegenüber der rechtlichen, die eigentümlich sittliche Bestimmungsart ganz in Wegfall kommen, so käme damit nichts geringeres in Wegfall als - die Autonomie. Denn diese ist der eigentïmliche Gesichtspunkt der rechtlichen Bindung entschieden nicht. Sie zielt zwar auf Autonomie, sie hat in ihrer überhaupt 
teleologischen Methodik sie sogar zum letzten bestimmenden Prinzip, dieses ist ja für Recht und Sittlichkeit ein und dasselbe; aber die rechtliche Bestimmung des einzelnen Wollens ist als solche entschieden nicht autonome, sondern heteronome. Sie muss es sein, eben weil Autonomie niemals gegebenes Faktum, sondern ewig nur Aufgabe, mithin von ihrer Gegenseite, der Heteronomie her erst anzustreben ist. Also die Heteronomie des Rechts gründet sich zwar (wie es von Fichte besonders lehrreich ausgeführt worden ist) zuletzt auf die Autonomie des Sittlichen, aber es ist dennoch, so wie es als konkretes überhaupt nur „ist", und bleibt; als konkretes, immer seiner Form nach heteronom.

Und ebendeshalb bedarf die Autonomie des Sittlichen noch einer eignen Vertretung, nicht im Recht, nicht uuter der Form des Rechts, sondern in besonderer, eigener, sittlicher, gleichwohl konkret (wie wir sagten: nach der Peripherie hin) gerichteter Erwägung. Diese hat, eben sofern sie den Standpunkt der Autonomie in Reinheit zu vertreten den eigentümlichen Beruf hat, ihrerseits nicht den Standpunkt des äusserlich verbindenden Gesetzes des sozialen Vereins, sondern den der Selbstbestimmung des Individuums einzunehmen und konsequent festzuhalten. In diesem, nur in diesem Sinne ist es methodisch wohlbegründet, dass reine Ethik $\nabla 0 \mathrm{~m}$ Standpunkte des Individuums, positives Recht vom Standpunkte der Wechselbeziehung im konkreten sozialen Verein die Willensbestimmung vorzunehmen habe. Dagegen wäre es falsch, der Materie nach das Gebiet des Praktischen zwischen Recht und Sittlichkeit so abzuteilen, dass die Sphäre der sozialen Beziehungen und damit das „Äussere“ der Handlung dem Recht, unabhängig von der Sittlichkeit, die Sphäre des Innenlebens des Individuums - eines "Wollens“ also, das nicht bis zu einem auf den Andern sich miterstreckenden Handeln gelangt - einer „Ethik“ zufiele, die nun umgekehrt auf Recht und soziales Zusammenwirken keine Rücksicht zu nehmen hätte. Gegen eine solche materiale Scheidung sind Cohens Einwendungen voll begründet, aber sie treffen damit nicht auch die formal-metbodrsche Unterscheidung im eben erkjärten Sinne.

Soit Kant ist der einzig zulässige Sinn der Individualität (in ethišschem Zusammenhange) die Autonomie, immerhin in Bezug auf ein begrenztes Einzelbewusstsein erwogen. Daher würde die gänzliche Ablehnung einer Willensbestimmnng vom Standpunkte des Individunms in der Tat die Preisgabe der Autonomie bedeuten. 
Aber diese steht vielmehr im Mittelpunkte der ganzen Ethik Coheus, der darin durchaus in der Bahn Kants verbleibt (s. bes. Kap. IV-VII). Auch wird von Cohen selbst im besondern die Eigenart des Standpunktes des sittlichen Individuums, und zwar auch im Sinne des Einzelwesens - nur, wie es auch allein richtig ist, allerdings stets in unaufheblicher Zurückbeziehung $\mathbf{z u}$ dem der Sozietät, nie in gänzlicher Loslösung von ihr - berücksichtigt und zur Geltung gebracht. Namentlich wird der im Zusammenhang unsrer Frage vorzïglich wichtige Begriff der Verantwortlichkeit von Cohen ganz und gar auf Selbst verantwortung gegründet, und es wird hierbei ausdrücklich eine Eigenart der Ethik nicht bloss der Religion, sondern auch dem. Recht und Staat gegenüber anerkannt (S. 370, vgl. 387), und zwar eben im Sinne der Behauptung des Individuums, das nicht in einem Bruchteil statistischer Wahrscheinlichkeit aufgehen dürfe (S. 372). Ein andrer, heisst es hier, sei der Standpunkt für das Urteil des Richters (über die "Schuldigkeit", nicht die "Schuld"), ein andrer der des Individuums: jener juristisch, dieser ethisch. Wie sollte eine solche Unterscheidung, den Voraussetzungen einer reinen Vernunftethik gemäss, anders als in eben erklärten Sinne verständlich werden? - Aber auch ganz allgemein und prinzipiell wird éin $R$ ic $\mathrm{ctungsunter-}$ schied, eben wie wir ihn behaupten, wenigstens an einer Stelle von Cohen anerkannt (S. 475): "Das Selbstbewusstsein ergeht sich in zwei Richtungen, in der des Individuums und in der der Allheit. Beide Richtungen haben den gleichen Wert für die Erzeugung des Selbstbewusstseins; beide Richtungen müssen beschritten und eingehalten werden. Aber es sind doch eben zwei Richtungen: so wird es zu erwarten sein, dass für jede dieser beiden Hauptrichtungen des Willens und der Handlung zwei besondere Wegweiser aufzurichten sind", die nur nicht auch zu besonderen Zielen hinführen können, denn das Ziel sei freilich nur das eine des Selbstbewusstseins, von dem wir schon hörten, dass es ebensosehr und gleich fundamental als soziales wie als individuales zu verstehen sei.

Hiernach liegt eine grundsätzliche Differenz der letzten sachlichen Auffassung zwischen Cohen einerseits, Kant, Fichte und deren Nachfolgern andrerseits nicht vor. Indessen muss man gestehen, dass die hier so bestimmt anerkannte Zweiseitigkeit der Aufgabe der praktischen Philosophie erst an sehr später Stelle in 
ethischen System Cohens auftritt, und auch von da ab nicht durchweg streng festgehalten und deutlich durchgeführt wird. Übrigens wird noch des öftern die bestimmte Beziehung der Tugendlehre auf das Individuum hervorgehoben (so S. 499, 520, am meisten bei der Tugend der Humanität, S. 629 ff.). Und es kommt dabei manches wieder zu vollen Ehren, was zuvor, bei der schroffen Zurückweisung jeder Begründung praktischer Lehren, die nicht bedingungslos den Standpunkt der "Allheit“ einnimnt, gänzlich beiseite geworfen $\mathrm{zu}$ werden schien: so die „Gesinnung“ (S. 427) und die "relativen Gemeinschaften“ (S. 486 und 570), die in der Tat nicht ausschliesslich aus der Allheit, sondern nur aus dem Gesichtspunkte der Besonderung und zuletzt der zu sozialem Wollen erst $\mathrm{zu}$ verbindenden Einzelnen ihre Begründung finden können. Wie aber hierbei, so wäre bei den Tugenden der Wissenschaft, der Philosophie (S. 509 f.), des reinen Denkens überhaupt (S. 514), der Bescheidenheit, der Tapferkeit gegen die Sinnlichkeit und im Leiden, der Freundschaft, der Liebe der Geschlechter und noch manchem andern mit einer ausschliesslichen Begründung auf das Recht offenbar nicht durchzukommen, die denn auch von Cohen nicht unternommen wird. Ein Zusammenhang zwar lässt sich auch da überall festhalten und muss festgehalten werden. Wirklich ist und bleibt das Individuum in jeder der hier in Betracht kommenden Beziehungen Individuum der Allheit. Aber die bestimmende „Richtung“ der praktischen Gesetzgebung auf die Allheit und auf das Individunm bleibt dabei immer gleich verschieden; eine gänzliche Zurückführung der "Tugend" des Individuums auf die der Gemeinschaft, ohne eine Besonderung, die zuletzt bis zum Einzelnen herabreicht, wäre offenbar unmöglich. Folglich kann die „Orientierung“ der Ethik auf Recht und Staat, so grundsätzlich wohlbegründet sie ist, als allein richtendes Prinzip für den Auf- und Ausbau des Systems der Ethik nicht festgehalten werden.

§ 10. (Stammlers "Reine Rechtslehre".) Wir sind uun vorbereitet, die Aufstellungen Stammlers über Recht und Sittlichkeit in direkte Prüfung zu nehmen. Wir hätten dabei in jedem Fall (auch wenn nicht der Bericht über das neue Werk hier besonders bezweckt würde) die jüngste und abschliessende Darstellung, die der "Theorie der Rechtswissenschaft", zugrunde zu legen. Sie bleibt $z$ war mit der der beiden vorausgegangenen Werke in allem Grundsätzlichen einig, sie gibt aber der hier fraglichen Lehre eine noch vereinfachte, damit durchsichtigere und also leichter $\mathrm{zu}$ 
prüfende Gestalt, meidet geflissentlich alle nicht zwingend zur Sache gehörigen Nebenbetrachtungen, historischen, religiösen oder sonstwie populären Anlehnungen und erstrebt und erreicht so eine Strenge des logischen Aufbaus der Theorie, die von der Kritik an den früheren Werken bisweilen, und nicht ganz ohne Grund, vermisst worden ist. Das Werk ist in der Tat nusterhaft in der schlichten und deutlichen Disposition der Probleme und unbeirrt durchgeführten Einheit des Verfahrens. Nichts kann willkommener sein für eine Kritik, der einzig daran liegt, über die Fragen selbst zu grösserer Klarheit zu kommen und womöglich sie zum Austrag zu bringen.

Rechtswissenschaft ist selbst Theorie, folglich die Theorie der Rechtswissenschaft Theorie höherer Stufe, Theorie der Theorie. Diese höhere Stufe kann nur Philosophie sein; und so würde wohl Stammler selbst nicht widersprechen, wenn wir den Titel "Theorie der Rechtswissenschaft" einfach als Umschreibung für Rechtsphilosophie deuten wïrder. Doch ist diese Umschreibung sehr zweckmässig, weil sie sogleich die Abwehr des Missverständnisses einschliesst, als wolle wieder einmal Philosophie die Wissenschaft meistern und von jenen "hohen Türmen" herab, um die bekanntlich "viel Wind" ist, auf sie herniederblicken, statt in dem "fruchtbaren Bathos der Erfahrung" sich heimisch zu machen und aus ihr vor allem zu lernen.

Der streng „kritische“, der Immanenzstandpunkt dieser philosophischen Rechtstheorie wird denn auch gleich in der Einleitung nachdrïcklich betont (Einl. 5, S. 21 ff.). Sie will nicht Erkenntnis neuer Gegenstände (S. 22) sein, nicht einen newen Inhalt des Rechts dem positiven gegenüberstellen (8, S. $32 \mathrm{f}$.), sondern sie forscht lediglich nach den reinen Bedingungen, denen jede rechtliche Aufstellung, um als solche anerkannt werden zu dürfen, genügen muss. Auch nicht ein vollkommenes, ideales, unbedingt richtiges Recht will sie dem bedingt gewordenen, ja notwendig uivollkominenen Recht als Muster entgegenhalten (S. 33), sondern sie fragt nach den allgemeingültigen Bestimmungen, die notwendig gelten müssen, wenn Jurisprudenz Wissenschaft sein soll. Jeder Rechtssatz will doch den Gedanken des Rechts vertreten, sonst versteht er sich selbst nicht (6, S. 25); diesen "Gedanken“ gilt es in Reinheit herauszuschälen. Solche Forderung kann keine positive Rechtslehre ablehnen, mag sie auch, als positive, ihre Erfüllung nicht zn ihrer Aufgabe rechnen, 
sondern sic, eben als eine eigene, eine Aufgabe eigner Art, einer besonderen Theorie nicht des Rechts sondern der Rechtswissenschaft überweisen. Jedenfalls handelt es sich nicht um eine blosse "schmückende Zutat", nicht um eine letzte Krönung des übrigens fertigen Baues der Rechtswissenschaft (S. 241), sondern um ihr Fundament, um die Gesetzlichkeit, nach der sie überhaupt als Wissenschaft „allein möglich“ ist.

Also: das Faktum der Rechtslehre als Wissenschaft liegt vor; nach der Möglichkeit dieses Faktums wird gefragt: so entspricht diese Problemfassung der Rechtsphilosophie, welche der Verfasser mit allem Grunde als neu und eigentümlich behaupten darf, in aller Strenge der Grundforderung der transzendentalen Methode Kants.

Sie entspricht ihr aber auch in der nun erst mit voller Wucht auftretenden Forderung der Reinheit d. i. unbedingten Allgemeingültigkeit aller Sätze der reinen Rechtslehre vom ersten bis zum letzten. Alle Besonderheiten des Rechts müssen, nicht der Materie nach, aber formal, nach der "Art ihrer Bestimmtheit" durch den Gedanken des Rechts eingesehen werden können, wodurch das Ganze aller möglichen Rechtserwägungen sich zu einer strengen Einheit zusammenfügt und dem obersten Grundsatze der Einheit des menschlichen Wollens überhaupt sich unterstellt $(1, S .3)$. So gibt es allerdings nicht unbedingt allgemeingültige Rechtssätze (2, S. 5; wie im theoretischẹn Gebiet nicht unbedingte Naturgesetze); die Allgemeingültigkeit betrifft allein das ordnende Verfahren, d. i. den "Rechtsgedanken in seiner formalen Bedeutung". Aber so wird die Darstellung einer reinen Rechtslehre in „festen Gedankengängen“ möglich, „in deren Verfolgung es allein begreiflich ist, einen gegebenen Bewusstseinsinhalt als einen rechtlichen zu haben" (S. 5). So und nur so wird zugleich das alte Desiderat einer eignen "Logik des juristischen Denkens" erfüllbar (S. 12). Ihre bedingenden und bestimmenden Richtlinien müssen eiu geschlossenes System bilden, an dessen Spitze der Regriff des Rechts steht, der seinerseits dem Grundgesetze des Wollens überhaupt sich unterordnet (S. 13 f.). Es ist unnötig, dev Kenner der Kantischen Transzendentalphilosophie erst darauf aufmerksan zu machen, wie genau diese Problemfassung der reinen Rechtslehre in jedem Zuge den Forderungen der "kritischen Methode“ entspricht. 
§ 11. (Begriff und Idee des Rech.t.s.) Für die weitere Disposition des hiermit gestellten Programms der reinen Rechtslehre aber ist an erster Stelle bestimmend die streng vollzogene und durchgeführte Distinktion zwischen Begriff und Idee des Rechts. Auch diese versteht sich ganz aus dem Gesichtspunkte der transzendentalen Methodik; nämlich sie vertritt genau den Unterschied der konstitutiven Grundsätze von den regulativen Prinzipien des Rechts. Der "Begriff“ des Rechts kann durch einen gegebenen, bedingten Rechtssatz restlos erfüllt sein, und muss es sein, wenn er als ein Satz des Rechts überhaupt soll ausgesprochen werden dürfen; die "Idee" des Rechts kann in einem bedingten Rechtssatze, auch selbst als bloss gedachtem Beispiel, nie restlos erfïllt sein; denn sie bedeutet nur die Forderung, ja die Frage nach einer "unbedingt einheitlichen Ordnung der einzelnen Mittel und Ziele" des Rechts, die durch diese und also durch einzelne Rechtssätze wohl von Stufe zu Stufe näherkommend, aber nie als unbedingte in Vollständigkeit dargestellt sein kann (VI, 1, S. 441). Der "Begriff“ bezieht sich also auf das Recht überhaupt, er gibt die Bedingungen an, welche erfüllt sein müssen, damit etwas überhaupt ein Recht (ein Willenssatz ein Rechtssatz) sei; die "Idee" dagegen betrifft die Beurteilung allemal eines bestimmten Rechts, unterschiedlich gegen anderes, danach, bis zu welchem Grade es der grundsätzlichen Forderung der unbedingt einheitlichen Ordnung des Miteinanderwollens nahekomme oder hinter inr zurückbleibe. Dies aber ist der Unterschied konstitutiver und regulativer Prinzipien; so ist z. B. der konstitutive Grundsatz der Kausalität eine allgemeingültige „Art der Bestimmung", als eine Bedingung, der jedenfalls genügt sein muss, wenn ein theoretischer Satz überhaupt als Satz der Naturwissenschaft soll ausgesprochen werden dürfen; nämlich dass er das Veränderliche der Erscheinungen, von denen er redet, überhaupt in gesetzlichen Zusammenhang einzustellen und aus solchem bestimmt zu setzen habe; welches Gesetz aber für sie gilt, wird durch den blossen, konstitutiven Grundsatz nicht bestimmt. Dagegen betrifft das regulative Prinzip, etwa der Spezifikation, gerade die besonderen, also bedingten Sätze der Naturwissenschaft und unterwirft sie einer Norm der Beurteilung danach, in welchem Grade sie, unterschiedlich gegen andre, der Erfüllung der un endlichen, unbedingt also nie $\mathbf{z u}$ erfüllenden Forderung (hier: der erschöpfenden Spezifikation) bedingt nahekommen und sie, so- 
weit es unter gegebenen Voraussetzungen möglich war, erfüllen, oder aber erkennbarerweise hinter ihr zurückbleiben.

Nun waren wir schon oben (S. 31 f.) uns darüber klar geworden, dass, wenngleich die Grundsätze der praktischen Erkenntnis überhaupt $\mathrm{zu}$ denen der theoretischen sich als regulative $\mathrm{zu}$ koustitutiven (als "Ideen" zu "Begriffen") verhalten, dennoch, wie innerhalb der Theoretik, so auch innerhalb der Praktik wiederum eine Scheidung konstitutiver und regulativer Prinzipien zu treffen und festzuhalten ist. Diese Scheidung ist es, die in Hinsicht des Rechts hier durchgeführt wird. Rein aus diesem methodologischen Gesichtspunkt ist also die Distinktion zwischen Begriff und Idee des Rechts und daher zwischen "Recht".schlechtweg und "richtigem Recht" ihrer Absicht gemäss zu beurteilen. „Richtig“" heisst niemals "das" Recht, sondern allemal ein bestimmt gegebenes, und zwar bedeutet es nie unbedingt sondern stets nur bedingt richtiges, d. h. ein solches, welches unter bestimmt gegebenen, veränderlichen, faktischen-Voraussetzungen die Idee des Rechts insoweit erfüllt, als es eben unter diesen Voraussetzungen möglich war. Richtiges Recht ist ein nach der Rechtsidee gerichtetes, nämlich bedingtes, „gesetztes" Recht (S. 480). Die Behauptung, dass es kein in diesem Sinne richtiges oder nichtrichtiges Recht gebe, wäre identisch mit der Behauptung, dass es kein bedingtes, kein gesetztes Recht gebe, das die Idee des Rechts nicht erfüllt und also der Berichtigung bedarf. Diese erfolgt aber notwendig gemäss dem praktischen Vernunftgesetze der unbedingten Einheit der $Z$ wecke, demselben, welches auch das Grundgesetz der Ethik ist. Es ist also nicht an dem, dass der Grund der Richtigkeit des Rechts irgendwo anders als in dem richtendem Prinzipe der Ethik gesucht würde; dass das Recht in absoluter Unabhängigkeit von dem Pribzipe der Ethik sich selber richtig machen sollte (Cohen S. 225 f.). Es ist ebenso wenig eine begründete Kritik, dass die Richtigkeit, zumal als eine bloss logische, hinterherkomme. Die logische Nachordnung der regulativen gegenüber den konstitutiven Prinzipien, der "Idee“ als Richtmass der konkreten Aufstellungen einer Wissenschaft gegenüber dem „Begriff“, der sie als Wissenschaft überhaupt „allein möglich macht", entspricht in voller Strenge den Gesetzen der transzendentalen. Methodik. Dieselbe logische Rangordnung besteht in der theoretischen Philosophie zwischen den koustitutiven Grundsätzen der „Wissenschaft" und den regulativen Prinzipien 
der "Forschung“; sie muss aber auch für die praktische, insbesondere für die Rechtsphilosophie so sicher anerkannt werden, als es einen konstitutiven Begriff des Recbts einerseits, eine regulierende Idee desselben andrerseits gibt. Wäre freilich das Recht schlechtweg die "Mathematik" der Geisteswissenschaften, so wäre von richtigem Recht so wenig wie von richtiger Mathematik zu reden. Aber der Mathematik entspricht vielmehr die reine Rechtslehre, auf welche das Merkmal der Richtigkeit von Stammler in der Tat nicht bezogen wird; der Naturwisseuschaft dagegen die Rechtswissenschaft, die als "positive“ es mit gar keinem andern als bedingtem Recht $z u$ tun hat. So wie nun ein Satz positiver Naturwissenschaft die Forderungen der Mathematik und der konstitutiven Grundsätze einer "möglichen" Naturwissenschaft überhaupt, z. B. die Forderung kausaler Bestinmung überhaupt, restlos erfüllen muss, und nur insofern ein naturwissenschaftlicher überhaupt ist; dabei aber doch nie unbedingt, sondern stets nur bedingt, für eine gegebene Stufe der Entwicklung naturwissenschaftlicher Erfahrung richtig sein kann, im Fortgang der Erfahrung aber der Berichtigung, also auch einer Beurteilung nach gewissen Normen der Richtigkeit (regulativen Prinzipien) unterliegt, so unterliegen die bedingten Rechtssätze, während sie die konstitutiven Forderungen des Rechtsbegriffs in jedem Fall erfüllen müssen, doch, eben als bedingte, gewissen Normen ihrer (eben nur bedingten; nie unbedingten) Richtigkeit, die also als regulative Prinzipien des Rechts, - immer aber gemäss demselben letzten Grundgesetz unbedingt einheitlichen Wollens, sich formulieren lassen müssen. Die "Richtigkeit" des Rechts ist sonach "logische" in keinem andern Sinne, als in dem die Praktik überhaupt Logik des Sollens ist, oder in dem überhaupt das allgemeine Gesetz (jeder Bedeutung) „logisch“ bestimmend ist für die ihm unterstehenden bedingten Sätze; nicht aber im unterschiedlichen Sinne der Logik als Gesetzlichkeit des theoretischen d. i. des Naturerkennens.

Das noch viel weitergehende Missverständnis aber, als solle das Recht überhaupt unabhängig vom Prinzipe des reinen Wollens begründet .werden, beruht auf der Nichtbeachtung des lediglich methodischen Sinnes der Unterscheidung zwischen der rechtlichen Gesetzgebung als „äusserer" und der sittlichen als „innerer". Um dieses Missverständnis gründlich zu entwurzeln, ist daher auf dies fundamental unterscheidende Merkmal des rechtlichen Wollens, 
dass es äusserlich „verbindend" sei, und damit überhaupt auf dic Art, wie der „Begriff“ des Rechts von Stammler bestimnt wird, des genaueren einzugehn.

$\S$ 12. (Recht als „verbindendes Wollen“.) Zunächst darüber hätte ein ernstlicher Zweifel niemals aufkommen dürfen, dass der Begriff des Rechts von Stammler streng apriori, und zwar aus dem obersten Gesetz des Wollens, keinem andern, als welches zugleich das oberste Gesetz der Sittlichkeit ist, deduziert und stets folgerecht dieser reinen Ableitung entsprechend von ihm verstanden worden ist. Das Recht ist, nach Stammler, „in Notwendigkeit mit den letzten Richtungen unseres Bewusstseins, die wir feststellen, gesetzt" (I, 2, S. 43), nämlich als eine „feste Art des Wollens, die mit diesem notwendig besteht" (ebenda); also selbst als ein unbedingt gültiger Begriff, nämlich der Begriff eines „schlechterdings allgemein bedingenden Verfahrens, den Inhalt von wollendem Bewusstsein einheitlich zu bestimmen“ (S. 45). Aus Erfahrung kaun dieser Begriff unmöglich geschöpft werden, obgleich er ohne $Z$ weifel aus ihr ermittelt worden. Aus welcher Erfahrung denn sollte er geschöpft sein? Natürlich aus der rechtlichen; die aber als solche selber erst gemäss dem Begriffe des Rechts bestinınt ist (I, 3, S. 46 f.). Man muss vielmehr auf die "verschiedenen Möglichkeiten der reinen Gedankeurichtungen" achthaben, um dem gesuchten Begriff die rechte Stelle in der Reihe der formalen Richtungen von unbedingter Gültigkeit anzuweisen (S. 47). Nun bezeichnen die letzten formalen Richtungen in unserem Bewusstseinsinhalte die zunächst psychologischen Ausdrücke Wahrnehmen und Wollen. Diese aber weisen, gleich den mehr objektiven, die ihnen entsprechen: Werden und Bewirken, auf einen scharf bestimmten methodischen Unterschied in der Art des Bestimmens unsrer Gedanken, nämlich den der Ordnung nach der Denkform von Ursache und Wirkung einerseits, von $\mathrm{Zweck}$ und Mittel andrerseits (II, 4, S. 49). Das Recht aber fällt ohne Zweifel unter den Begriff des Wollens, des Bewirkens, also der Zweckordnung, und nicht unter den der bloss kausalen Ordnung eines Werdens oder Geschehens. Beide Gebiete des Bewusstseins aber unterstehen gleichermassen der „Wissenschaft", als „unbedingt einheitlichem Ordnen" möglichen Inhalts von Bewusstsein $(I, 6)$ : Naturwissenschaft einerseits, Kulturwissenschaft andrerseits, oder Kausalwissenschaft und Zweckwissenschaft. Beide fordern weiterhin eine fun- 
Uamentale, methodische Grundlegung; nach gewöhnlicher Terminologie: Logik und Ethik, besser: Logik der Kausal- und der Zweckwissenschaft $(I, 7)$; , welche letztere nicht eine blosse Fortsetzung der ersteren ist, sondern sich unabhängig „in eigenem Gedankenzuge, vom ersten Beginn an bis zur Idee der Willensreinheit" aufzubauen hat (S. 67). In dieser also müssen die reinen Begriffe des Rechts als solche des Wollens zu finden sein. Denn nicht nur ein Produkt des Wollens ist das Recht, sondern selbst eine „formale Eigenschaft" menschlichen"Wollens; es "stellt eine eigene Klasse von Willensinhalten dar, die es von sich aus bestimmt und zusammenhält", es ist "eine bedingende Art und Weise des Setzens und Verfolgens von Zwecken" (I, 8, S. 69), auf deren nähere Bestimmung es nunmehr ankommt.

Das zuoberst unterscheidende Merkmal des rechtlichen gegenüber sonstigem Wollen nun ist: der "verbindende" Charakter desselben. Mehrfaches Wollen kann übereinstimmend sein hinsichtlich des Gewollten. Aber nicht das schon ist verbindendes Wollen, sondern ein solches allein, das "ein mehreres Wollen als Mittel füreinander bestimmt", oder wodurch Willensinhalte wechselseitig als Mittel füreinander verbunden werden (I, 9, S. 75). Es kommt also an auf eine Gemeinsamkeit des Wollens, die nicht bloss Gleichheit des Zwecks bedeutet. Die Zwecke brauchen gar nicht die gleichen zu sein und sind es meist nicht; sondern darauf kommt es an, dass bestimmte Zwecke in gemeinsam eingreifender Weise zu setzen und zu verfolgen sind. Daraus ergibt sich stets ein Gegenübertreten des verbindenden zu dem dadurch verbundenen Wollen (S. 77); das erstere "steht über" dem letzteren, welches es zur Gemeinsamkeit zusammenschliesst. Es können dabei dieselben Personen (z. B. zwei Vertragschliessende) wechselseitig als verbindend auftreten; es können andre Personen auf beiden Seiten, verbindend und verbunden, auftauchen, oder zum Teil in beiderlei Rollen erscheinen; immer aber ist der verbundene und der verbindende Willensinhalt systematisch zu unterscheiden, und es ist hierbei nie vou den einzelnen verbundenen Willensinhalten auszugehen, sondern von dem Wollen, das sie verbindet und über ihnen steht (S. 77). Die verbundenen Willensinhalte allerdings werden stets auf verschiedene Personen verteilt sein, weil das „neue Problem des Verbindens" eben aus der Notwendigkeit eịnes Zusammenwirkens mehrerer Wollenden zu gemeinsamem Zweck nur hervorgeht (S. 78). 
Es ist, was früher schon als „äussere Regelung“ von Stammler definiert und als Grundbedingung des Rechts festgelegt worden war (S. 79). Zur "Regelung" kommt man, wenn man von dem Erfordernis eines Zusammenwirkens den Ausgang ninmt. Die logische Bedingung dafür aber ist das verbindende Wollen. Hierbei, und somit allgemein bei aller sozialen Erwägung, ist nie von dem Inhalte getrennten Wollens auszugehn, auch nicht von einer Mehrzahl von solchen, dann erst zusammenzuzählenden Willensinhạlten, und keineswegs von einer ursächlichen Einwirkung mehrfacher Zwecksetzungen aufeinander. Sondern es ist der Standpunkt von vornherein im verbindenden d. h. gemeinsamen Wollen als solchem, als „in grundlegender Weise besonders geartetem "Wollen zu nehmen, das über den einzelnen Willensinhalten, die es verbindet, steht; das Einzelwollen für sich ist in seinem mehrfachen Auftreten lediglich als Mittel für einander zu nehmen (S. 79 f.).

Diese begrifflichen Festlegungen mussten in so breiter Ausführlichkeit wiedergegeben werden, weil an ihnen das Verständnis der ganzen Stellungnahme Stammlers in unserer Frage hängt. Gleich hier ist darauf besonders zu achten, dass in diesen Grundbestimmungen in zweifelloser Klarheit der Standpunkt der Allhe it im sichern Unterschied von jeder bloss „zusammengezählten“ Mehrheit Einzelner, eingenommen ist. Damit ist der von Haus aus soziale Charakter des Rechts in grundsätzlicher Schärfe festgelegt.

Der soziale Charakter, nicht der soziale Ursprung. Denn nicht das soziale Dasein, das Dasein einer Sozietät bedingt das verbindende Wollen, sondern umgekehrt, das verbindende Wollen allein begründet soziales Dasein, begründet, konstituiert unmittelbar den Bestand einer Gesellschaft (I, 11, S. 83). Soziales Wollen ist nicht "Wollen der Gemeinschaft.", in dem Sinne, als ob diese ein besonderes, mit Bewusstsein begabtes Wesen sei, das etwas wollen könne. Sondern der formale Unterschied des verbindenden vom vereinzelt gedachten Wollen ist es erst, der ein soziales Dasein, der überhaupt den Gedanken einer Gesellschaft konstituiert. Soziales Dasein und verbindendes Wollen gehören also begrifflich aufs engste zusammen: jenes ist nur die Betätigung des zweiten, und dieses bedeutet die formale Bestimmung des ersten (S. 85); das heisst, gemäss den früheren Formulierungen Stammlers: soziales Leben ist „äusserlich geregeltes" Zusammen- 
wirken; oder schlechtweg: Zusammenwirken, in dessen Gedanken das bedingende Element der äusseren Regelung notwendig liegt (S. 85). Ob ein gesellschaftsloses Dasein, ein "Naturzustand" des Menschen möglich oder je historisch wirklich gewesen sei, ist in diesem Zusammenhange obne allen Belang, auf das logische Verhältnis kommt es allein an; da aber ist die Vereinzelung nur zu denken als Vorbereitung zur Einstellung der vereinzelt eingeführten Mittel und Zwecke über die bedingte Zusammenfassung in der Person ihres Trägers hinaus schliesslich in eine geordnete Beziehung zu den überhaupt möglichen Reihen der Zweckverfolgung, d. h. nur als Vorstufe zum Gedanken des verbindenden Wollens; denn in "folgerechtem Ausdenken" ist es gar nicht zu umgehen, dass das Wollen der Einzelnen, wie sehr immer in sich nach Mittel und Zweck geordnet, danu selbst wieder in Verbindung miteinander gesetzt und die Willensinhalte der Einzelnen als Mittel für einander erwogen werden (S. 89 f.).

So aber scheidet sich in begrifflicher Klarheit: in nere Ordnung von Zweckvorstellungen, auf den vereinzelt vorgestellten Menschen bezogen, und äussere, auf das Verhältnis der Zwecke verschiedener Menschen gehend, die sie in gemeinsamer Art der Zweckverfolgung verbindet (I, 12, S. 91). Das Recht aber ist ohne Zweifel eine Art des verbindenden Wollens; nicht als blosse Zusammenzählung von Willensinhalten Einzelner, sondern als über den Einzelnen stehend (S. 93); nicht als "Wille der Gemeinschaft", da diese ja nicht ein wollendes Bewusstsein für sich besitzt; sondern indem das verbindende Wollen selbst als logisches Prius den sozialen Verein, heisse er run Gesellschaft oder Gemeinschaft oder wie sonst, erst möglich macht (S. 94).

Dieser entscheidenden Aufstellung vermag ich (wie früher, Sozialpäd. 3. Aufl., S. 158 ff.) nur vollinhaltlich beizutreten. Der unterscheidende formale Charakter des sozialen Wollens scheint mir dadurch zutreffend bestimmt, und damit das unerschütterliche Fundament für die Entwicklung der reinen Begriffe des Rechts als der konstituierenden "Form" des sozialen Lebens in einwandfreier Weise gelegt $\mathrm{zu}$ sein. Hat auch ohne Frage dieses erstwesentliche Merkmal des Rechtsbegriffs der Rechtsphilosophie von jeher mehr oder minder bestimmt vorgeschwebt, ist es vor allem in der Vertragstheorie als das eigentlich gemeinte gedankliche Grundmotiv unschwer wiederzuerkennen, so wird dadurch das Verdienst nicht geschmälert, diese vielleicht immer gemeinte, aber nirgends 
bisher in zweifelsfreier Klarheit logisch herausgearbeitete Grundbestimmung sicher und rein dargestellt und in unanfechtbarer, sehr fundamentaler Deduktion begründet zu haben.

$\S$ 13. (Sittliche gegenüber rechtlicher Erwägung.) Nicht das gleiche aber lässt sich von der parallelen Bestimmung des formal unterscheidenden Charakters der sittlich en gegenüber der rechtlichen Erwägung sagen. Sie solì das wünschende Wollen im Unterschied vom wirkenden angehen (I, 6, S. 83). Wünschen ist Wollen ohne Mittel, definiert Stammler, an sich gewiss zutreffend (S. 82). Solange aber das Wollen wünschender Gedanke bleibe, gehöre es zwar zum Inhalte unseres Bewusstseins und müsse auch lauter und rein d. h. gesetzmässig gestaltet werden; aber es bleibe, da einsetzbare Mittel fehlen, getrennt für sich, auf die Person des Wünschenden beschränkt; es falle daher nicht unter den Begriff gemeinsamen Wollens, also nicht unter soziale Erwägung.

Schon dies letztere leuchtet nicht ein, Wünschen heisst bewirken wollen, und nur nicht können, lediglich aus Ermangelung der Mittel der Verwirklichung des Gewollten. Sobald die Mittel gegeben sind, wird der Wunsch, wenn es überhaupt entschiedener Wunsch war, zur Tat werden; dann kann er aber auch schon, ele er es wird, nicht der Beurteilung gänzlich entzogen sein, der das Handeln, auf das er seinem ganzen Begriff nach gerichtet ist, notwendigerweise untersteht. Und so bleibt in der Tat der „wünschende Gedanke" - oder, um den dann dafür eintretenden Begriff sogleich einzusetzen: die Gesinnung - der rechtlichen Erwägung keineswegs fremd. Das Recht wird allerdings über wünschende Gedanken, solange sie in keiner Weise in Handlung übergehen, auch nichts im besonderen bestimnen; aber wo immer der Wunsch in Handlung übergeht oder auch nur überzugehen droht, wird er stets auch vom Recht mit in Betracht gezogen und, wenngleich immer in Beziehung auf eine mögliche Handlung, als seinen Ausfluss, auch unmittelbar in rechtliche Erwägung genommen.

Vor allem aber, so vieldeutig das Wort „Ethik" sonst gebraucht werden mag, so hat es doch, seitdem Aristoteles wohl als erster es zur Bezeichnung der Wissenschaft von der Gesetzlichkeit des Wollens verwendet hat, sicher noch keine Ethik gegeben, die nicht, wenn auch vom Innern der Gesinnung aus, das Wirken und Handeln, sei es nun als ausserdem auch unter rechtliche Erwägung fallend, oder ganz von solcher absehend, ins Auge 
gefasst und unter Normen gestellt bätte. Auch wenn innerhalb der Ethik die Frage der Gesinnung von der des Wirkens oder Handelns geschieden wurde, hat man wohl nie die Gesinnung ausser Bezug zu der ihr entsprechenden Handlung gedacht, sondern nur die zunächst auf die äusserlich fassbare Handlung beschränkte Beurteilung vertiefen und verschärfen wollen durch die Ausdehnung grundsätzlich der gleichen Beurteilung auf die Gesinnung, aus der sie floss und die allein zuletzt für sie verantwortlich sei. Gerade in rein formaler Erwägung, meine ich, sei es unwidersprechlich, dass die praktische Beurteilung, heisse sie nun rechtlich oder sittlich, in jedem Fall primär die Zwecksetzung und nur sekundär die zur Verfolgung des Zwecks ins Spiel gesetzten Mittel ins Auge fassen müsse. Dann aber wird die ganze Frage, ob im gegebenen Fall es an den Mitteln zur Verwirklichung des Bezweckten etwa fehlte und darum das Wollen beim Wünschen stehen blieb, zu einer derart untergeordneten, dass daraus eine grundsätzlich neue Beurteilungsweise unmöglich entspringen kann. Der Rückgang der praktischen Beurteilung von der Handlung auf die Gesinnung bedeutet den Rückgang auf die Zwecksetzung oder auf das Gewollte rein als solches; aber dies Gewollte ist in jedem Fall eine gewollte Handlung; allein in Beziehung auf die Handlung, die gewollt wird, wird das Wollen beurteilt, gleichviel ob es in gegebenen Fall bis zur Handlung wirklich gedieh oder im Wünschen stecken blieb. Wie sollte das bloss negative Merkmal des Fehlens der Mittel eine grundsätzlich neue Beurteilungsart herbeifübren?

Diese Einwendungen liegen so nah und sind so unabweislich, dass man sich nach einem besonderen Grunde umsieht, der es erklärt, wie ein sonst streng auf erschöpfende Begründung ausgehender Forscher hier von der bisher gradlinig verfolgten Zielrichtung abbiegen konnte. Der Grund scheint dieser zu sein: nachden das rechtliche Wollen als das verbindende erkannt war, schien das verbindungslose Wollen als eine eigne Provinz im Reiche des Wollens übrig zu bleiben, welche, da die Forderung der Gesetzlichkeit unzweifelhaft auf alles Wollen sich erstrecken muss, zwar nicht einer eignen Gesetzgebung, aber doch einer eigenen Anleitung zur praktischen Bewährung der gesetzgebenden Idee des Wollens zu bedürfen schien. Allein hier offenbart sich nun die Unzulänglichkeit des Gesichtspunkts der blossen Klassifikation, der bei den Verfahren 
Stammlers überall in erster Linie leitend erscheint. Oben schon ergab sich uns, dass nicht die innere Willensbestimmung als eine eigne Provinz koordiniert neben der äussern, ausserhalb ihrer liegt, sondern nur einer solchen Bestimmungsart, die von aussen nach innen gerichtet ist, eine andere, die von innen nach aussen geht, in methodiseh sicherer Unterscheidung gegenübergestellt werden kann. Beide können dabei der Materie nach sogar ganz zusammenfallen, und bleiben dabei doch, eben in der "Art" $d$. h. der Richtung des Bestimmens, nicht bloss verschieden sondern entgegengesetzt.

Von diesem Standpunkt bleibt eine Scheidung und Entgegensetzung nach "Gesinnung" und "Tat" allenfalls nur in dem Sinne möglich, dass die rechtliche Beurteilung primär die Tat, und nur in Zurückbeziehung auf diese die Gesinnung, die sittliche primär die Gesinnung, und nur in Zurückbeziehung auf sie die Tat beurteile. Aber überhaupt nicht wesentlich und zuerst nach dem, was beurteilt wird, ist die ursprüngliche Unterscheidung der Beurteilungsart zu treffen, sondern nach dem Prinzip, wonach die Bestimmung des Gewollten vollzogen wird. Nämlich das Gesetz der Sittlichkeit fordert die durchgängige Einheit der ZWecke, gleichviel ob in blossen Wünschen oder auch im Wirken, "von innen her", das heisst rein aus dem eignen inneren Gesetze des Wollens selbst als vernünftigen (also der praktischen Vernunft), und mutet die Anerkennung seiner Forderung (nämlich der unbedingten Einheit der Zwecke) jedem Vernünftigen, rein auf den zweifellosen Ausspruch sein er eignen praktischen Vernunft hin, an; sodass es einer äusserlich verbindenden Norm gar nicht erst bedürfen - sollte. Das Recht dagegen fordert inhaltlich dieselbe Übereinstimmung der Zwecke "von aussen her", das heisst, sofern sie in der Tat eben nicht von selbst von jedem, aus eigner Vernunft, gewollt wird, sondern indem sie dies Wollen ihm, auch wenn er nicht seine eigne Vernunft befragen würde, a $n$ mutet, daher in gebietender Weise; ganz wie es Stammler erklärt: im Sinne „verbindenden" Wollens, $d . b$. in dem Sinne, die Übereinstimmung der Zwecke, sofern sie nicht von einem jeden aus seiner eignen Vernunft schon angestrebt wird, dennoch in die Wege zu leiten und zum Willen eines jeden $z \mathfrak{m}$ achen. Ebendamit zielt die rechtliche Gesetzgebung doch auf die schliesslich freie, autonome Anerkennung des Vernunftgesetzes, setzt sie im allg emeinen sogar voraus (wie übrigens Stammler aus- 
drücklich anerkennt). Dies gerade konnte leicht verleiten, die formale Verschiedenheit der rechtlichen von der sittlichen Bestinmung zu übersehen, die rechtliche Verpflichtung selbst und als solche schon für die sittliche zu nehmen. Andrerseits will aber die sittliche Gesetzgebung nichts weniger als mit der blossen guten „Gesinnung" vorlieb nehmen, sondern sie will ganz gewiss sich auf das Wirken und Handeln erstrecken. Und daher kanu sie schwerlich umhin, die äussere Verpflichtung des Rechts zum wenigsten als Mittel zum böheren, sittlichen Zweck mit in ihre Rechnung zu stellen und durch ihre eigene, an sich höhere, weil unbedingte Forderung zu legitimieren und zu sanktionieren. So ist wohl allzeit die Beobachtung des rechten äussern Verhaltens, als mindestens vorschulend zur reinen, freien Sittlichkeit der innern Gesinnung, auch im Namen der Sittlichkeit, absehend von allem Recht, gefordert worden. Und so droht dann leicht wiederum von der Seite der Sittlichkeit der Unterschied beider Bestimmungsweisen sich zu verdunkeln und schliesslich aufzuheben. Macht man sich aber klar, dass es sich um einen Richtungsunterschied handelt und überhaupt nur handeln kann, so wird ebenso der echt philosophische Zng zur restlosen Vereinigung beider so tief ineinandergreifenden Beurteilungsarten, wie andrerseits die mehr positivistische Neigung, beide durchaus getrennt zu halten, begreiflich, aber es werden beide zugleich als Einseitigkeiten erkannt, und es bleibt schliesslich in reinem Einklang miteinander stehen die konkrete Einheit beider Beurteilungsarten und ihre unverwischbare abstraktive Scheidung.

Mit Stammlers eigenen letzten Voraussetzungen und gerade mit dem Wesentlichen seiner Absicht scheint diese Lösung sehr wohl vereinbar, ja durch sie geradezu gefordert zu sein. Gerade er müsste aus seinen Voraussetzungen einräumen, dass, wenn das verbindende Wollen allerdings eine eigene formale Art des Bestimmens begründet, nicht darum auch das getrennte Wollen eine solche begründen muss; da die Vereinzelung, wie er selbst so klar darlegt, überhaupt nur als "logische Vorstufe" zur Verbindung in Frage kommen darf, als faktische Voraussetzung sich kaum ausdenken lassen will. Nicht diese phantastische, fiktive Vereinzelung des Wollens kann den wissenschaftlich brauchbaren Korrelatbegriff des verbindenden Wollens ergeben; sondern da (wie bald uoch des näheren darzulegen sein wird) die Heteronomie des Rechts doch zur Antonomie nuwidersprechlich zuriickstrebt und aus deren 
Standpunkt sich überhaupt nur rechtfertigen kann, so ist die richtige Korrelation vielmehr die des Bestimmens vom Gesichtspunkt der Heteronomie aus, aber als abzielend auf die Autonomie einerseits, vom Gesichtspunkte der Autonomie aus, aber sich spezifizierend in zunächst heteronome Normierungen andrerseits.

$\S$ 14. (Die Merkmale des Rechtsbegriffs und ihre kategoriale Begründung.) Nicht von gleicher Bedeutung für unsere letzte Frage, aber in systematischer Hinsicht doch nicht ohne Bedeutung sind die beiden weiteren Unterscheidungsmerkmale, durch deren Hinzufügung der Begriff des Rechtes sich vollendet: die der "Selbstherrlichkeit" und der "Unverletzbarkeit". Beide verschärfen noch und präzisieren den "verbindenden“" Charakter des Rechts: die Selbstherrlichkeit (Autarchie) des Rechts besagt, dass es dem einzelnen Wollen nicht freistellt, ob es dem Rechte unterstellt sein wolle oder nicht, sondern ihm die notwendige Unterordnung unter es auferlegt (I, 13, S. 97). Durch dieses Merkmal sondert sich das Recht von der blossen Konventionalregel, die zur Verbindung des Wollens bloss "einlädt", das heisst das Eintreten in sie dem einzelnen Wollen freilässt und nur, sofern es in sie eintreten will, ihm die bestimmte Richtung vorzeichnet. Die sachliche Bedeutung dieses Merkmals liegt besonders darin, dass es den Charakter des Rechts als $\mathrm{Z}$ wangsregelung rechtfertigt und erklärt. Der Begriff des Zwangs ist hier, wie in Klarheit ausgeführt wird, durchaus nicht kausal sondern ausschliesslich final zu verstehen; der Zwang ist kein andrer als der praktisch-logische der unverbrüchlichen Unterordnung des einzelnen Wollens unter das allgemeine Gesetz zu wollen; das Gesetz lässt, eben als solches, keine Wahl. Auch der "imperative" Charakter, den man dem Recht zuspricht, ist dafür wenigstens kein reiner Ausdruck. Gebot und Verbot sind allenfalls Ausstrahlungen des Rechtsgedankens, aber nicht konstituierende Merkmale desselben (I, 14, S. 104).

Was aber die "Selbstherrlichkeit" vonseiten der zu verbindenden Willensinhalte ausdrückt, dasselbe, also kurz gesagt die Unverbrüchlichkeit des Rechts, den Ausschluss der Willk ür, drückt das letzte Merkmal vonseiten des „zielgebenden“, also des verbindenden Wollens selbst aus: das Rechtsgesetz will angesehen sein als in "geschlossener" Weise, ein für allemal, nicht bloss von Fall zu Fall verbindend (I, 15, S. 105-107). Nämlich es ist an sich denkbar, einerseits, dass die „Aufnahme des Ziels“, für 
das die einzelnen Willensinhalte als Mittel verbunden werden solleu, vouseiten dieser bloss von Fall zu Fall erfolge, andrerseits, dass das zielgebende Wollen selbst nur von Fall zu Fall und nicht in bleibender Art einsetzt. Das erstere wird durch die Bedingung der "Selbstherrlichkeit", das letztere durch die der „Unverletzbarkeit" ausgeschlossen. Diese bedeutet darum nicht Unabänderlichkeit des jeweils gesetzten Rechtes (I, 16); nur ist ein gesetztes Recht allein so abänderlich, dass beim Wechsel des Inhalts immer die gleiche bedingende Weise des Ordnens gewahrt bleibt. Grundsätzlich muss daher das einmal bestehende Recht bestehen bleiben, bis es durch anderes, im gleichen Sinne "unverletzbares" Recht abgelöst wird. Doch wird dadurch nicht ausgeschlossen, dass neues Recht auch durch Rechtsbruch, oder überhaupt aus rechtlosem Zustand, entstehen kann.

In den besagten vier Merkmalen nun ist der Begriff des Rechts - als des „unverletzbar selbstherrlich verbindenden Wollens" - abgeschlossen. Es liegt nun nahe, für die Aufstellung und Ordnung dieser Merkmale eine kategoriale Begründung zu fordern. Ich glaube, dass diese Forderung einerseits unabweisbar, andrerseits unschwer zu erfüllen ist.

Voraussetzung ist der Unterschied praktischer von theoretischer Objektsetzung überhaupt. Daher ist nicht eine besondere konstitutiv-kategoriale Begründung für das Merkmal des Wollens zu fordern, sondern es kann hierfür nur die Modalität, nämlich die Notwendigkeit praktischer Bestimmung überhaupt, in Frage kommen. Durch diese wird in der Tat das gesetzmässige Wollen, als das allgemeine Objekt der praktischen Erkenntnis, ebenso konstituiert, wie durch die Notwendigkeit des Gesetzes im theoretischen Sinne die gesetzmässig bestimmte "Tatsache", als das allgemeine Objekt der theoretischen Erkenntnis.

Das Merkmal des Verbindens aber ist das genaue praktische Korrelat der Wechselwirkung, es bezeichnet also die praktische Objektsetzung nach ihrem Relationscharakter.

Die Unverletzbarkeit, als "Geschlossenheit" des zielgebenden Wollens, drückt die Gesetzmässigkeit der Willensbestimmung nach ihrer qualitativen Bedentung aus; denn die Zieleinheit eben bestinmt das Wollen, in den Einzelheiten seines Inhalts (dessen was zu wollen sei), oder seines realen Gehalts, gemäss der Forderung der Kontinuität in einer Gattungseinheit; als dem Ursprunge aller inhaltlichen Einzelheiten. 
Die Selbstherrlichkeit dagegen, als Forderung der ausnahmslosen Umfassung alles besonderen und einzelńen zu verbinzdenden Wollens, bezeichnet denselben Gesetzescharakter des bestimmenden Wollens nachseiten der Quantität, die Allgemeinheit des Umfangs, in dem es bestimmend sein solle für das jeweilige einzelne Wollen.

Die Richtigkeit dieser, hier einmal auf gut Glück gewagten Aufstellungen müsste sich dann natürlich in genauer Durchführung durch die ganze reine Rechtslehre bewahrheiten. Ich glaube, dass sie sich bewähren; einiges Hierhergehörige wird weiter unten (§ 16) anzuführen sein.

§ 15. (Vom Gelten des Rechts.) Mit dem verbindenden Charakter des rechtlichen Wollens und dessen näheren Bestimmungen hängt eng zusammen die interessante und wichtige Frage vom "Gelten" des Rechts (Abschn. II). Ein Recht, im Unterschied von dem Recht, heisst ein besonderes Wollen, das unter dem Rechtsgedanken steht. Dieses ist damit schon "gesetztes“ oder "positives", aber nicht auch schon "geltendes“ Recht. Das Positive bedeutet den „bedingten Bestandteil eines besonderen rechtlichen Wollens" (S. 120). Also gibt es, im zweiten Sinne des Rechts (als "ein" Recht), überhaupt kein anderes als positives, wozu den Gegensatz nur noch der formale Begriff "des“ Rechts überhaupt bildet. Das positive Recht kann aber sein 1. geltendes oder nicht geltendes, 2. richtiges oder nicht richtiges positives Recht. Diese beiden Gegensatzpaare sind voneinander ganz unabhängig: geltendes wie nichtgeltendes Recht kann richtig oder nichtrichtig, richtiges wie nichtrichtiges geltend oder nichtgeltend sein. Das geltende Recht nun unterscheidet sich durch die Möglichkeit der Durchsetzung. - Es bedarf kaum eines Wortes, um anch hier die genaue Parallelität mit den Gesetzen der theoretischen Erkenntnis zu beweisen: die Gewähr der Tatsächlichkeit ist keine andre als die Durchführbarkeit ihrer Voraussetzung in der Gesamtheit der theoretischen Ansätze, die für das bis dahin erreichte Stadium der Entwicklung der theoretischen Erkenntnis der "Natur" gelten. Auch hier steht dem jeweils tatsächlichen Gelten gegenïber die bleibende „Richtigkeit“ d. b. Möglichkeit der Behauptung des fraglichen Ansatzes nicht bloss in jeweils erkannten Gesetzeszusammenhang, sondern auch für die ganze fernere Entwicklung der Gesamtempirie. 
Die Frage nach den näheren Bedingungèn der Durchsetzbarkeit des Rechts (auf die hier nicht einzugehen ist) führt weiter auf die Psychologie des Rechts, zu der daher hier einige anregungsreiche Bemerkungen gemacht werden. Nicht die Begründung des Rechts darf in der Psychologie gesucht werden, vielmehr ist die Psychologie des Rechts selbst nur in Zurückbeziehung auf eine objektive Deduktion der reinen Rechtsbegriffe möglich (S. 149). Ausdrücklich bekennt sich Stammler (S. 160) zur Methodik der rekonstruktiven Psychologie, und diese führt auch in den Konsequenzen $\mathrm{zu}$ einer der meinigen nahestehenden Grundansicht von den subjektiven Bedingungen für den Bestand eines Rechts; nämlich die wesentlichen Voraussetzungen der subjektiven Möglichkeit eines Rechtszustands sind: die Bestimmbarkeit des Willens, seiner Materie nach, einerseits, eine schon in seiner letzten subjektiven Wurzel, der Strebung, liegende ursprüngliche Tendenz zur Einheit, besonders in Richtung auf soziales Zusammenwirken, andrerseits (vgl. Sozjalpäd. S. 155 ff.).

$\S$ 16. (Die Kategorieen des Rechts.) Zum streng objektiven Aufbau der reinen Rechtslehre zurückkehrend unternimmt nunmehr Abschn. III die Kategorieen des Rechts in geschlossenem System, nach Art und Zahl unwandelbar (S. 192), alle Möglichkeiten rechtlicher Gedankenrichtung erschöpfend, als die unter dem Gedanken des Reçhts überhanpt möglichen Arten allgemein ordnenden Verfahrens aufzustellen; womit erst die Frage in der ganzen zu fordernden Strenge sich beantwortet: „wie Jurisprudenz als Wissenschaft möglich sei“. Denn sie wäre nicht Wissenschaft ohne eine solche kategoriale Grundlegung. Die Kategorieen ergeben sich, allemal paarweise, aus den vier Momenten des Rechtsbegriffs, nämlich als

Kate-
go-
rieen $\left\{\begin{array}{l}\text { des Wollens: Rechtssubjekt-Rechtsobjekt; } \\ \text { des Verbindens: Rechtsgrund-Rechtsverhältnis; } \\ \text { der Selbstherrlichkeit: Rechtshoheit-Rechtsunterstelltheit; } \\ \text { der Unverletzbarkeit: Rechtmässigkeit-Rechtswidrigkeit. }\end{array}\right.$

1. In gesetzmässigem Wollen bestimmt der Zweck die Mittel; Endzweck aver und Selbstzweck ist allein das Wesen, welches fähig ist, seine Zwecke in Sinne unbedingtgültigen Verfahrens zu richten (S. 196): also das Willens-Subjekt als möglicher Träger eines als Endzweck gültigen Orduungsverfahrens (S. 199); mithin, wenn der Wille Rechtswille ist: das Rechtssubjekt. Rechtsobjekt dagegen ist, was als blosses Mittel zu be- 
dingten Zwecken unter dem Rechtsgedanken ins Auge gefasst wird (S. 198). Subjekt eines Rechts also (wird man zu verstehen haben) ist das, um deswillen, als Selbstzwecks, dem Objekte nach ein bestimmtes Verhalten rechtlich gefordert ist. Es wird daraus z B. gefolgert, dass es grundsätzlich unmöglich ist subjektlose Rechte anzunehmen (S. 201). Dagegen ist insoweit nichts darüber bestimmt, wer oder was als Rechtssubjekt zu gelten habe; ob z. B. alle Rechtserwägung schliesslich auf den Menschen als Rechtssubjekt zurückgehen müsse (S. 199), und in welchem näher bestimmten Sinne. Das Rechtssubjekt ist überhaupt nicht ein Dingbegriff, sondern ein reiner Methodenbegriff (S. 200, vgl. 356, 373); daher die angebliche „Fiktion“ (S. 332) der "juristischen Person" vielmehr eine vollbegründete Anwendung des Begriffs des Rechtssubjekts als einer „notwendigen Bedingung zur einbeitlichen Ordnung der Rechtsgedanken" (S. 356. Dagegen ist der Begriff des "subjektiven Rechts“ von dem des Rechtssubjekts durchaus zu scheiden, S. 381).

Der idealistische und zwar streng im methodischen Sinn idealistische Charakter dieser Aufstellungen braucht kaum besonders bemerkt zu werden. Da aber Rechtssubjekt und Rechtsobjekt einfach die Setzung als Zweck und zwar Endzweck einerseits, als Mittel andrerseits vertreten, so ist die Aufstellung in der Tat so rein und fundamental, wie es zum kategorialen Charakter dieser Begriffe erforderlich ist. Unsern obigen Voraussetzungen über die Grundkategorieen der Praktik überhaupt würde die Aufstellung sich in der Art einfügen, dass der bestimmende Zweck der Modalitätsstufe der Notwendigkeit (in praktischer Bedeutung), das durch ihn zu bestimmende Objekt der der Möglichkeit und (im jeweils gegebenen Fall) der Wirklichkeit entspricht. Das praktisch letzthin Notwendige ist eben nichts andres als der notwendige Bestand der praktischen Gesetzgebung selbst, die nur als Antonomie, also in Beziehung auf ein (der Möglichkeit nach) sich selbst gesetzgebendes Subjekt (Person) möglich ist.

2. Nicht minder zweifelsfrei leitet aus dem verbindenden Charakter des rechtlichen Wollens das zweite Gegenverhältnis, das vou Rechtsgrund und Rechtsverhältnis, sich ab. Die Frage nach dem Rechtsgrund ist die nach dem bezweckten $\mathrm{Zu}$ sammenwirken; diesem bestiumenden Zweck entspricht, als das zu Bestimmende, das Zusammenwirken selbst, also die verbundenen Willensinhalte; das rechtliche Bestimmtsein mehrerer Willens- 
inhalte als Mittel für einander" (S. 204. 205). Es folgt daraus z. B., dass es Rechtsverhältnisse nur unter Rechtssubjekten geben kann (S. 207).

Wie anch dies unsern Voraussetzungen entspricht, ist ohne weiteres ersichtlich. Es kommt hier wieder die Relationsbedeutung des Rechts, als praktischer Wechselwirkung, zu sehr klarem Ausdruck. Allenfalls wäre dabei, als das letzte za Bestimmende, die dem Rechtsverhältnis entsprechende Handlungsweise des Einzelnen (obwohl als im Rechtsverhältnis mit dem Andern Verbundenen) noch ausdrücklich hervorzuheben; mitverstanden ist sie gewiss.

3. Der Selbstherrlichkeit des Rechts entsprechen die Kategorieen der Rechtshoheit, als der "Gedankenrichtung eines rechtlichen Wollens, nach der es den $\mathrm{Zweck}$ seines Bestimmens in sich trägt", und der Rechtsunterstelltheit, d. h. "Einordnung rechtlich verbundener Willensinhalte als Mittel für ein verbindendes Wollen" (S. 209); was, wenn es nicht allzu nah heranrücken soll an das, was durch die Kategorieen des Rechtssubjekts und des Rechtsverhältnisses schon zum Ausdruck gebracht war, wohl im bestimmten Sinne der allgemeinen Subsumption zu verstehen ist; eine "sich gleichbleibende Richtung des Erfassens und Sichtens", heisst es z. B. S. 211; und überhaupt durchweg ist die Unter- und Überordnung, also die Subsumption, hier der massgebende Gesichtspunkt. Daher ist man wohl berechtigt, als den kategorialen Grundcharakter der aus dem dritten Merkmal des Rechtsbegriffs abgeleiteten Grundbegriffe den der Quantität anzunehmen.

4. Einer kleinen Korrektur bedarf allenfalls die Aufstellung des vierten Kategorieenpaares. Nämlich in dem Gegensatze der Rechtmässigkeit, als Übereinstimmung, und der Rechtswidrigkeit, als des Widerspruchs der zu verbindenden Willensinhalte mit dem sie verbindenden (verbinden wollenden) rechtlichen Wollen soll das Merkmal der Unverletzbarkeit sich ausprägen. Aber es will ja diesen Widerspruch vielmehr ausschliessen. Unter den drei übrigen Titeln stand allemal zur linken das bestimmende Prinzip des Rechts, zur rechten das, was durch es zu bestimmen sei: das Rechtssubjekt als End- und Selbstzweck bestimmt das Rechtsobjekt als Mittel, der Rechtsgrund das Rechtsverhältnis, die Rechtshoheit die Rechtsunterstelltheit. Denıentsprechend sollte auch in der vierten Korrelation eher auf der 
rechten Seite die „Rechtmässigkeit" stehen, mit der durch einfachc Negation auch die Rechtswidrigkeit ohne weiteres gegeben ist; auf die linke Seite dagegen gehört das diese Bestimmende, also die unverbrüchliche Verpflichtungskraft des Rechts. Es ist, wie die Ausführungen (III, 18 und V, 7) klar erkenneu lassen, wesentlich an die Durchführung des Rechts und die Berichtigung des rechtswidrigen Verhaltens, an den Rechtsschutz, nach Bindings Ausdruck die Rechtsbewährung gedacht; daher begreift sich, dass der Gedanke an die Ne gat io $\mathrm{n}$, an die Rechtsverletzung und deren Wiederausgleichung sich hier besonders aufdrängt. Aber wenn gewiss der Negation gerade hier eine berechtigte Erwägung zufällt, so dürfte es sich doch in letzter Instanz nur um die $\mathrm{Neg}$ ation der Negation, also die Berichtigung oder auch Vorbeugung (S. 258) handeln, die als "Bewährung" sich zutreffend nach ihrem wesentlich doch p o sitiven Sinn ausdrückt. W as aber ist zu bewähren? Das Recht selbst, als Verpflichtung, oder, wenn man alles Subjektive abstreift: als Schuldigkeit, in dem Sinne: was man $\mathrm{zu}$ tun oder zu lassen schuldig sei; allgemein also das man schuldig sei das Recht zu beobachten.

Das mag nun weit abzuliegen scheinen von dem, was wir oben als die kategoriale Bedeutung des Merkmals der Unverletzbarkeit uns klarzumachen suchten. Und doch muss die Aufstellung, wenn sie zutreffend sein soll, den wesentlichen Sinn dieses Merkmals genau ausdrücken, welcher war: die aller Willkür entzogene, geschlossene $\mathrm{E}$ in he it der rechtlichen Bestimmung, vonseiten des gesetzten $\mathrm{Z}$ we ckes selbst, also dem Inhalt nach, nicht bloss vonseiten der ihr zu subsumierenden einzelnen Willensbestimmungen (was ja schon die Rechtshoheit und Rechtsunterstelltheit ausdrückt). Aber die Kontinuität der inhaltlichen Best im mungen des Rechts, die, im logischen Sinne, das Gesetz seiner Qualität nach bezeichnet, ist das, worauf es hier entscheidend ankommt. Daher darf nicht die blosse Erwägung, das s ü b e r h a upt das Recht sich jeder vonseiten des Rechtsunterstellten etwa versuchten Negation gegenüber zu behaupten, sie wiederum zu negieren habe, hier sich vordrängen, sondern es muss der Gesichtspinukt massgebend bleiben, dass vonseiten des verbindenden Willens selbst die In halts e inheit, die innere Kontinuität dessen, wozu er verbindet; in Strenge zu behaupten, also jede $D$ iskontinuität a uszuschliessen sei. Diesem Ge- 
sichtspunkt aber unterstellt sich in der Tat in aller Klarheit eben die „Bewährung" des Rechts gegen jede versuchte Verletzung, die als Rechts bruch in der Tat Störung der Kontinuität, dem Inhalt nach, und nicht nur Weigerung der Rechtsunterstelltheit (das wäre ein bloss quantitativer Abzug an der Rechtshoheit) bedeutet. Übrigens ist für den Qualitätscharakter der hier fraglichen Grundbegriffe des Rechts doch auch gerade der Umstand bestätigend, dass genau an dieser Stelle die Rücksicht auf die mögliche Negation des Rechts unabwieislich wird: erklärt sich doch überhaupt die Eigenart der Negation aus dem Gesichtspunkte der logischen Qualität. Unter diesem Titel stehen bei Kant, wie man sich erinnert: Bejahung, Verneinung, Limitation, wobei die letztere (in der Ausführung anfechtbar, in der Tendenz dennoch richtig) die Neuerzengung einer vertieften Bejahung aus der Verneinung (nämlich Verneinung der Verneinung) bedeutet. Die Rechtsverletzung ist Verneinung, streng im Qualitätssinn: Brechung, Unterbrechung der Kontinuität, die Reparation deren Wiederherstellung. Also handelt es sich in der Tat um die Behauptung nicht nur des quantitativen Bereiches der Rechtshoheit (dass kein einzelnes Wollen sich ihr entziehe), sondern der Inhaltseinheit des Rechts, gegenüber aller versuchten Zerreissung derselben; also um die Behauptung seines Qualitätscharakters; sodass also auch hier unsere kategoriale Begrïndung der Rechtsbegriffe sich bewährt und zur weiteren Klärung hilft. Angemerkt sei hierbei noch, dass Stammler den Begriff der Strafe als einen reinen Grundbegriff des Rechts (ebenso wie den des Zwangs im kausalen Sinn, s. 0.) mit nicht geringerer Entschiedenheit ablehnt als (z. B.) Cohen (S. 259 ff.). An ihre Stelle tritt also einfach die "Berichtigung“.

Übergangen werden dürfen die an die Kategorieenlehre sich anschliessenden Ausführungen über die reinen rechtlichen Begriffe abgeleiteter Art (III C) und die unter den Grundkategorieen sich ergebenden Hauptaufgaben des Rechts (III D), obgleich dabei so wichtige Begriffe wie der der Rechtshandlung und der rechtlichen Zurechnung (16) zur Sprache kommen; desgleichen übergehen wir die ganze'Lehre von der Methodik der Rechtswissenschaft (IV). Dagegen fordert wenigstens ein kurzes Verweilen die Untersuchung über das System des Rechts (V), sofern sie den Bestand einer (einzelnen) Rechtsordnung und ferner die Frage der Ausdehvung des Rechts betrifft; denn diese Betrachtungen haben näheren 
Bezug anf das, was dann als wichtigster Fragepunkt uns noch zu beschäftigen haben wird: die Idee des Rechts und die Möglichkeit seiner Entwicklung im Gange der Geschichte.

$\S 17$. (Das System .des Rechts.) Eine einzelne Rechtsordnung $(\mathrm{V}, 8)$, als "eigenes begrenztes Ganzes" (S. 384), ist nicht mehr aus reinen Begriffen des Rechts zu bestimmen (S.385), sondern ist schon eine Anwendung derselben und zwar gemäss den Einteilungsgesichtspunkten, die unter dem Begriff des objektiven Rechts sich ergeben und die ihrerseits aus den Kategorieen des Rechtsgrundes und der Rechtshoheit sich ableiten. Sie bedeutet demgemäss den „Inbegriff von objektivem Rechte, der in seiner Einheit als Rechtsgrund alles darunterstehenden rechtlichen Wollens gedacht ist" (S. 386 f.). Die Rechtsordnung wird demgemäss vorgestellt als unabhängig nach aussen, voll bestimmend nach innen. Ob eine solche Rechtsordnung „existiert“, entscheidet sich nach den Erwägungen über das Gelten, d. h. nach der Möglichkeit der Durchsetzung (S. 387). Vergebens versucht man die bestimmte Rechtsordnung auf einen vermeintlich unabhängig von ihr feststehenden, wohl gar absoluten Begriff einer realen leiblichgeistigen Einheit des "Volkes" zu gründen. Ein Volk ist vielmehr eine Gesamtheit unter einer Rechtsordnung vereinigter Menschen, sein Begriff beruht also vielmehr selbst erst auf dem der Rechtsordnung. Ebensowenig fördert hier der Begriff Uer Nationalität. Denn fragt man, was der Begriff des Nationalen selbst bedente, so ist es "noch nicht gelungen ihn in etwas anderem zu sehen als in dem Wollen des Zusammenstebens" (S. 393). Die Nation deckt sich nicht mit dem Rechtsverband, sie bedeutet nicht nur Rechtseinheit, sondern daneben noch vieles andere. Schon darum kann sie die Rechtsordnung nicht begründen. Sie gehört durchaus deß bedingten Betrachtung innerhalb der Sphäre des verbindenden Wollens überhaupt an. Dagegen deckt sich wirklich mit dem Rechtsverband der Staat. Aber auch er bedingt nicht erst das Recht, sondern wird durch es bedingt; ein Staat ist nichts als eine besonders geartete Rechtsordnung (S. 397). Schliesslich aber kann es bei irgendeiner räumlich abgegrenzten Rechtsordnung überhaupt nicht sein Bewenden haben. Denn da dem Rechte an sich das Ganze des sozialen Lebens untersteht $(\mathrm{V}, 15)$, da keine "natürliche“ (ausserrechtliche) Freiheit unter sozialer Erwägung anzuerkennen ist, sondern nur die verhältnismässige, welche das Recht selbst be- 
stimmt (S. 419), so kann ein (rechtloser) Naturzustand überhaupt uur in vorbereitender, nicht abgeschlossener wissenschaftlicher Erwägung zugelassen werden; welche letztere aber eben auf die Notwendigkeit verbindenden Wollens zwingend hinführt (S. $424 \mathrm{f}$.). Auch alle Erwägung über staatlose Gebiete (mare liberum u. dgl.) führt höchstens wiederum auf eine nur verhältnismässige Freiheit, die als solche selbst nach rechtlichem Wollen zu bestimmen ist (S. 426). Besonders die zwischenstaatlichen Beziehungen fordern wiederum neue rechtliche Regelung. Die Zerlegung des möglicben Rechtsinhalts in einzelne Rechtsordnungen ist überhaupt nur eine bedingte Betätigung des rechtlichen Wollens; sie ist in ihrer begrenzten Gestalt nur eine zufällige Erscheinung gegenüber der bleibenden Form des Begriffes vom Recht, und sie kommt in ihrer Vereinzelung der Aufgabe der besonderen Ausführung des Rechtsgedankens nur in unvollständiger Weise nach (S.431). Die Überordnung eines höheren Rechts über den verschiedenen Rechtskreisen wird auch stillschweigend immer vorausgesetzt; ein verbindendes Wollen also, das als ein rechtliches über jenen stehe (S. 432). Zum vollen Begriff der Souveränität eines Staates, als einer rechtlichen Unabhängigkeit, ist gerade erforderlich, dass er mit anderen Staatswesen unter einem sie verbindenden Wollen stehe. "Damit ist nun der Begriff eines Weltrechtes eingebracht", als eines Rechtes, "das von dem Gedanken des einheitlichen Zusammenhanges alles besonderen Rechtes getragen ist. Dieses Weltrecht ist nicht erst zu fordern, oder gar zu erfinden; es ist schon da und nur in den geschichtlich vorliegenden Äusserungen des rechtlichen Wollens zu entdecken ... Es ist sonach nicht an dem, dass alles Recht vom Staate abzuleiten und abhängig wäre, ... es steht vielmehr gerade umgekebrt" (S. 433). Die besondere Rechtsordnung vermag eben in ihrer Vereinzelung nicht ein unbedingtes Ende darzustellen; es kaun aber in der Bewährung des unbedingt einheitlichen Rechtsbegriffs nicht an einer zufälligen Verwendung von ihm haltgemacht werden. Selbst das "Völkerrecht" genügt der hier sich erhebenden letzten Forderung noch nicht, da es sich zu sehr auf eine Beziehung unter den Staatswesen moderner Beschaffenheit zurückzieht und nur diese in einer neuen, wiederum bedingt abgegrenzten Staatengemeinschaft vereinigt, die regelmässig noch irgendwelche daneben bestehenden selbständigen Rechtsverbände oder einzelnen Menschen von sich ausschliesst (S. 434). Demgegenüber muss der Begriff 
des Weltrechtes, w'enn auch nur als der Gedanke des unbedingt möglichen Ordnens alles einzelnen Rechtes und aller besonderen Rechtsorduungen in einer zusammenfassenden Weise, behauptet werden (S. 435).

Mit dieser Erwägung der „Unbegrenztheit des Rechtes“, in welcher der Gedanke der "Allheit" siegreich durchdringt und jede zufällige Beschränkung des Rechtsgedankens überwindet, rechtlose Willkür auch in zwischenstaatlichen Beziehungen grundsätzlich ausschliesst, sind wir nun an die zweite grosse Aufgabe der Rechtsphilosophie schon dicht herangekommen: die der Aufstellung der Idee des Rechts (VI).

$\S$ 18. (Die Idee des Rechts.) Es handelt sich bei der Idee (wie schon festgestellt wurde) nicht um einen Endzweck, im Sinne eines zu verwirklichenden Zustandes (S. 439), also auch um kein „Ziel" im gewöhnlichen Sinne (S. 444), sondern, ebenso wie beim Begriff des Rechts, um ein ordnendes Verfahren, nur in einer neuen Richtung, oder gleichsam in einer neuen Dimension: sei der Begriff des Rechts der Mittelpunkt, um den die Rechtsfragen nach der Weise konzentrischer Kreise gelagert sind, so erhebt sich die Idee darüber gleichsam als die Spitze des Kegels, zu der von jedem Punkte der Kreisfläche feste Richtlinien führen (S. 441). Was besagt dies ohne Gleichnis? Man denkt sich ein Wollen, das von allen blossen Einzelheiten frei sei und seine massgebliche Bestimmtheit nur durch die feste Richtung, nicht durch irgend ein begrenztes Ziel als solches erhalte. Denn gerade um als Richtmass für alles besondere Wollen eintreten zu können, muss es selbst etwas anderes als das letztere sein, darf es nichts bedeuten als den reinen Gedanken einer sich stets gleichbleibenden Art und Weise des Richtens (S. 443). Die Idee ist der Gedanke der unbedingten Einheit des Wollens, gegenüber aller bedingten Besonderheit desselben. Diese Einheit drückt sich aus als Idee des freien Wollens (S. 445), oder als Willensreinheit, oder als Vernunftgemässheit des Wollens. Die Idee mag zunächst negativ erscheinen, denn das erste, was unter ihr klar wird, ist freilich, dass ein bedingtes Wollen die Idee des unbedingt reinen Wollens nie erfüllen kann. Aber die Idee bat den bedingten Inhalt des Wollens zu leiten, zu richten, messend $\mathbf{z u}$ beurteilen (S. 449). Die Freiheit des Wollens bedeutet nicht Ursachlosigkeit, sie besagt überhaupt nichts über das Werden des einzelnen Wollens, sondern sie besagt eine feste, bleibende, 10- 
gisch-systematisch unabhängige Form des Urteilens nach der Richtlinie des in seiner Reinheit festzubaltenden Gedankens eben der unbedingten Einheit (Richtungseinheit) des Wollens.

Und zwar, sofern es sich um das verbindende Wollen handelt, wird die Idee des "reinen" Wollens $\mathrm{zu}$ der der rein gewollten Gemeinschaft (S. 471 f.), der Gemeinschaft frei Wollender (S. 471), oder kurz: der reinen Gemeinschaft (S. 474). Sie besagt, dass nicht zwei oder mehr Willensinhalte, die für sich getrennt daständen, je für sich nach dem Grundgesetze des Wollens gerichtet und dann äusserlich zusammengehalten würden, sondern dass die gemeinsame Zwecksetzung, die in dem "verbindenden Wollen" ihren begrifflichen Ausdruck findet, als ein einziges, logisch eigenartiges Streben dem idealen Gedanken der reinen Gemeinschaft unterstellt, an ihm gemessen und von aller bloss bedingten, begrenzten Bedeutung befreit werde (S. 472), an keinem endlichen Punkte mehr ihre notwendige Grenze finde (S. 473). Die Ide e der reinen Gemeinschaft bezeichnet diese rein als $\mathrm{Me}-$ thode, als "abgezogene Art und Weise des Ordnens“, das Ideal als den freilich nur gedachten Zustand, der jenem Ordnungsprinzipe voll entsprechen würde (S. 474). Unter diesem wie unter jenem Ausdruck aber handelt es sich nicht um ein zu erreichendes Ziel, sondern rein um den Begriff der sozialen Gesetzmässigkeit als solcher (S. 475). Auch um eine Forderung handelt es sich wenigstens unmittelbar nicht, sondern rein um eine Begriffsbestimmung. Das soziale Ideal, als Formel für den Gedanken der reinen, unbedingten Gesetzmässigkeit des verbindenden Wollens, zeigt die Möglichkeit eines richtigen Rechts, aber fordert ein solches von sich aus nicht.

Eines richtigen Rechts: denn mit der Idee des Rechts ist der Gedanke seiner möglichen Richtigkeit oder Unrichtigkeit schon gegeben. Mag noch so streitig sein, was im gegebenen Fall das Richtige ist, der Begriff der Richtigkeit selbst verändert sich in seiner formalen Bedeutung nie (S. 478), er ist durch den Gedanken der reinen Gemeinschaft klar bestimmt. Auch was naturgesetzlich für wahr zu erachten sei, ist im besonderen streitig, aber dadurch wird der. Begriff der Gesetzmässigkeit nie wankend und auch die Möglichkeit, ein besonderes Naturgesetz mit objektiver Gültigkeit aufzustellen, nicht zweifelhaft (S. 478). So ist es auch hier; es ist im ganzen sehr wohl möglich, in kritisch geklärter Methode einen überzeugenden Beweis dafür zu erbringen, dass die Richt- 
linien eines besonderen rechtlichen Wollens von der Idee des Rechtes geleitet sind oder von ihr abweichen; im ersteren Falle ist in dieser Sachlage "richtiges" Recht festgestellt (S. 480). Nur bedeutet diese "objektive" Richtigkeit nicht auch absolut massgebliche Bedeutung, sondern diese Eigenschaft besitzt allein die Idee des Rechts als reine Form des Richtens (S. 481).

$\S 19$. (Nochmals die Beziehung der Sittlichkeit auf das getrennte Wollen.) Kann bis soweit die streng idealistische Gedankeneinstellung auch in diesen Aufstellungen unmöglich bestritten werden, so steht dagegen auch hier wieder störend neben der Richtigkeit rechtlichen Wollens noch eine Richtigkeit sittlicher Lehre, als bezüglich auf das getrennte Wollen des Einzelnen für sich (S. $450 \mathrm{ff}$.). Immer beruft sich die Begründung darauf, dass doch das verbundene Wollen eine eigene Art der Erwägung fordere; was wir nicht bestreiten. Aber nichts wird dafür beigebracht, dass daneben dem getrennten Wollen noch ein eigengeartetes logisches Verfahren entsprechen müsse. Vielmehr wird ausdrücklich anerkannt: zu dem Inhalte weines Bewusstseins gehört auch seine Beziehung zu dem des Bewusstseins Anderer (S. 451). Wir behaupten: sie gehört so wesentlich dazu, dass es ein Ich ausser dem Gegenverhältnis zum Andern unter praktisch-gesetzmässiger Erwägung gar nicht gibt. Dann aber muss die besondere Gesetzgebung für getrenntes Wollen fallen.

Die Ziele - das erkennt Stammler selbst an - gehen stets auf Beziehungen unter Menschen; aber das Bestimmen (nach der Zweckbeziehung) könne das Wollen des Einzelnen für sich od er das gemeinsame Wollen betreffen. Z. B. die Frage des Zürnens einem Anderen gegenüber könne nur als Bestimmung der wünschenden Gedanken eines jeden in getrenntem Wollen begriffen werden, dagegen die des Tötens beziehe sich auf die Gemeinsamkeit im Znsammenwirken (S. 450 f.). Aber das auf den Andern bezügliche Wollen des Einzelnen ist eben in Hinsicht der Wechselbeziehung (die in jedem Fall Wechselbeziehung Wollender und in Hinsicht des Wollens ist) gesetzmässig zu bestimmen; also gibt es gar nicht die von der sozialen getrennte, auf das Wollen des Einzelnen für sich (als zu bestimmendes Objekt) beschränkte Bestimmungsart, und kann sie gar nicht geben.

Überhaupt nicht im Inhalte des Wollens darf die methodologische Unterscheidnng, um die es sich handelt, gesucht werden; Inhalt der Willensbestimmung sind, wie Stammler ja anerkennt, 
in jedem Fall wechselseitige Beziehungen.. Sondern der methodische Unterschied kann allein liegen in der Richtung des Bestimmens: von der Autonomie zur Heteronomie oder - wie Stammler selbst es für die rechtliche Bestimmung richtig behauptet (S. 209) - von der Heteronomie zur Autonomie.

Als erstes Gesetz sittlicher Lehre stellt Stammler das der inneren Lauterkeit auf; es ist "Von der Idee des freien Wollens hergenommen und bedeutet diese selbst in ihrer Betätigung bei der Aufgabe eines gesetzmässig gerichteten Innenlebens" (S. 453). Wir würden statt dessen sagen: bei der Aufgabe eines gesetzmässig, und zwar $\nabla$ on in $\mathrm{n}$ en her gesetzmässig zu richtenden Lebens. Von innen her, das heisst: aus „kritisch begründeter Selbsterkenntnis" (S. 454). Sehr wohl; aber dieses "Selbst" gibt es, in "kritischer Begründung“, nur als „reines", und das heisst schon nicht mehr: getrenntes oder je zu trennendes; ein solches Merkmal träfe allenfalls nur auf das Individuum als empirisches $\mathrm{zu}$; ob auch nur da, braucht nicht erst gefragt zu werden, da wir es mit diesem hier gar nicht zu tun haben.

Auf den Grundșatz der Lauterkeit werden zwei weitere gestïtzt: der der Wahrhaftigkeit - dass kein Gegensatz bestehen dürfe zwischen Sein und Scheinen - und der der Vollkommenheit - dass keine Einzelheit im Mittelpunkte des Wollens stehn, kein bedingtes Mittel zum Endzweck gemacht werden dürfe. Beim ersteren macht sich Stammler selbst den Einwurf, ob nicht mit. dem Grundsatze, nicht anders äusserlich zu erscheinen als man wirklich sein kann und will, schon die soziale Beziehung vorausgesetzt werde; das sei aber nicht der Fall, es handle sich dennoch hier um die rechte Gestaltung des Innenlebens; darum, dass schon in dem Wollen für sich selbst keine Absplitterung erfolgen dürfte etc. - Indessen man hat $f \ddot{u} r$ sich selbst nur zu wollen, was für jeden Andern. Die Beschränkung der Willensbestimmung, der Materie nach, auf das eigne Ich ist aus dem Standpunkte der reinen praktischen Idee von vornherein unzulässig. Es gibt keine eigne Verpflichtung gegen sich selbst, unterschiedlich vom Andern, sondern nur Verpflichtung gegen das Gesetz - oder strenger gesprochen: zufolge des Gesetzes der reinen praktischen Vernunft überhaupt. Diese Verpflichtung erstreckt sich, der Materie nach, gewiss auf den Wollenden selbst ebenso wie auf jeden Andern, in der Tat in gar keiner andern methodischen Art und Begründung auf ihn wie auf Andre. Vollends, wenn nach. 
dem Grundsatze der Vollkommenheit keine Einzelheit im Mittelpunkte des Wollens stehen darf, so ganz gewiss auch nicht das einzelne wollende $\mathrm{Subjekt}$, unterschiedlich vom andern. Im Mittelpunkt, mag man sagen, steht d a selbst; aber dann eben das reine, das nicht mehr meines als jedes Andern ist.

Die A rbeit, die mit diesen Grundsätzen dem Menschen aufgegeben wird, müsse doch jeder Einzelne selbst verrichten, sagt Stammler; niemand könne sie ihm abnehmen, auch der staatliche Gesetzgeber nicht. Sie bieten die Möglichkeit der grundsätzlichen Vervollkommnung nur dem Einzelnen für sich in seinem getrennten Wollen, und s e ine Sache sei es ganz allein, dem unbedingten Ziele der inneren Lauterkeit in stetem Entschlusse sich hinzugeben (S. 456). - Gewiss hat jeder zuerst an sich selbst zu arbeiten; aber ebenso gewiss doch auch am Andern, und Audre an ihm; wahrlich auch der Staat durch seine Gesetzgebung, die überhaupt keine ernstere Aufgabe hat. Aber allgemein ist das hier nicht die entscheidende Frage, wem die Arbeit an der gesetzmässigen Gestaltung des Wollens zufalle, sondern 1. ob sie ihr Ziel im Einzelnen getrennt für sich, oder im "Reiche" der Geister zu suchen, und 2. von welchem Gesichtspunkte aus sie sich zu bestimmen habe. Die erstere Frage kann nur im Sinne der Gemeinsamkeit entschieden werden; weil aber und sofern das Ziel gemeinsam, wird es im letzten Betracht wohl auch die Arbeit auf es hin sein müssen. Bei der zweiten Frage ergibt sich ein Unterschied, nämlich jener methodische Unterschied der Bestimmungs richtung, den wir von Anfang an behauptet haben, der aber nicht zutreffend als der der Bestimmung des Wollens des „Einzelnen für sich" und des gemeinsamen Wollens definiert wird, da hier gar nicht das zu bestimmende Wollen, sondern das bestimmende, und der Gesichtspunkt, unter dem die Bestimmung zu geschehen habe, der Punkt der Frage ist.

Seiner Voraussetzung getreu unterscheidet Stammler weiterhin zwischen Begriff and Idee der Moral ebenso wie des Rechts. Es gebe also unrichtige, nämlich heteronome, und richtige d. h. nach unbedingt gültiger Methode gerichtete, also autonome Moral, ebenso wie heteronomes gegenüber autonomem Recht; falsch dagegen sei es, den Unterschied von Recht und Moral als den des heteronomen und autonomen Wollens zu definieren. - Hieran ist soviel richtig, dass das Recht, obgleich stets heteronom in seinem 
Ausgangspunkt, auf Autonomie notwendig hinzielt, und als „richtiges" nur von Standpunkte und im Sinne der Autonomie zu beg r ü nde $\mathrm{n}$ ist. Allein man kann darum, auf der einen Seite, doch nicht sagen: heteronomes Recht ist unrichtiges Recht, oder schlechtweg Unrecht. Denn auch das jeweils richtigste Recht bleibt immer nur bedingt richtigès, also nie unbedingt autonomes. Auf der andern Seite aber ist gerade in der Richtung der Autonomie noch über Stammler hinaus zu behaupten: wenngleich das Recht keineswegs schon seinem Begriffe nach autonom ist (vielmehr seinem Begriffe nach, als ä usserlich verbindendes, von der Heteronomie nie absolut loszukommen vermag - absolute Autonomie würde gar keiner äusseren Bindung mehr bedürfen noch sie sich gefallen lassen können), so gibt es doch gar kein Recht anders als unter der Idee der Autonomie; denn alles "gesetzte" Recht untersteht ebenso notwendig und unbedingt der Idee wie dem Begriff des Rechts, gleichviel ob und wieweit es diese Idee erfüllt. Auch das schlechteste Recht muss darum zum wenigsten den Schein aufrechthalten, als ob es der Idee des Rechts entspreche, da es sonst die unbefangene Vernunft aller, die es verbinden will, gegen sich empören würde. So ist es in bestimmtem Sinne wiederum richtig zu sagen: es gibt kein heteronomes Recht, d. h. keines, welches die Autonomie grundsätzlich verleugnete. So aber vollends keine heteronome Moral, die, wenn auch als schlechte, doch überhaupt als eine Moral sich behaupten dürfte. Denn wenn das Recht als Recht zwar nicht endgültig aber doch in seinem Ausgangspunkte heteronom ist, so bedeutet dagegen Moral als solche autonome Bestimmung; Bestimmung allermindestens, und zwar unmittelbar, unter dem Gesichtspunkte der Autonomie. Eine sittliche "Maxime", Andre zu beneiden, zu hassen, zu verachten (S. 457), wäre eine sittliche Maxime der Unsittlichkeit, wäre die sich offenkundig widersprechende Behauptung, dass eine in sich einheitswidrige Willensbestimmung einheitsgemäss sei; also nicht „eine Moral, wenngleich eine schlechte", sondern die Verneinung aller Moral, der schlichte Widerspruch gegen sie - als welchen sicher auch

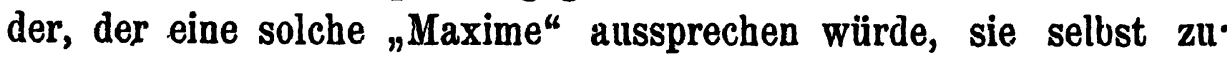
bezeichnen nicht anstehen würde. Dagegen kann ein "Recht“ der Sklaverei, oder der Todesstrafe, oder des Krieges Jahrhunderte und Jahrtausende hindurch in gutem Glauben als "Recht" in Ansehen bleiben, ehe es als unrichtiges Recht klar bezeichnet und 
in genügender Allgemeinheit eingesehen, bekämpft und zuletzt vielleicht, vielleicht auch nicht - überwunden wird.

Voll im Rechte ist ja Stammler, wenn er in Beantwortung der Kritik Cohens (VI, 10) es zurückweist, dass er das Recht von der Sittlichkeit habe loslösen und für sich "richtig machen" wollen, ohne den Grund der Richtigkeit in der Ethik festzulegen und festzuhalten (Cohen, Eth. ${ }^{1}$ 214, in 2. Aufl., S. 225: "unzweideutig in der Ethik zu suchen, zu legen und festzuhalten"). Über a 11 e m menschlichen Wollen steht ihm, und stand ihm auch früher, „als Leitstern die Idee der Willensreinheit"; sie beherrscht alle Möglichkeiten der Zwecksetzung ausnahmslos. Es gibt nicht zwei Gesetzmässigkeiten des Wollens, sondern nur ein einziges „moralisches Gesetz", wie $\mathrm{Kant}$ es nennt, dessen B ew ährung nun „im Abstiege zu den Einzelfragen verschiedene Aufgaben vorfindet“, nämlich diese beiden obersten der Ordnung des „sittlichen", als getrennten, und des "sozialen", als verbundenen Wollens, deren Unterschied nicht auf einer Verschiedenheit der darüberstehenden $\mathrm{G}$ e s e t z m ässigk e it beruht, sondern auf einer Trennung nach begrifflichen Merkmalen in allgemein gegebene Klassen des Wollens, „auf die die systematische Ethik, als Lehre von dem freien Wollen, in einheitlicher Bedeutung anzuwenden ist" (S. $488 \mathrm{f}$.). Die Einwendungen Cohens in d i es er Beziehung als Folgen eines blossen, nur durch die Verschiedenheit des Wortgebrauchs (s. S. 495 und 67, 303) und allenfalls einzelne minder deutliche Wendungen des Ausdrucks entschuldbaren Missverständnisses zu bezeichnen ist Stammler vollberechtigt. Auch in der weiteren Replik ist beinahe alles, was die Gesetzlichkeit des Rechts als die des verbindenden Wollens angeht, zutreffend und bedarf nach allem Gesagten für uns keiner neuen Beleuchtung mehr. Nicht überzeugend aber bleibt auch hier die parallele Behauptung einer selbständigen Aufgabe der "sittlichen Lehre“ im Sinne der Gesetzesordnung getrennt betrachteten Wollens. Es sei „nicht wahr, dass es keine wünschenden Gedanken ohne Handlung geben könne." Aber das ist nicht die Frage, sondern ob der Wunsch, der in jedem Fall Wunsch des Handelns ist, in grundsätzlich anderer Erwägung der Idee des freien Wollens zu unterstellen sei als die Handlung selbst; eine Frage, die auch rom Recht, überall wo das Wünschen in den Bereich seiner Erwägung überhaupt kommt, fraglos verneint wird und wohl von jeher verneint worden ist. Es beurteilt Absicht und Vorsatz gewiss nicht 
g leich der Tat, aber es nimmt auf sie alle Rücksicht im Urteil über die Tat, und beurteilt sie, in e in er zusammenhängendeu Erwägung mit dieser, als Vorstufen zu ihr, d. h. unter denselben obersten Gesichtspunkten. Und so verfährt es nicht bloss zufällig oder gar irrtümlicher Weise, sondern aus dem unabweislichen Grunde, dass man zuletzt eben ", kein Einzelner is t"; dass die Vereinzelung des Wollens, welche die logische Voraussetzung der (i. e. S.) sittlichen Erwägung nach Stammler bilden soll, in Hinsicht der gesetzlichen Bestimmung der Handlung überhaupt keine zulässige Voraussetzung ist.

Stammler selbst kommt übrigens in einer das „richtige Wollen des vereinzelten Menschen “ besonders betreffenden Erörterung (II, 11) dieser Einsicht ganz nahe, indem er nicht nur (nochmals, s. o. S.50 u.54) anerkennt, dass die Vorstellung gänzlicher Vereinzelung überhaupt nur eine vorläufige Annahme in der Untersuchung der Mittelreihe des wirkenden Wollens sein kann, die "bei sicherem Ausdenken folgerichtig zu dem Begriffe des verbindenden Wollens führt" (S. 499), sondern selbst schon in der, notwendig in den Blickpunkt des Individuums sich stellenden, Tugend- oder Pflichtenlehre nur eine „erste Einführung für den einheitlichen Gedanken des richtigen Wollens in dessen verbindender Art" erkennt. Denn auch die „Verpflichtung gegen sich selbst" erweitere sich "bei zutreffender Weiterführung sofort zu der ferneren Anleitung, niemals den Träger der Idee, den Menschen in seiner Eigenschaft als Selbstzweck zu dem bedingten Mittel eines begrenzten Strebens eines Andern zu gebrauchen; ein Gedanke, der in unmittelbarer Deutlichkeit aus der Fassung des sozialen Ideales entspringen muss und selbst wieder den Blick auf die notwendige Formel der Gemeinschaft frei wollender Menschen richtet." Fein und tief auch erkennt er, dass die vorläufig auf den Einzelnen beschränkte Erwägung es höchstens zu negativen Festsetzungen bringt, eine positive Ordnung der Zwecke dagegen erst aus dem Gesichtspunkte des verbindenden Wollens möglich wird (S. 500), weil in der Gemeinschaft erst ein Feld positiven Wirkens, das unter sittliche Erwägung fällt, sich ergibt. "Sollen die besonderen Bestrebungen des vereinzelten Menschen in ihrem positiven Inhalte als richtig oder unrichtig bestimmt werden, so sind sie in Gedanken mit dem Wollen anderer Menschen zu verbinden und nun nach der Methodedes sozialen 
Ideals z u führen." Damit ist grundsätzlich eben das anerkannt, was uns die Scheidung zwischen Richtigkeit des (i. e. S.) sittlichen und des sozialen Wollens, so wie Stammler sie vertritt, unannehmbar macht. Denn nicht nur könnte die bloss negative Vorbedingung, die bloss „einstweilige“ Isolierung des Individuums eine eigene grundsätzliche Erwägung nicht begründen; sondern selbst in der strengsten, als Abstraktion zulässigen Isolierung ist von dem Gedanken des Menschen als Selbstzwecks eben nicht abzusehen; Selbstzweck aber ist nicht der Mensch in seiner „einstweiligen Isolierung“, sondern allein als in "Reiche“ der Zwecke gedacht. Da aber diese letzte Voraussetzung uns gemeinsam feststeht, so sollte ferner kein Streit mehr darüber möglich sein, dass die schliessliche und umfassende praktische Erwägung nur die der Individuen in Gemeinschaft - wie gewiss auch der Gemeinschaft nur als der der Individuen - sein kann; unterhalb welcher immerhin eine zweiseitig gerichtete Erwägung bestehen bleibt, nämlich gerichtet einerseits auf das Individuum, obwohl unter der Idee der Allheit, andrerseits auf die Allheit, als Allheit der Individuen; wie es nicht bloss in meiner "Sozialpädagogik" aufgestellt worden, sondern, wie oben gezeigt, auch in Cohens "Ethik des reinen Willens" der Sache nach anerkannt, wenn auch nicht in genügend deutlicher Auseinanderstellung durchgeführt ist.

Die ferneren kritischen und metakritischen Erörterungen dieses Abschnitts können übergangen werden, da sie entweder unser Thema nicht betreffen oder nicht zu neuen Zweifeln und Fragen Anlass geben. Der philosophische Leser sei aber im Vorbeigehen wenigstens aufmerksam gemacht auf die Auseinandersetzungen mit Rickert und mit Hegel (VI, 17. 18 u. 21). Ebenso dürfen die beiden Abschnitte (VII) über die Technik und (VIII) über die Praxis des Rechts dem Interesse des Juristen überlassen bleiben. Dagegen gehören unmittelbar zu. unserem Thema noch die Erörterungen des letzten (IX.) Abschnitts iiber die Geschichte des Rechts, in denen wir einen beachtenswerten Beitrag zur Geschichtsphilosophie überhaupt sehen.

\$20. (I dee und Geschichte.) Nur unter einer Idee gibt es eine Geschichte. Denn das grundlegende Verfahren der Geschichte ist das teleologische, nicht das kausale; die kausale Erwägung kommt fïr die Eigenart historischer Betrachtung „von 
der Seite her", sie vermöchte nicht dem "gesamten Zuge der Zweckreihe", den die Geschichte vorzuführen hat, nachzukommen (S. 761). Man kanu zwar, wenn man will, sich auf kausale Untersuchung beschränken, die teleologische beiseite schieben; aber das ist "objektiv ohne Belang"; durch den Gegenstand der geschichtlichen Untersuchung ist die teleologische Ordnungsweise als die massgebliche gefordert. "Wie die Reihe der Töne in einer Symphonie, die als Musikstück aufgenommen wird, etwas anderes ist als das kausale Werden derselben Töne, wie das Verfolgen der Melodie nicht aufgeht in der Erkenntnis der Erregung gewisser Schallwellen, sondern unter einer eigenartigen Richtung unseres Bewusstseins steht" (S. 762), so verhält es sich mit allem, was ein Objekt der Geschichte ist. Die Frage nach Ursache und Wirkung ist natürlich nicht abzulehnen, mag der Aufweis kausalen Zusammenhangs im geschichtlichen Werden noch so grosse Schwierigkeiten bieten; aber sie trifft nicht das, wonach in der Geschichte eigentlich gefragt ist. Es treten eben nicht bloss neue Wahrnebmungen oder Erscheinungen an die Stelle andrer Wahrnehmungen oder Erscheinungen, sondern es treten andere $\mathrm{Z}$ we cke an der Stelle der bisher verfolgten auf, oder es kommen für die alten Zwecke wenigstens neue Mittel ins Spiel. Die Geschichte eines Objekts, das ganz nur in Zusammenhängen von Zweck und Mitleln besteht, kann selbst nicht unter andrer, letzter, grundsätzlicher Erwägung als der nach Zweck und Mitteln stehen. Soziale Geschichte aber - und Geschichte im hier fraglichen Sinn betrifft eben das soziale Leben - ist selbst Geschichte von Zwecken (S. 764). Unter blosser Kausalität könnte überhaupt von keinem Wollen, also auch nicht vom Rechte die Rede sein (S. 765). Das Verfahren der Geschichte wird aber damit notwendig analytisch, vom Ergebnis zu seinen Voraussetzungen zurückgehend. Überhaupt setzt die historische die systematische Betrachtung logisch voraus; denn wenn cin Gegenstand in seinem Wesen nicht stehen bleibt, so ist er eben nicht mehr er selbst, und es wäre dann die vorgeführte Geschichte nicht mehr seine Geschichte (S. 766). Das "Wesen" aber besteht hier im Zweck, es kann also auch die geschichtliche Untersuchung im besondern, das "Aufrollen einer geschichtlichen Reihe", immer nur in einer Ordnung nach Mitteln und Zwecken, und zwar im Rückgang rom Späteren, Gewordenen auf die teleologischen Voraussetzungen dieses Werdens sich vollziehen, denn das Vergangene 
ist, im teleologischen Zusammenhang erwogen, stets Mittel für ein Zukünftiges, das angestrebt wird; das Vergangene wird daher erst verstanden in abhängiger Beziehung zu dem nachmals Gewordenen (S. 769). Die Analogie mit dem naturwissenschaftlichen Experimentieren liegt hierbei darin, dass man nicht ins blaue "Tatsachen" zu erfassen und in diesen etwas von logischem Zusammenhang zu erkennen hoffen darf, sondern nach voraus entworfenem Plane, nach einem voraus gefassten Gedanken des möglichen Zusammenhanges, fragend an das Mannigfaltige der Erscheinungen herantreten muss, um dann diesen Gedanken an den Tatsachen methodisch zu bewähren oder zu berichtigen (S. 774). Somit bleibt die systematische Erwägung für die geschichtliche allzeit leitend. Die Besonderheiten nur sind empirisch aufzunehmen, ihr Verständnis ruht in jedem Sinne auf systematischer Erwägung, sei es im Sinne des Begriffs oder und dies stets in letztem Betracht - der I d e e.

Auch förderliche Le hren kann man aus der Geschichte nur dann entnehmen, wenn man voraus weiss, wonach man zu fragen hat; dieses Wissen selbst aber gewinnt man nicht erst aus der Geschichte, sondern man muss es schon mitbringen, um überhaupt förderlich Geschichte treiben zu können. Was historisch „wichtig“ ist und was nicht, ist allein danach $\mathrm{zu}$ beurteilen, was geeignet ist den Gang der Menschengeschichte in seiner (teleologischen) Einheit zum Bewusstsein zu bringen (S. 788). Möchte der Bestand der Natur als ein fester angesehen werden dürfen, im Wollen des Menschen gibt es keinen festen Bestand, sondern in einer rastlos flutenden Veränderlichkeit der Ziele und Mittel durch die unabgeschlossene Reihe der Generationen hat die Richtung auf die Allheit der menschlichen $Z_{\text {we cke sich zu behaupten }}$ (S. 789), welche Aufgabe zuletzt keine geschichtliche mehr, sondern nur in systematischer Erwägung lösbar ist (S. 790). Nur so wird die Geschichte selbst zur Einheit, und damit überhaupt nur zu einem eigenen Gegenstand wissenschaftlicher Behandlung. Dies kann auch nicht so verstanden werden, dass an die empirischen Einzelheiten, als blosse „Vorkommnisse", die teleologische Erwägung erst von aussen herangebracht würde; das hiesse den Begriff der Geschichte in seiner Selbständigkeit vernichten; es bliebe dann ein Naturgeschehen mit einem nebenher angehängten moralischen Urteil, von dem man nicht weiss, von wannen es kommt, noch was es bei jener, elementar nach dem Kausalitäts- 
gesetz begriffenen Veränderung eigentlich zu suchen hat (S. 793). Das einzelne Ereignis, das für sich überhaupt keine selbständige Bedeutung hat, erhält vielnehr seine wissenschaftliche Bestimmung von vornherein nur durch das Einstellen in die grundlegende, nämlich teleologische Einheit und das Richten nach ihr (S. 793); das heisst, das Gesetz der Geschichte muss den geschichtlichen Einzelerwägungen selbst i $m \mathrm{~m}$ a $\mathrm{n}$ en $\mathrm{t}$ sein.

Das ist das "Sein des Werdens", das die Geschichte aufstellt. Die Grundart der Geschichte ist also in der Tat nicht das "Geschehen", sondern eine bestimmte einheitliche Art des Denkens und Urteilens über es, und zwar nicht in kausaler, sondern teleologischer Erwägung. Eine bloss kausale Einordnung der Geschehnisse verneint den Begriff der Geschichte. Der fundamentale Fehler der "materialistischen" Geschichtsauffassung ist, dass sie die teleologische Eigenart der Geschichte verkennt und so überhaupt das Problem verfehlt, nämlich wie die Reihe der aufeinanderfolgenden und sich bedingenden Willensinhalte der Menschen in dem Gedanken einer unbedingten Einheit g e richtet werden könne (S. 797). Auch unter dem vieldeutigen Wort „Entwicklung“" wird zwar eine Gesetzmässigkeit des Werdens ohne Frage gesucht, auch schwebt dabei unklar der Gedanke einer Zweckbeziehung vor; man denkt doch die Entwicklung als Fortschreitüng nach einem wenn auch ungewissen Ziele hin, oder als Bewegung vom Niederen zum Höheren. Aber erst mit der klaren Einsicht in das Ziel, dem die Entwicklung zustrebe, wird der Gedanke der Entwicklung präzis und wissenschaftlich brauchbar. Ein Ziel aber ist freilich nicht angebbar im Sinne eines einmal zu erreichenden Endzustands; sondern das „Endziel“ kann nur die Gesetzmässigkeit meinen, im Sinne der idealen M e thode des Richtens und Bestimmens. Dies Endziel aber kennen wir; es kann kein andres sein als das soziale Ideal (S. 802), oder die Idee des freien Wollens, gipfelnd in dem Gedanken der reinen Gemeinschaft (S. 804). Also ist die Geschichte der Menschen: das Fortschreiten ihres gemeinschaftlichen Wollens (S. 805); nicht die „Verwirklichung“ der Idee des richtigen Wollens, denn die damit bezeichnete Aufgabe „ruht und rastet nimmer"; wohl aber ihre fortschreitend reinere Bewährung innerhalb des stets bedingten, unvermeidlich unvollkommenen menschlichen Begehrens und Strebens. - Damit ist in ganzer Entschiedenheit das soziale Ideal als schlechthin richtung- 
weisend anerkannt, unterbalb dessen erst etwa die Fortschritte der Wissenschaft und Kunst, oder auch der individuellen Sittlichkeit, in besondere historische Erwägung genommen werden könnten, denn sie ergäben für sich nicht die durchgreifende Einheit, die für den als Ganzes zu erfassenden Begriff der Geschichte des Menschengeschlechts $\mathrm{zu}$ fordern ist (S. 806). „Die“ Geschichte kann allein die der Menschheit sein, die eine Einheit nur unter dem sozialen Ideal bildet.

Gibt es denn aber zuletzt eine Gewähr des Fortschritts? Lässt sich auf den Sieg des Richtigen denn vertrauen? Die Idee selbst kann in das Werden allerdings nicht eintreten - also gibt es nur ein unentschiedenes Hin und Wieder, wobei das Ganze des menschlichen Treibens nicht von seiner Stelle rückt (S. 814)? - Allein das Vertrauen auf den Sieg des Richtigen will nicht von uns lassen; und es ist auch keineswegs grundlos. Immer schärfer und gesicherter setzt doch der Rechtsgedanke sich durch; man darf erwarten, dass, so wie ein „Naturzustand" innerhalb rechtlich geordneter Gemeinschaften nicht mehr statthat, es auch mit dem Naturzustand unter den Völkern schliesslich ein Ende nehmen werde (S. 815). Es kann doch nicht für immer dabei bleiben, dass, während im Innern einer Rechtsordnung doch die elementare. Einsicht allgemach zur Herrschaft gelangt, dass es widersinnig ist in einer Gemeinschaft, in der die Menschen" die Widrigkeiten des Daseins gemeinsam zu bekämpfen haben, selbst wieder von einem "Kampfe ums Dasein“, nämlich der Einzelnen gegeneinander, zu reden, dagegen im Verhältnis unter den Völkern immer noch naiv nach Stirners Idee eines „Vereins von Egoisten“ verfahren wird (S. 717). „Die Unbegrenztheit des Rechts $(V, 17) \ldots$ ist inmer stärker zur Tat geworden". Es liegt kein Grund vor, sich vorzustellen, dass dieser Sieg des Rechtsbegriff sieder in dauernder Weise rückgängig gemacht werden könnte ... Mehr als das: wir sehen für den Gesamtentwurf des menschlichen Treibens den Zug nach dem Richtigen so deutlich und stark, dass sein fortschreitender Erfolg im ganzen Verlaufe der Geschichte mit Zuversichtlichkeit erwartet werden darf (S. 815); wofür Stammler nicht zögert sich, mit Kant, auf die französische Revolution zu berufen. Freilich versteht sich, auch nachdem die Idee des Richtigen klar erkannt ist, die Hingebung an das richtige Wollen noch nicht von selbst. Ein naturgesetzlicher Zwang zu ihr lässt sich mit Fug 
nicht behaupten; seine Annahme würde das Wollen und sein Grundgesetz vielmelır geradezu ausscbalten (S, 819). Die Hingabe an das Richtige ist also nur ein Postulat für den, der Einheit und unbedingte Ordnung seiner Gedankenwelt will (S. 820). Fiir einen grundsätzlichen Zweifler und Jeugner also gäbe es ein absolutes Heilmittel freilich nicht. Aber solche grundsätzliche Anzweiflung - die ja nicht etwa sich selbst als richtig behaupten dürfte, denn damit würde sie die Forderung des Richtigen überhaupt anerkennen - ist wohl nicht so ganz ernst zu nehmen (S. 820). Den Will en des Richtigen aber einmal vorausgesetzt, ist alles Weitere Sache streng wissenschaftlichen Erweises. Der einzig sichere Weg, Andere zur Hingabe an das richtige Wollen zu bestimmen, ist in der T'at: die überzeugende Lehre (S. 827).

Die letzte Frage ist die nach einem „v ollkommenen Abschluss". Hier mündet die Untersuchung in die Frage nach der Einheit einer Weltanschau ng. Sie besagt, dass auch die beiden grossen Gebiete der "Wahrnehmungen" und der "Zwecke", wenn noch so sehr jedes für sich in geschlossener Gesetzmässigkeit vorzustellen, doch nicht als Trennstücke nebeneinander stehen bleiben dürfen (S. 833). Diese Forderung ist es, welche in der Frage nach dem Woher und Wohin und nach dem Wozu des Daseins, also den zwei grossen Fragen sich ausdrückt, die von jeher über die $W$ issenschaft hinaus zur Religion gedrängt haben. Dieser doppelten Frage "kann sich niemıand, der etwas auf sich hält, grundsätzlich entziehen". Ihr aber antwortet zuletzt doch nur - die Wissenschaft, indem sie, vertieft zur Philosophie, jedes besondere Gebiet menschlichen Strebens der Herrschaft unbedingt bestimmender Grundprinzipien unterwirft und es so „in die unbedingt höchste Einheit, die den Wert und die Würde des Menschendaseins verleiht, in geklärtem Sinne zurückgibt" (S. 834). So gelangt man zu der eigenen gefesteten Grundstinmung, die in dem Earipideischen Worte sich ausspricht, "Glücklich der Mann, der die reine Art der Wissenschaft kennt... unberührt von dem schädigenden Streiten der Bürger und von unrechten Taten schaut er auf das unsterbliche, Wesen des All, des niemals alternden, und auf dessen richtende Weise." -

So klingt das Werk, dem sonst wohl der und jener Kritiker geneigt sein mag, im Gegensatz zu der rednerischen Lebendigkeit namentlich des ersten grossen Buches ("Wirtschaft und Recht"), 
eine gewisse Steifheit logischen Schematisierens als Fehler oder doch als Mangel anzurechnen, voll aus im warmen Bekenntnis nicht bloss $\mathrm{zu}$ den Grundgedanken, sondern auch zu der Grundstimmung des methodischen Idealismus.

Nur zu einer Anmerkung geben diese letzten Erwägungen noch willkommenen Anlass. Eiwes der Hauptbedenken, die gegen die "Lehre von dem richtigen Rechte" sich erheben konnten, wird durch diese Darstellungen gegenstandslos. Nämlich es konnte nach den Darlegungen jenes Buches immerhin so scheinen, als solle der Stoff, auf den die Grundsätze des richtigen Rechts anzuwenden sind, in roher Empirie der Geschichte, lediglich im Sinne des faktisch Gegebenen, entnommen werden und auf diesen dann jene Grundsätze bloss hinterher, formal richtend und allenfalls berichtigend, einwirken. So aber wie jetzt der Begriff der Geschichte selbst gefasst und begründet ist, steht ja das geschichtliche Werden, welches jenen Stoff darbietet, selbst schon von Anfang an unter der Herrschaft der praktischen Idee und zwar der Idee des Rechts. Es gibt also gar kein geschichtlich gewordenes Recht, das nicht schon von Haus aus der Idee des Rechts unterstände, mag es auch eine noch so niedrige Stufe ihrer Verwirklichung darstellen. Umso weniger könnte es der fortschreitenden Berichtigung nach Massgabe dieser selben Idee sich entziehen. Gern erkläre ich, dass auch durch meine früheren Einwendungen, soferì sie das Verhältnis des Rechts zur Geschichte betrafen (Sozialpäd. S. $163 \mathrm{f}$.), jedenfalls die jetzige Darstellung nicht getroffen wird.

Im übrigen wäre auch hier die Frage der kategorialen Begründung zu erheben. $\mathrm{Zu}$ dieser aber sind die wesentlichen Voraussetzungen oben schon gegeben worden; ihre Bewährung an den hier behandelten Fragen darf dem mitgehenden Verständnis des Lesers überlassen bleiben. 